\title{
Navigating between fragmentation and cohesion
}

\author{
Citation for published version (APA):
}

Pekdemir, C. (2018). Navigating between fragmentation and cohesion: theory and practices of global governance for sustainable development. [Doctoral Thesis, Maastricht University]. ProefschriftMaken Maastricht. https://doi.org/10.26481/dis.20181218cp

Document status and date:

Published: 01/01/2018

DOI:

10.26481/dis.20181218cp

Document Version:

Publisher's PDF, also known as Version of record

\section{Please check the document version of this publication:}

- A submitted manuscript is the version of the article upon submission and before peer-review. There can be important differences between the submitted version and the official published version of record.

People interested in the research are advised to contact the author for the final version of the publication, or visit the DOI to the publisher's website.

- The final author version and the galley proof are versions of the publication after peer review.

- The final published version features the final layout of the paper including the volume, issue and page numbers.

Link to publication

\footnotetext{
General rights rights.

- You may freely distribute the URL identifying the publication in the public portal. please follow below link for the End User Agreement:

www.umlib.nl/taverne-license

Take down policy

If you believe that this document breaches copyright please contact us at:

repository@maastrichtuniversity.nl

providing details and we will investigate your claim.
}

Copyright and moral rights for the publications made accessible in the public portal are retained by the authors and/or other copyright owners and it is a condition of accessing publications that users recognise and abide by the legal requirements associated with these

- Users may download and print one copy of any publication from the public portal for the purpose of private study or research.

- You may not further distribute the material or use it for any profit-making activity or commercial gain

If the publication is distributed under the terms of Article $25 \mathrm{fa}$ of the Dutch Copyright Act, indicated by the "Taverne" license above, 


\section{Navigating between fragmentation and cohesion}

Theory and practices of global governance for sustainable development

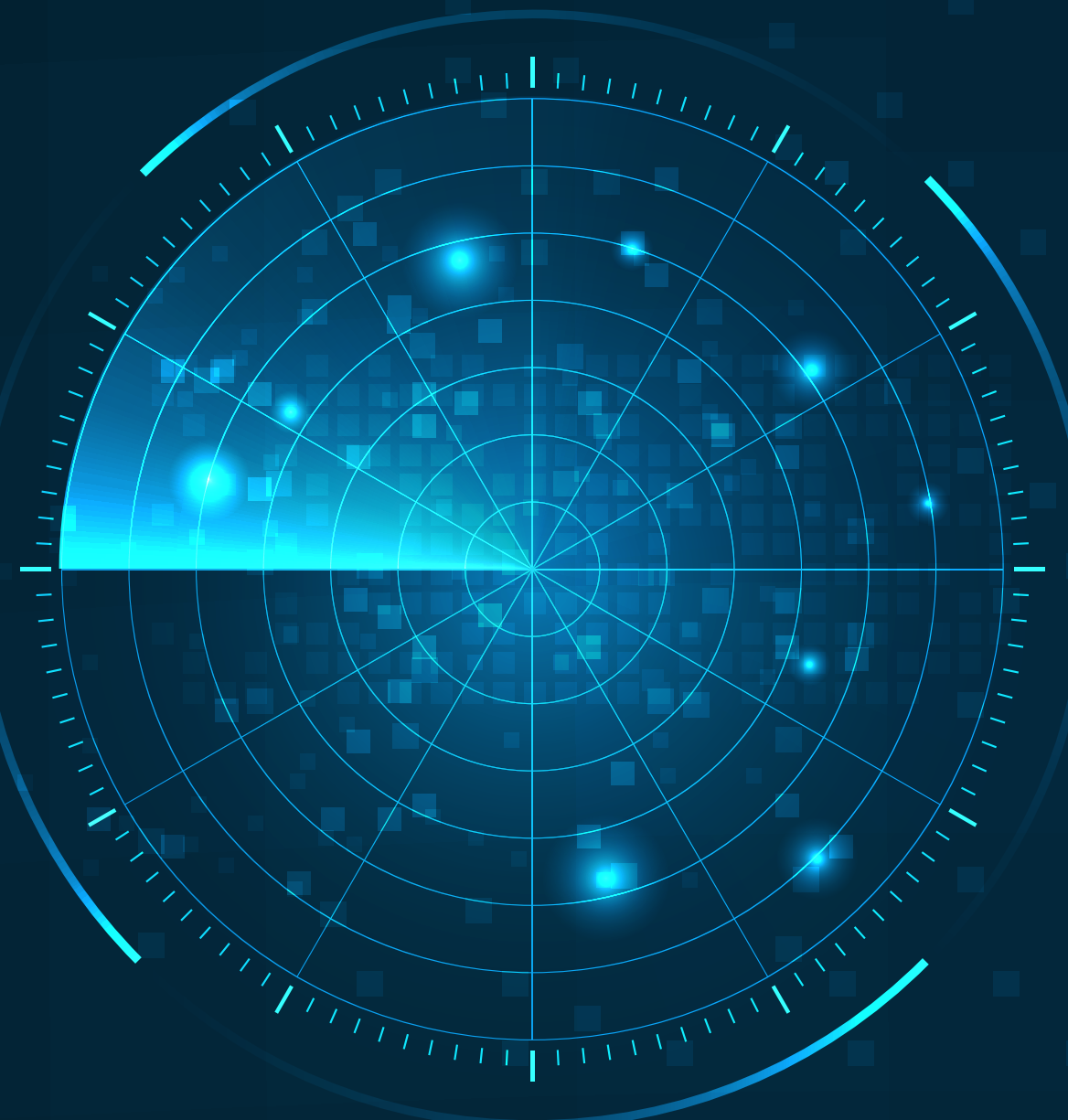

Ceren Pekdemir 



\section{Navigating between fragmentation and cohesion}

Theory and practices of global governance for sustainable development 
(C) copyright Ceren Pekdemir, Maastricht 2018

Printing: ProefschriftMaken || www.proefschriftmaken.nl ISBN 978-94-6380-150-8 


\title{
Navigating between fragmentation and cohesion
}

\section{Theory and practices of global governance for sustainable development}

\author{
DISSERTATION
}

To obtain the degree of Doctor at Maastricht University, on the authority of the rector Magnificus, Prof. Dr. Rianne M. Letschert in accordance with the decision of the Board of the Deans, to be defended in public on Tuesday 18 December 2018 at 15.45 hours

by

Ceren Pekdemir 


\section{Supervisor}

Prof. dr. P. Glasbergen

\section{Co-supervisor}

Dr. R. Cörvers

\section{Assessment Committee}

Prof. dr. M. Peeters (chair)

Prof. dr. S. Andresen (Fridtjof Nansen Institute, Norway)

Prof. dr. T. Conzelmann

Prof. dr. M. D. Davidson (Maastricht University/University of Amsterdam)

Dr. L. W. Fransen (University of Amsterdam) 


\section{Contents}

\section{Chapter 1}

Introduction

\section{Chapter 2}

On the transformative capacity of private fair labour arrangements

\section{Chapter 3}

On the regulatory potential of regional organic standards:

Towards harmonization, equivalence, and trade?

\section{Chapter 4}

Private meta-governors and their practices:

An inventory of their mechanisms

of change

\section{Chapter 5}

The quest for cohesion in global governance: An exploration of tensions in the global governance of organic production, and labour rights

\section{Chapter 6}

Conclusion and reflection

References

Appendix

Summary

Samenvatting

Valorisation

Acknowledgements 



\section{Chapter 1 \\ Introduction}





\subsection{Background}

Sustainable development problems archetypally cut across policy domains, territorial jurisdictions, and socio-economic and political divides. Inducing global sustainable change is therefore at best challenging. Since the first UN Conference on Environment and Development in Rio de Janeiro in 1992, numerous governance arrangements from the public and private domain have been initiated to contribute to sustainable development and the implementation of agreements. Whereas state-centred approaches and intergovernmental organisations still remained at the heart of the Summit Rio+20 in 2012, the contributions of private actors in the last two decades, both from civil society and the market domain have been momentous and cannot be overlooked.

The emergence of private sustainability governance is viewed as a response to the inadequacies of interstate negotiations, institutions, and policies (Abbott, 2012). Its development coincides with neoliberal political and economic trajectories spurred on by many developed nations. Together with increased globalised processes of many of the world's services and goods, the traditional perception of the state transformed in neoliberal societies and induced the notable shift from 'government' to 'governance'.

The concept of governance is ultimately concerned with creating the conditions for ordered rule and collective action (Stoker, 1998). It refers to a new process of governing, a changed condition in ordered rule, or the new method by which society is governed which is attributed to the changing boundaries between public and private domains (Rhodes, 1996). The idea of governance for sustainable development embodies an explicit steering logic that also involves societal self-steering (Meadowcroft, 2007). Whether oriented towards the attainment of sustainable development as contributing to environmental protection, social development, or economic development, it is within this context that private actors have proliferated and have become increasingly engaged with transnational regulatory activities of diverse issue fields.

What characterize nearly all collaborative arrangements for sustainable development are their voluntary and non-hierarchical features. These collaborations can take several forms, and governance scholars refer to multi-stakeholder partnerships when there is participation by actors from two or more spheres of society, which may be the state, market and civil society (Glasbergen, 2007). Collaborations between market and civil society actors are referred to as private arrangements (Paton, 2011) or sometimes more specifically as NGO-business partnerships (e.g., Pattberg, 2004). The inclusion of both public and private actors is also signified as public-private partnerships (e.g., Schäferhoff, Campe, \& Kaan, 2009), or more broadly as collaborative governance (e.g., Ansell \& Gash, 2008).

The shift from government to governance has implicated a move away from traditional hierarchical forms of organisation and the adoption of network forms (Bellamy \& 
Palumbo, 2010), from an emphasis on laws to more flexible and voluntary forms of regulation and implementation (e.g., Abbott, 2012; Bartley, 2011) and having to deal with various sources of authority and power (Meadowcroft, 2007). In fact, many policy domains in international relations are not regulated, and often not dominated, by a single international regime but are characterised as fragmented (Biermann, Pattberg, van Asselt, \& Zelli, 2009). This fragmentation can refer to the character of institutions (from implicit norms to international organisations), the type of governance arrangement (public, private, public-private), the issue field (from sectoral concerns to human rights), and the spatial scope (from bilateral, regional to global).

Fragmentation in global governance for sustainable development is not understood as problematic per se. Sustainability problems are complex and require specific responses that may not be delivered by a single arrangement. However, fragmentation becomes problematic when the capacity of governments or international organisations are weakened in their desired effects (Ivanova \& Roy, 2007) or more broadly, if it hampers the efficient and effective realisation of generally accepted public values (Derkx \& Glasbergen, 2014).

Contemporary academic and political debates converge on the urgency for a more enhanced, effective, and more coherent institutional framework for the governance of sustainable development. At the core of the debate lies uncertainty about whether the diversity and multiplicity in governance arrangements should be embraced, or if coherence should be promoted to actively constrain fragmentation (Ivanova \& Roy, 2007).

This area of tension between fragmentation and cohesion has remained largely unexplored, and this dissertation aims to analyse how this tension manifests itself, what its characteristics are, and what the implications are for sustainability governance. In this introductory chapter, the concepts of fragmentation and cohesion will be explored and embedded within different theoretical perspectives. Against this backdrop, the opportunities and limitations of both fragmentation and cohesion will be delineated. In the research approach several aspects of the conceptualisation of fragmentation and cohesion will be further specified after which the research questions of this dissertation will be articulated. In conclusion, the methodology - including concepts and methods will be made explicit and the dissertation structure will be outlined.

\subsection{Fragmentation and Cohesion}

The new global public domain, characterised as the increasingly institutionalised transnational arena concerning the production of global goods and provision of services, has introduced opportunities and constrains upon both global and national governance that did not exist in the past (Ruggie, 2004). Once including sovereign states in the interstate realm only, the new global public domain has become the domain of private 
actors and public-private partnerships as well. Global value chains quintessentially concern sustainable development, as the production of global goods and provision of services on the global level transcends national boundaries on social, environmental, and economic issues. Its emergence is closely connected to globalisation, and the opportunities and constrains presented to the governance of the global public domain are influenced by what Rosenau (2003) has described as the two basic contrary processes underlying globalisation: "One involves all those forces that press for centralization, integration, and globalization, and the other consists of those forces that press for decentralization, fragmentation and localization" (p.14).

These two forces are at the centre of a general debate on fragmentation and cohesion of global governance. The concepts are used to describe the same empirical reality of the overall regulatory setting. However, whether reality is regarded as fragmented or cohesive is also dependent on the scale of analysis (local, national, regional, international, transnational) and is furthermore influenced by normative perceptions about the desirability of fragmented and cohesive governance structures. In the sections below, the concepts will be placed within the wider academic debate, and opportunities and limitations that derive from fragmentation and cohesion on global sustainability governance will be elaborated.

\section{Fragmentation}

The concept of fragmentation has gained prominence in several social scientific disciplines and has most widely been employed in international law and political sciences. Within the political sciences, the disciplines of international relations and global governance of environmental and sustainable development are most notable. In its broadest sense the term is used to signify the diversity, multiplicity, divergence and distribution of regulatory powers of the overall institutional settings and resulting policies of different international policy domains and transnational issue fields.

The background of fragmentation in international law is traced back to the mid- $20^{\text {th }}$ century where conflicts between treaty regimes and legal instruments were anticipated (Jenks, 1953). This gained prominence due to the proliferation of international treaties, and the term treaty congestion was used as a concept to study overlaps among treaties and to describe the problems of treaty conflict (e.g., Brown Weiss, 1993; Hicks, 1999). Furthermore, the emergence of specialised and relatively autonomous legal institutions, complexes, and spheres of legal practices of contemporary international law has also given rise to the study of fragmentation. Particularly, the use of respective principles and institutions of specialised systems of law coupled with the unawareness of legislative and institutional activities in adjacent fields and of the general international law principles and practices posed serious concern (International Law Commission, 2006). 
At the turn of the $21^{\text {st }}$ century the term fragmentation was included in the work programme of the International Law Commission (2000, para. 729) and shortly the concept of fragmentation was taken up by the international legal community (e.g., Hafner, 2004; International Law Commission, 2006; Koskenniemi \& Leino, 2002) where the term sparked debates about the opportunities and threats arising from the fragmentation of international law (van Asselt, 2014).

Subsequently, the concept was adapted by international relations and global governance scholars. International regime theory had already laid the groundwork from the end of the 1960s onward, in which power was recognized as being dispersed among many different agents, including states, international organizations, and multi-national companies. These actors were then assumed to operate as tacit coalitions under similar understandings of procedures and desirable outcomes (Verbeek, 2011). The concept of fragmentation was particularly taken up by academics on environmental governance (e.g., Andresen, 2001; Bernstein \& Ivanova, 2007; Biermann et al., 2009). In this field there is by-and-large a consensus that institutional fragmentation is a structural characteristic of contemporary international relations (Zelli \& van Asselt, 2013) yet also here the perspectives differ on whether the causes and consequences are to be positively or negatively assessed (e.g., Abbott, 2012; Ivanova \& Roy, 2007) and on its implications for effectiveness of governing (Pattberg \& Widerberg, 2015).

In international trade theory and policy, the phenomenon of fragmentation in production and trade is understood to be a defining characteristic of global value chains (Stephenson, 2013). Particularly the geographical fragmentation of supply chains is considered to have benefitted multinational corporations. Cost-saving occurred through paying lower wages in non-industrialised countries, as well as through loose or non-existent regulation of labour and environmental practices (Sobel-Read, 2014). Furthermore, problems have been associated with private standards at the level of the multilateral trading system: first by posing unnecessary or unjustifiable restrictions on trade, and second by questioning the validity and effectiveness of the resulting system of (self-) regulation. Issues of fragmentation, overlaps, multiplicity, credibility, and varying degrees of transparency in relation to how standards are set have been identified. Furthermore, questions have also been raised on how the conformity of requirements is assessed and audited, and the extent to which traceability systems are reliable (Meliado, 2017).

The analytical usage of the concept is not uniform, and an exploration of the definition sheds more light on the different uses of the word. The Oxford English Dictionary defines the noun "fragment" (2014) in a figurative and transferred sense as: "A detached, isolated, or incomplete part; a (comparatively) small portion of anything; a part remaining or still preserved when the whole is lost or destroyed". The suffix "-t-ion", which forms nouns of action, is defined as "A breaking or separation into fragments" (2014). Three considerations come to the surface. First, there is an inference of a 
'complete' or 'whole' in either the past, present or future tense. Second, the noun of action signifies there are forces causing it. Third, a differentiation can be made between the process (breaking) and a state of affairs (separation).

In relation to the first consideration, the idea of complete or whole governance systems is only implicitly fashioned, particularly by use of concepts as policy coherence, harmonisation, equivalence, and metagovernance (which will be discussed in greater depth in the following subsection on cohesion). It remains mostly a conceptual and political construct, and non-fragmented or universal systems are rather mentioned in terms of theoretical conceivability (Biermann et al., 2009) and the organisation of governance systems is considered unstructured as it is not organised around a coherent set of rules and decision-making procedures in a hierarchical manner (Pattberg \& Widerberg, 2015).

With regard to moving or driving forces, global liberalism and neo-liberalism are mainly identified as the dominant ideological trajectory of globalisation that has shaped the outcomes of the political and social discourse of sustainable development in the last decades. International financial institutions, multinational corporations, and professional elites have, among others, contributed to neoliberal ideas, rules, and practices becoming dominant in international policy domains (Bartley, 2007).

Above all, institutionalised rules of free trade and the ideas stressing faith in free markets have shaped the way in which social, economic, and environmental problems can be solved. It is within this context that the shift from government to governance has taken place. According to Bernstein and Ivanova (2007), the accompanying lack of progress within multilateral environmental agreements contributed to the (further) fragmentation of environmental governance.

While academic disciplines from law and public policy allude more to fragmentation (or cohesion) as a process that can be (re)directed (by its practitioners indeed), governance scholars are more prone to regarding fragmentation as a state of affairs. The sum of the formal and informal rule systems at all levels, is considered a highly disaggregated and only a minimally coordinated system of governance (Rosenau, 2003). The institutional variety in the absence of hierarchical coordination (Benvenisti \& Downs, 2007) is therefore considered a pervasive characteristic of the transnational domain. This point of departure does not necessarily problematize fragmentation as an important issue, but rather the coordination (or its absence) of fragmented or differentiated governance actors in global governance (Zürn \& Faude, 2013). This is where the proponents of cohesion enter the debate.

\section{Cohesion}

The changes in global governance and the accompanying growth in regulatory complexity also spurred the quest for cohesion, sometimes also referred to as 
'convergence' (e.g., Vogel \& Kagan, 2002). The underlying arguments behind inquiries into cohesion stem from the observation that complexity and fragmentation can be unconducive in realising societal goals, as it may for instance sort contradictory effects.

Different conceptions of cohesion in the social sciences propose different forms of partnership, cooperation and coordination to overcome the condition of fragmentation and enhance concerted aims and action. This conceptualisation has taken a variety of forms, and in the following different strands and conceptions of scholarly work on cohesion will be delineated.

\section{Policy coherence}

The pursuit for coherence in policy has been addressed in scholarly work of public policy and multi-level governance (e.g., May, Sapotichne, \& Workman, 2006; Winship, 2006), particularly in issue fields such as development aid and multilateral environmental agreements (e.g., Jones, 2002; Mickwitz et al., 2009; Sianes, 2013).

The term coherence in this context implies that policies are associated or can be grouped together because they share a set of ideas or objectives. While variations across policy domains are present, it is considered that many policy areas are marked by inconsistent policies and little commonality of goals. For this reason policy scholars generally agree that more coherence of policies is desirable (May et al., 2006).

Although questions of cohesion in this body of literature are restricted to public governing and the efficient management of the public sector, it nevertheless offers a perspective on the intentions and meanings behind the quest for cohesion in policy domains. As Jones (2002) describes, policy coherence offers a positive vision on how to reach societal goals as it emphasises the cumulative value-adding potential "from efficiently interweaving the contributions by different policy communities" (p. 329). Through systematic promotion of mutually reinforcing policy actions, across departments and agencies, Jones envisions that synergies are created towards realising defined objectives.

Policy coherence is thus essentially concerned with overcoming inconsistencies between policies and across departments and agencies, in order to realise consistency in action.

\section{Harmonisation}

Harmonisation is related to the concept of policy coherence, but is primarily a topic of scholarly discussion from different fields of law and has its roots in international law. In this domain, states are bound by the treaty obligations and are expected to try to implement them as far as possible, even in case of conflict in norms. In this regard, harmonisation is a generally accepted principle that when several norms bear on a single 
issue they should, to the extent possible, be interpreted so as to give rise to a single set of compatible obligations (International Law Commission, 2006).

Harmonisation has been an important feature of modern legal systems. The role of harmonisation in the European Union is notable (Bhatia, 2010). Of particular significance in this regard is that the European Union's official motto, that has been adopted in 2000, is "united in diversity". This core value signifies the coming together of countries in the European Union for peace and prosperity, while still acknowledging the different cultures, traditions, and languages therein (European Union, n.d.). At the same time, the harmonisation of laws of the Member States is a core instrument (Andenas \& Andersen, 2011). It is intended to minimise the degree of variations and decrease the amount of significant underlying differences in order to achieve similarity between national jurisdictions (Andreadakis, 2011). In Europe, harmonisation served the purpose of political and economic creation of a regulatory environment for the European Union. Within this context, it has been purposefully endorsed as a policy of the European Commission to achieve uniformity in laws of member States to facilitate free trade and protect citizens (Bhatia, 2010). Harmonisation implies that diverse legal provisions or systems are coordinated resulting in a set of minimum requirements or standards. Harmonisation is not understood as the unification of law, with a system of similar or identical laws. The objective of harmonisation is rather the creation of a framework within which laws coincide and operate efficiently without inconsistencies or inequalities. Such a framework can be created through the introduction of a set of basic standards, of which the flexibility need to be agreed in advance to avoid problems if standards need alterations (Andreadakis, 2011).

While harmonisation intends to give rise to a set of compatible rights and obligations, a differentiation can be made in the objectives of harmonisation. In international law, the purpose of harmonisation is to avoid or solve conflicts in norms, whereas in the European Union it is more instrumental as a means to facilitate free trade and the protection of citizens. Furthermore, within the legal literature, the concept is sometimes separated into two forms: procedural and consequential harmonisation. Procedural harmonisation refers to the manner in which the process of harmonisation is undertaken, and relates essentially to the techniques used for adoption of harmonised law or adaptation towards a harmonised law. Consequential harmonisation on the other hand, is about achieving desired outcomes. The different topics in which harmonisation is sought, are for instance on institutions, mechanisms, terms, principles and on processes (e.g. how laws will be implemented and interpreted) (Andenas, Andersen, \& Ashcroft, 2011).

The topic of harmonisation is not limited to legal literature. Outside the intergovernmental settings, the informal harmonisation processes have become more important. Model codes, standards, principles, and other outcomes of harmonisation processes, have received attention. Particularly the interaction with intergovernmental 
institutions, and their reception in the private or national sphere has been accounted to merit further attention (Andenas \& Andersen, 2011).

For instance, the United Nations Forum on Sustainability Standards (UNFSS) was specifically developed as a platform of international dialogue on voluntary sustainability standards. A key issue on the agenda of this platform is harmonisation, which is understood as relating to processes that aim at the establishment of identical standards, technical regulations and conformity assessment requirements (Bowen \& Hoffman, 2015). Due to the emphasis on identical standards, the concept of harmonisation differs from the interpretation as offered in the legal domain. Various other disciplinary fields have picked up on the concept as well, including international relations, European studies, and political theory but a common framework to analyse harmonisation is lacking, both within the legal domain as well as across the disciplines (Andenas et al., 2011).

\section{Equivalence}

Equivalence is sometimes referred to as the second model of harmonisation, also termed convergence, approximation, or less-than-full harmonisation (Donahue, 2000). Its origins have been both accounted to Europe's difficulties in achieving full harmonisation of standards (Donahue, 2000) as well as international harmonisation of standards as required by trade rules by WTO and NAFTA as "equivalence determinations" (Wallach, 2002). Under the equivalence model, countries can accept each other's disparate models without actually equalising the standards. It is only agreed that their different standards will be treated as if they are the same, signifying a functional equivalence. When countries pledge their standards as equivalent, a mutual recognition agreement (MRA) is constituted (Donahue, 2000). Once declared "equivalent", goods are allowed free passage to the respective markets, also in case of significant differences (Wallach, 2002). This also means that weaker or less protective regulatory systems and standards can serve as a bypass route around more stringent standards, thereby invalidating stringent standards (Donahue, 2000; Wallach, 2002).

Just as the concept of harmonisation has gained significance beyond the realm of international law and legal literature, equivalence has similarly become an important notion for transnational regulation which also pertains to private standards. Nongovernmental actors, including NGOs, retail consortia, manufacturers, producers and trade cooperatives promote and stimulate the use of standards and certification schemes. Among other issues, such as the use of only specified certification bodies and the costs of third-part certifications, the lack of equivalence between schemes is also recognised to be an issue that leads to a multiplication of certification processes and the lack of recognition of certificates issued within defined markets (Wouters \& Geraets, 2012).

Similar to the meaning in law, equivalence of standards denotes the acceptance that different standards or technical regulations achieve the same objectives, even if through 
different means. Present day, both harmonisation and equivalence have gained prominence through various initiatives (see Bowen \& Holmes, 2013) in order to address regulatory and trade challenges that arise from public, private and public-private efforts.

\section{Metagovernance}

The concept of metagovernance has also been advanced as potentially fulfilling a steering function to bring more cohesion in the norms and rules in policy domains. Most of the scholarly work on metagovernance, sometimes also referred to as 'network management' (e.g., Rhodes, 1997) is from public policy and management scholars (e.g., Klijn \& Edelenbos, 2007; Peters, 2007). In these works, networks are widely recognised as a new form of public organisation and there is a focus on the strategic attempts to manage interaction processes between actors in networks.

Defined as the 'organization of self-regulation' (Jessop, 1998) and as a way to govern private self-regulation (Kooiman \& Jentoft, 2009; Meuleman, 2006, June; Peters, 2007; Torfing, 2012; Vermeulen, 2015), metagovernance is conceptualised to designate processes of coordination intended to reduce different and sometimes conflicting governance modes (Jessop, 2002; Meuleman, 2006, June). Governance processes in networks can deliberately be guided on both content and process (Klijn \& Edelenbos, 2007), and metagovernance can cover different guidance mechanisms to stimulate change (Rhodes, 1997).

The role of public actors has stood central in these works (see also Steurer, 2013). Although the involvement of governments in bringing more cohesion in the norms and rules in policy domains is considered to become less hierarchical and less centralised that is, at least in liberal democratic societies, it is still imagined that governments should bring coherence among governance networks and provide the ground rules for governance. While private actors and networks are envisioned to act free, in metagovernance they are still under a 'hierarchical shadow' of states (Jessop, 1998). In analogous conceptions of metagovernance, governments and its officials have the ability and legitimacy to set a regulatory framework for governance actors, in which actors from the public and private sphere can act (Bell \& Park, 2006; Christopoulos, Horvath, \& Kull, 2012; Parkins, 2008; Whitehead, 2003).

In recent work on metagovernance, the importance of private actors as part of a joint effort for metagovernance is underscored (Kooiman \& Jentoft, 2009), and private metagovernance has been recognised to take on a steering role for sustainable development (Bitzer, Glasbergen, \& Leroy, 2012; Derkx \& Glasbergen, 2014; Glasbergen, 2011).

A slightly distinctive concept of meta-organisations has also been employed in organisational theory, where meta-organisations are recognised to have other organisations as members. A similarity between members and certain common interests is here considered a vital prerequisite that enables the members of meta-organisations to 
work together with horizontal relationships, voluntary membership, and equal influence (Ahrne \& Brunsson, 2008).

The work of the non-governmental organisation of ISEAL Alliance is exemplar of private metagovernance. The objective of this arrangement is to strengthen sustainability standards systems. These standards may regulate production processes in different sectors and industries (ISEAL Alliance, 2015). Particularly the development, implementation, and stewardship of internationally applicable good practice and guidance on the implementation of credible standards systems is at the heart of ISEAL Alliance's work (Derkx \& Glasbergen, 2014).

\subsection{The Fragmentation and Cohesion Debate}

There are many arguments identifiable within the general debate on fragmentation and cohesion that point towards possibilities and signal shortcomings on both sides of the debate. In this discussion, different terms are sometimes used to indicate fragmentation. For instance, variety (e.g., Stupak, Lattimore, Titus, \& Tattersall Smith, 2011) is used to

signify that regulatory frameworks on the same general topics are distinct in character or quality; multiplicity (e.g., Ivanova \& Roy, 2007) is used to indicate the large number and/or wide range of regulatory frameworks; and organisational complexity (Gupta, Pistorius, \& Vijge, 2016) is used synonymously to fragmentation. In the following, the two sides of the debate are delineated where after there will be a reflection on this debate.

\section{The advantages of fragmentation and limitations of cohesion}

One of the main arguments favouring fragmentation in global governance is that different needs can be catered to and different strengths can be capitalised. To start off with, the inclusion of private arrangements for sustainability governance can supplement traditional international regulation. This has contributed to governance at multiple scales, including the proliferation of agreements, agencies, partnerships, and alternative forms of governance. These could be advantageous in reaching sustainable goals (Bernstein \& Ivanova, 2007). Furthermore, fragmentation may also contribute to context specific solutions, as non-centralised or decentralised governance is to some extent an essential condition for effectively addressing sustainability concerns through their locally manifestation and often necessitating tailored responses. The multiplicity of private arrangements allows for the adjustment of standards and procedures to local circumstances (Abbott \& Snidal, 2009). The multiplicity may also foster specialisation and expertise. It is sometimes compared to a division of labour, where actors focus on specific strengths in response to different needs (Auld, 2014; Overdevest \& Zeitlin, 2014). 
An interlinked argument in favour of fragmentation is that it leads to multiple routes of intervention. International norms are uniform and express what is esteemed and valued. Norms shape policy when they become translated into concrete governance programs (Berliner \& Prakash, 2012) and diverse private arrangements can adjust for specific sectors or issues more than uniform norms (Abbott, 2012). If diverse stakeholders are proactively involved in sustainability governance, the same regulatory issues can be addressed in multiple and diverse ways as each actor has its own interests, values, and competencies (Derkx \& Glasbergen, 2014). The competition akin to this may function as a source of innovation (Glasbergen, 2009, December). On the whole, the cumulative effort of public and private governance exceeds that of either approach alone (Abbott, 2012).

An advantage of multiple routes of intervention can be that it may also permit for the unregulated areas to become regulated. This argument particularly finds resonance in legal accounts, where the increased diversity in legal norms and the growth of international law to formerly unregulated fields is considered a positive sign (Lindroos \& Mehling, 2005). On account of this, international law has grown to cover important new issue areas of international relations, including human rights and the environment (van Asselt, 2014), and has also stimulated multilateral environmental agreements. Also multistakeholder arrangements thrive within this environment, as barriers to entry are low and not as costly or complex as pursuing international regulation. Particularly concerned private governance actors can easily experiment with and advance new methods and programs to persistent sustainability problems (Abbott, 2012).

Cohesion does not promote the resilience that fragmentation offers in the previous arguments. For the sake of concerted and consistent action, variation and diversity would reasonably be less likely encouraged and would hence lead to limited routes of intervention. Next to the question of legitimacy - who should exercise this authority and dictate the terms for cohesion? -, creating the conditions for concerted action through regulation is time intensive and costly. Cohesion may then pose the risk that dominant views will be pursued or left unchallenged, and not inclusive of actors with lesser means. The advantages that fragmentation offers would be jeopardised. Particularly in the case that the diversity of regulatory frameworks reflects different interests and objectives, it promotes global regulatory pluralism, a value that according to some ought to pervade the institutional design of transnational space (Cafaggi, 2016).

The fragmentation between private arrangements has also been hypothesised as stimulating a race to the top, possibly increasing the effectiveness of regulations on the whole (Bertels \& Peloza, 2008; Overdevest \& Zeitlin, 2014). Private governance arrangements competing in similar issue areas may well apply pressure towards stricter standards and verification mechanisms, and more democratic or representative arrangements. Competition is conjectured to stimulate favouritism of consumers and 
other concerned audiences, and private arrangements may raise their standards to distinguish themselves from others (Derkx, 2011).

Regulatory competition may not only stimulate a race to the top, another line of argumentation is that the advancement of different solutions in different contexts will lead to the diffusion of best practice to other regulatory contexts (Jänicke \& Jacob, 2006). When private schemes can learn from one another, this may lead to regulatory innovation (Cafaggi, 2016). A similar perspective to the diffusion of best practices proposes that regulatory diversity allows the governance system as a whole to learn and evolve faster because it allows for experimentation, demonstration effects, and the imitation or scaling up of successful programmes (Abbott \& Snidal, 2009).

In turn, more cohesion in regulation does not automatically imply better policy. It could even be detrimental, as learning and innovation through fragmentation could be hampered and lead to lowest common denominator outcomes (Fransen \& Conzelmann, 2014). Even more fundamentally, policy coherence in itself does not signify anything about the appropriateness of a given set of policies to the problem or issue at hand, also not in regard to the stringency level of regulation. In this sense, both 'good' and 'bad' can have varying degrees of coherence (May et al., 2006).

\section{The advantages of cohesion and limitations of fragmentation}

The main policy concepts for cohesion are by and large concerned with the need for consistency in norms, rules, and actions. At the core of arguments favouring cohesion lays dissatisfaction with the negative consequences emanating from fragmentation. The freedom that the largely uncoordinated global governance system allows for sustainability issues to be taken up, arguably also allows for limited or undesired effects.

First of all, a fragmented state of governance is conducive for the poor use of existing information and resources, both across and between policy levels (Bernstein \& Ivanova, 2007). Concerted action is therefore an important driver of cohesion. In furtherance of a mutual cause or purpose, different actors strive to align efforts in the same direction.

Beyond concerted action, coherence is also understood to allow for consistency in action (Winship, 2006) and policies (Bernstein \& Ivanova, 2007). Through for instance meta-governance, activities are mutually reinforced ensuring that the efforts and activities of arrangements are aligned to achieving a common agenda. Through fragmentation, a serious threat is posed on the uniformity and coherence of laws and policies. Issues that are at the heart of sustainable development, such as environmental protection and human rights, are obscured through arrangements and policies that may only be paying lip service to the causes (a phenomenon also called 'greenwashing' (e.g., Ramus \& Montiel, 2005; van der Ploeg \& Vanclay, 2013). As has been considered before, cohesion does not guarantee stringency in protecting values; nonetheless, the state of fragmentation is also 
considered to not lead to a race to the top but to a race to the bottom in which lowest denominator options might prevail (e.g., Vogel \& Kagan, 2002). Furthermore, where cohesion does not imply better policy, fragmentation in governance systems implies that within the same policy domain, inconsistency in objectives and differences in course of action are taking place. This is considered problematic particularly in cases where agreed upon core values, such as basic human rights, are breached and legitimatised through governance arrangements that obscure or redefine basic rights. A fragmented state of affairs may certainly also be exploited to the advantage of particular powers, whether governments or industry players, who may fear losing a vested interest.

The range of different governance arrangements present in the current global system of governance - all with some power resources - in fact also offer the opportunity to build coalitions (Meadowcroft, 2007). Not a singular arrangement is considered to hold sufficient authority, resources, and knowledge to translate policy objectives into practice. The concerted efforts of multiple actors are vital, as each does not hold significant capabilities but are also dependent on other actors to strengthen policy intentions and translate it into action (Bernstein \& Ivanova, 2007). Institutional interplay, or interaction among similar arrangements can be political and functional, and therefore supports achieving their goals by pooling resources (Oberthür \& Gehring, 2004).

Through coalitions and interplay, cohesion is in principle conducive for a more efficient use of resources as institutional demands can be either coordinated or better aligned. Numerous arrangements on the same issues increase the costs necessary for operations. Regardless of the source of funding, without alignment or some coordination, strong overlap in operations signify an inefficient use of resources.

\section{Reflections on the debate}

The conceptual divide between fragmentation and cohesion goes beyond a crude distinction of favouring one side of the debate over the other. It also goes beyond a consequential evaluation in which the state of regulatory fragmentation simply calls for cohesion. The academic debate rather exposes that there are different analyses and implications for the governance of sustainable development. Ontologically, the regulatory reality and the related problems are characterised differently (e.g. fragmentation hinders effective policy-making). Normatively, different conceptions of what is good or desirable are proposed (e.g. global regulatory pluralism is desirable). Strategically, different courses of action are endorsed to overcome regulatory problems (e.g. strategic alignment through equivalence).

Furthermore, the fact that there are two sides to the debate does not entail that the two concepts are necessarily juxtaposed. As the different perspectives on prompting more cohesion in policy domains reveal, multiplicity or diversity is not considered as a problem in itself, but the calls for cohesion rather envision a system of governance in which 
standards and regulations are not contradictory. For instance, under the equivalence or harmonisation model, disparate standards can be accepted as long as the amount of significant underlying differences is decreased. These models in essence oppose normative conflict, rather than for instance opposing multiplicity or diversity.

Another observation is that there has been a stronger inclination from public policy studies towards cohesion than posited by governance scholars, where the latter is largely undetermined particularly concerning the question whether the diversity and multiplicity in governance arrangements should be embraced for sustainable development, or if coherence should be promoted to constrain fragmentation. Whether explicit or implicit, at the heart of the debate there are concerns and questions concerning efficiency and inefficiency, convergence or divergence of goals, road maps for action and cooperation, and power.

\subsection{Analytical Perspective}

The central focus of this dissertation is on fragmentation and cohesion of governance systems in environmental and social issue areas, particularly those that pertain to global value chains. Due to the economic interconnectedness of global value chains, the functioning of markets and trade conditions also plays a role in this investigation. A subsequent focus of this dissertation is to understand how fragmentation and cohesion is determined and influenced by the governance capacity of arrangements and issue-specific systems as a whole. The notion of governance systems will therefore function as the analytical perspective through which fragmentation and cohesion of different policy domains is investigated, whereas the concept of governance capacity functions as an evaluative concept. Several issue areas have been chosen as case studies. In the following, these concepts and issue areas will be explained in further detail.

\section{Governance systems}

The governance system approach is rooted in governance theory and is concerned with the governability of public issues. As a starting point, governance systems are comprised with governance actors that relate to each other and the issue. The affiliation to the same issue field in itself links the actors indirectly to each other; through interacting with each other the actors can have a direct linkage. Scholars have applied it to diverse issue fields, including the governance of forests (Guéneau, 2007), marine protected areas (Jentoft, van Son, \& Bjørkan, 2007), and fisheries (Burns \& Stöhr, 2011a, 2011b).

The governance system of an issue field demarcates how rules and policies are made, reformed, interpreted, implemented, and enforced. Governance actors can both be subject as well as steering agents within the system. These actors can represent diverse interests, including the political domain (parties, states, international government 
organs), the market domain (private companies, business alliances and associations), civil society (non-profit organizations, NGOs) and other groups and associations as for instance scientists, other experts, or any social entity that conducts activities of deciding, governing, coordinating, regulating, allocating resources, etc. (Burns \& Stöhr, 2011b).

The governance system approach relates to the concept of governance architecture, which is defined as "the overarching system of public and private institutions that are valid and active in a given issue area of world politics. This system comprises organizations, regimes, and other forms of principles, norms, regulations, and decisionmaking procedures" (Biermann et al., 2009). This definition also explicitly refers to a system of an issue area. However, there is a slight difference in the unit of analysis in transnational governance as the term institutions is adopted which refers to broader structures and mechanisms of social order that guide behaviour. The unit of analysis within this dissertation lies explicitly on governance actors themselves, the governance system they comprise as a whole, and the rules and norms that derive from them.

\section{Governance capacity}

The concepts of capacity, capacity development, and state capacity have been particularly prevalent in international development literature from the late 1980s (Baser \& Morgan, 2008; Enriquez \& Centeno, 2012). The definitions are closely related and sometimes interchanged with the term capability. Capacity generally refers to the overall ability of an organisation or system to create public value (Baser \& Morgan, 2008) and capacity development is defined as the process through which individuals, organizations and societies obtain, strengthen and maintain the capabilities to set and achieve their own development objectives over time (UNDP, 2008).

The concept of capacity has recently also been used by governance scholars who respectively imply regulatory or governance capacity (see table below).

Table 1.1 Definitions for governance and regulatory capacity

\begin{tabular}{ll}
\hline Definitions & Authors \\
\hline $\begin{array}{l}\text { Governance capacity are the capabilities (or lack of capabilities) of } \\
\text { institutional arrangements to effectively carry out global policies which }\end{array}$ & (Held \& Young, 2013) \\
could generate desired changes. & (Biermann et al., 2014) \\
$\begin{array}{l}\text { The capacity of institutions to resolve problems of public policy and } \\
\text { implement effective rules is a requirement for effective governance. }\end{array}$ & \\
$\begin{array}{l}\text { Regulatory capacity is the sum of the resources available to actors (both } \\
\text { public and non-state actors) within regulatory regimes for getting things } \\
\text { done, including expertise. }\end{array}$ & (Scott \& Brown, 2010) \\
\hline
\end{tabular}

From these definitions, several elements come to the fore. The first two are rather straightforward in that governance capacity is described as the ability to implement 
policies (e.g. regulatory capacity) and the condition of contributing to policies (e.g. public policy). Due to the global focus of international development literature and governance theory, it is specifically envisioned that governance capacity has the ability to contribute to policies on the global level, which may be both international as well as transnational in scope. The other elements relate to whether capacity is defined in terms of available resources (input capacity), the ability to achieve certain outcomes (outcome capacity) and connected to this a criterion of success (e.g. effectiveness).

The differentiation between 'input capacity' and 'capacity as an outcome' has also been a subject of international development literature. Input capacity refers to whether arrangements have the capacity, in terms of resources and capabilities, to achieve their stated objectives (Bitzer, 2010).

This includes monetary and organisational resources and expertise from personnel, and can refer to the sum of all sources available to actors for getting things done (e.g., Abbott \& Snidal, 2009; Scott \& Brown, 2010).

Outcome capacity on the other hand, is about the ability to achieve certain outcomes and results (Bitzer, 2010). Capacity is in this context understood as the resulting combination of individual competencies, collective capabilities, or overall system abilities, that enable systems to create value (Baser \& Morgan, 2008), that is, contributing to economic, social, and environmental value for individuals, organisations and society (Austin \& Seitanidi, 2012). Governance capacity in particular has been defined as "the capabilities (or lack of capabilities) of institutional arrangements to effectively carry out global policies which could generate desired changes" (Held \& Young, 2013, p. 310).

It is in this regard very much related to the question of effectiveness in addressing sustainability problems, as effectiveness is about producing the intended or expected results to solve the problems. Pattberg and Widerberg (2015) explain that effectiveness is however difficult to research for two main reasons. Firstly, even though many arrangements address an identifiable governance deficit, sustainability problems are embedded in broader socio-economic developments that arrangements can seldom control. Secondly, transnational arrangements often focus on information disclosure and raising public awareness, rather than targeting an environmental or sustainability indicator directly. While sustainability performance might be improved as a result of these mechanisms, making causality claims remains a research challenge. Due to these difficulties, this dissertation will therefore predominantly follow the definition of governance capacity as an outcome-oriented concept and operationalises governance capacity as the capabilities (or lack of capabilities) of governance systems to effectively carry out transnational policies which could generate sustainable changes in global value chains. 


\subsection{Research Aim and Questions}

Considering the analytical perspective and evaluation criteria, as described above, this dissertation seeks to address the following main research questions:

i. What tensions between fragmentation and cohesion manifest themselves in various global governance systems?

ii. How do these tensions influence the governance capacity of these systems?

iii. What attempts have been made to handle these tensions and how are they able to contribute to the governance capacity?

In the context of governance for sustainable development, the increasing prominence of particularly social and environmental standards in global value chains is unmistakable. With the intention to account for the broad range of both public and private actors involved in the policy domains, as well as to grasp the diversity in issue areas covered by governance actors, this dissertation focuses on four different cases, which are each presented as an empirical chapter. The ordering of the cases in this dissertation has been determined on the basis that the final empirical chapter dissertation can be better contextualised by readers as it expands on the findings of earlier chapters. Furthermore, each of the cases contributes to answering one or multiple research questions.

The first case study is on private fair labour arrangements (chapter 2). Historically, the labour movement and the development of labour law broadly arose in parallel to the industrial revolution as the need to protect the common interest of workers developed. On the international level, after the first decade of the $20^{\text {th }}$ century a tripartite organisation - the International Labour Organization - was developed bringing together governments, employers and workers representatives. This organisation sets and promotes standards and fundamental principles and rights at work. In the last decades of the $20^{\text {th }}$ century however, non-governmental organisations arose also setting standards for private actors. The case study on private fair labour arrangements explores the dimensions along which fragmentation and cohesion of governance can be studied. It does so by focusing on the governance system for fair labour in global value chains. The analysis centres on the characteristics of the system as a whole, which is evaluated from three dimensions: a structural-organisational, a normative-cognitive, and a collaborative-relational dimension. It is then argued how these characteristics influence the governance capacity of the system as a whole. This chapter contributes to answering the first two research questions.

The second case study is on regional standards for organic production (chapter 3). Historically, the concern for organic production arose during the second industrial revolution. While in ancient agriculture there were philosophies of agriculture being in harmony with nature, organic farming as we know it today can be traced back to the early 
$20^{\text {th }}$ century and originated in reaction to the rapidly changing farming practices (Geier, 2007). The organic movement was the first initiator of organic standards, but in the last decades of the $20^{\text {th }}$ century, national and regional standards also arose to codify and legally protect the requirements for organic production and labelling. The case study on regional standards for organic production examines the role of regionalisation of standards, which are standards within geographical regions with at least two neighbouring countries. In particular, regional standards for organic production have been promoted and created in an attempt to make the regulatory field of standards on organic production more cohesive. In this chapter, the extent to which cohesion on norms and standards have been achieved and whether regional standards for organic production have been conducive for regional and international trade is investigated. This chapter contributes to answering all three research questions.

The third case study is on private metagovernance (chapter 4). In many global value chains, voluntary standards arose to tackle sustainability issues. The plethora of initiatives and voluntary standards link many farmers and producers from developing countries with consumers from developed countries, and are used to assure that suppliers satisfy minimum norms, whether in the social, economic, or environmental sphere. The proliferation of these initiatives has brought forward diverse, and oftentimes overlapping, efforts for the voluntary regulation of different value chains. The case study on private metagovernance explores the potential of private metagovernance to bring more coherence into global value chain governance for agricultural production and fisheries. Four mechanisms are identified that enable arrangements to influence the conditions of self-regulation and steer governance in issue-specific fields. The opportunities and limitations of private metagovernance are assessed on basis of three case studies in the coffee, cocoa, and fisheries sectors. This chapter contributes to answering the third research question.

The fourth case study is on tensions in global governance systems (chapter 5). Taking two issue fields discussed in earlier chapters, namely the global governance of labour rights and organic production, the case study explores tensions arising in the respective fields through efforts to foster cohesion. It is postulated that tensions are firstly dependent on the system characteristics of fragmentation of an issue field and secondly, dependent on the ways in which cohesion is sought. This chapter contributes to answering all three research questions. 


\subsection{Research Methodology}

The chapters in this dissertation are based on empirical studies. Although the methods that have been chosen for each study are delineated in the separate chapters, here the methodological approach, choice of methods, and approach to data analysis are discussed. Research in the social and political sciences are in general dominated by the methodological traditions of naturalism and constructivism (Moses \& Knutsen, 2012). Scientific realism, the methodology and tradition within philosophy of science closest to my scientific disposition, blends both the naturalist and constructivist approaches to science. Ontologically, scientific realism relates most to naturalism in that it recognizes that there is a real world independent of our experience. However, there is also the recognition that there are many layers to the study of reality. To uncover the truth is therefore very challenging, because reality can only be accessed through human minds which - from a constructivist viewpoint - are not considered to be neutral or objective. Rather, the individual and social characteristics persons have maylead them to regard the same thing but perceive it differently (Moses \& Knutsen, 2012).

The choice for methods within the scientific realist tradition is very wide. It is mainly considered dependent on the nature of the study and what one wants to learn about it (Sayer, 2000). Given that this dissertation aims to explore and describe the way in which the governance systems for sustainability issues are structured, qualitative empirical studies were considered a suitable approach as they can provide rich contextual data to help understand the governance systems in different issue fields. In this dissertation, the main research methods which have been used are semi-structured in-depth interviews and document analysis. With regard to semi-structured in-depth interviews, in total more than seventy interviews were held with persons commonly involved in policy-making and strategic management. Relevant organisations and persons were identified across the different issue areas. Once granted access into the different organisations and networks, purposeful sampling was used for the identification of information-rich respondents to obtain insights. In addition, snowball-sampling was used to get into contact with other experts from the network of the respondents. As for document analyses, the collected and analysed documents were primarily public records, and generally consisted of relevant laws and regulations, annual reports, mission statements, and policy manuals. Personal documents were also examined, and comprised newspapers and articles on meeting proceedings.

The qualitative data analysis of transcriptions was facilitated by the use of MAXQDA software. Particularly through the coding of individual components of transcripts, data was categorised to facilitate analysis. Codes, such as a word or short phrase were used to symbolically assign a summative, salient, and essence-capturing attribute to the languagebased documents (Saldana, 2009). While interview questions were developed and 
sometimes contextualised to interviewees within the broad methodological framework of governance theory, grounded coding was employed to the documents themselves which allowed themes and patterns to emerge from the transcripts themselves. Quotes from interviewees have been used relatively sparingly in this dissertation, essentially to illustrate findings, provide evidence and perspectives to the overall narrative.

Everything considered, both primary and secondary data have been generated and used for the qualitative empirical studies. In the ensuing chapters, the sources are interpreted, features of phenomena are emphasised, and associations between variables will be highlighted. The scientific realist position, which in brief considers there to be a real independent world but recognises the difficulty in accessing it, requires an acceptance that knowledge can indeed be fallible. For this reason I underscore the realist's position of Karl Popper, who stated that all laws and theories can be considered hypothetical or conjectural; that is, as educated guesses.

\subsection{Relevance of This Study}

This dissertation starts off with the observation that issue areas concerned with sustainable practice are characterised by a growing number of standards and regulations. Public and private standards on both environmental and social issues have gained significant prominence in international and regional value chain governance. While this trend can be observed for many different issue areas, they are nonetheless rooted in different institutional contexts and have developed in distinctive ways. The governance systems of some issue areas may demonstrate more regulatory cohesion, whereas other issue areas appear fragmented. It is assumed that some systems are more conducive to realise sustainable change than others. Elaborate explorations and convincing arguments are still lacking in this regard.

The aim of this dissertation is to inform this discussion, both theoretically as well as pragmatically. It is sought to contribute to the (interdisciplinary) scholarly work on governance of sustainability, and in particular add to the conceptual and evaluative discussion on fragmented and cohesive regulatory issue fields. This dissertation specifically contributes to the current literature by emphasising the role of relations between actors within governance systems. Furthermore, the analysis goes beyond the environmental policy domain of sustainable development by incorporating a social policy dimension as well. Finally, by taking into consideration the historical development of issue fields, this dissertation also offers explanations for changes in the variation of fragmentation and cohesion over time.

Since the examined governance systems comprise actors and standards from the public as well as the private domain, this dissertation is furthermore intended to inform 
policy-makers across the different societal domains. These include (inter-)governmental organisations, non-governmental organisations, and businesses. Particularly the role of collaborative efforts (and the absence thereof in specific issue fields), both between and across actors from the different societal domains, may specifically inform public and private actors on the possibilities and consequences of collaboration and coordination for sustainable development. 



\section{Chapter 2 \\ On the transformative capacity of private fair labour arrangements}

Published as:

Pekdemir, C., Glasbergen, P., \& Cörvers, R. (2015). On the transformative capacity of private fair labour arrangements. In A. Marx, J. Wouters, G. Rayp, \& L. Beke (Eds.), Global governance of labour rights (pp. 209-229). Cheltenham, UK: Edward Elgar Publishing Limited. 



\subsection{Introduction}

Violations of labour law and regulations continue to persist in the 21st century. In 2013 alone, the world witnessed the collapse of Rana Plaza, an eight-storey commercial building, and numerous fires at manufacturing sites in Bangladesh (Burke, 2013), to mention only a few disastrous examples. While violations of fair labour standards occur throughout the world, they are predominant in manufacturing countries and could be prevented through compliance with national and international labour standards.

The International Labour Organization (ILO) is a United Nations (UN) agency devoted to the promotion of social justice and internationally recognised human and labour rights. It is the most authoritative norm- and standard-setting body on the international level. It has a tripartite governing structure, meaning that workers and employers have an equal voice with governments in its deliberations. In voting procedures, governments offset worker and employer voting capacity because each member country is represented by two government delegates, an employer delegate, and a worker delegate. The core rights have been established in a total of 189 conventions, and deal with issues including child labour, forced labour, non-discrimination and equal pay, freedom of association and collective bargaining. Member countries become subject to the ILO's regular supervisory system responsible for ensuring that ratified and binding conventions are applied. Enforcement of the conventions relies upon the jurisprudence of domestic courts, as there are no international courts on labour rights.

A major shortcoming in the influence and power of the ILO is that it lacks enforcement mechanisms. The agency can register complaints against entities that are violating international rules. However, it does not impose sanctions on governments due to the principle of non- intervention in nation-state sovereignty and the influence of national self- interests on international institutions (Scherer \& Smid, 2000). As a result, conventions are far from being fully institutionalised and core labour rights are still extensively violated in many parts of the world (Helfen \& Sydow, 2013).

The inability to enforce labour rights at the international level is a modern-day problem characteristic of a world that is globalised in its production processes. With the advance of economic liberalisation there has been a shift in sourcing practices by large corporations as they source from networks of global suppliers without legal ties (Barrientos \& Smith, 2007). Commodities sold by brands and retailers in the developed world are often produced in long supply chains in which those at the bottom of the system incur cuts to their labour costs. The complexity of the supply chain and the manner in which the options of many of its actors are constrained epitomises a structural injustice (Young, 2006). Complicity to this structural problem is vast as some producers purposefully violate labour laws or are negligent. International brands, and suppliers or contractors who pressurise producers, contribute to cutting labour costs while largely 
escaping responsibility for unfair labour conditions in supply chains. Southern governments compete for a 'favourable' investment climate which comprises low taxes and minimal regulation (Young, 2004). Consumers also sustain unfair labour practices as they remain unaware or are ignorant of the conditions in which commodities are produced or feel unable to change this. The problem is hence embedded in modern-day consumerism and economic sourcing models and is sustained by the scale of the problem (from local to global), the displacement of human rights responsibilities to manufacturing countries wanting economic prosperity (North and South divide), and the lack of regulatory authorities and enforcement mechanisms of national and international institutions (institutional incapacity). A facilitating factor to the lack of enforcement of fair labour by public actors is that within the neoliberal agenda public issues are increasingly left to private parties. While social relations within supply chains are politicised and conflicts on the normative principles for deter-mining responsibility for social conditions are contested (Macdonald, 2014), neoliberal ideas, rules and practices have become dominant in many domestic and international policy domains, in which faith is placed in free markets and the accompanying political agenda of removing impediments to flows of capital. The prolongation of unfair labour practices within the 21st century is hence a structural problem for which responsibility not only lies with all the actors, but also with the political and institutional structures that sustain the system.

Within this political environment private nongovernmental initiatives for fair labour have arisen from the mid-1990s onwards (Bartley, 2007) to fill the gap left by national governments that do not implement and enforce the standards of the ILO. These arrangements may be multi- stakeholder in nature when they are partnerships including actors from both civil society and the business domain, also referred to as intersectoral partnerships (Bitzer, Glasbergen, \& Leroy, 2012) or cross- sector partnerships (Selsky \& Parker, 2005). They may be intra-sectoral when they are constituted of partners solely from civil society or the market domain. These arrangements are involved in regulatory activities that are voluntary in nature, and in this way they transform the nature of existing regulation (O'Rourke, 2003). Seeking to function along the lines of outsourced production, their strategies may encompass setting standards, providing training for businesses, monitoring the implementation of standards, certifying factories, and accrediting certification programmes. Within the private domain, there are at present numerous private arrangements which are involved with various modes of regulation for fair labour on the transnational level. The result is a rather pluralist governance system, in which each of these initiatives tries to gain competitive edge and market share (Derkx \& Glasbergen, 2014).

The effectiveness of these private arrangements has been called into question, and recent accounts have been critical about their governance potential (Locke, Amengual, \& Mangla, 2009; Marx, 2008). In this chapter we argue that this ineffectiveness should not 
be understood as a consequence of individual arrangements, but as originating from some characteristics of the system of arrangements as a whole, which impairs the transformative capacity of private arrangements in the issue field. We define transformative capacity as the ability to bring about substantial change in (un)fair labour practices. To analyse the transformative capacity of the system of arrangements, we will develop an analytical perspective that incorporates three dimensions: a structuralorganisational, a normative-cognitive, and a collaborative-relational one (section 2). After an explication of our research methods (section 3), we analyse the system on these dimensions (sections 4-6). The last section offers overall conclusions of the study and formulates some suggestions to improve the system.

\subsection{Analytical Perspective}

In this chapter we take a systemic view on the private fair labour governance system. This view is based upon the closely connected governance system (Burns \& Stöhr, 2011a, 2011b; Guéneau, 2007; Jentoft, van Son, \& Bjørkan, 2007) and organisational field approach (Dingwerth \& Pattberg, 2009; Machado-da-Silva, Filho, \& Rossoni, 2006; Smith \& Fischlein, 2010). The governance system approach has its roots in governance theory and addresses questions of governability regarding public issues. Its main premise is that no single organisational entity has the capacity to handle governing challenges effectively. Therefore, governance theory places the solution of these problems in the network of public and private actors that have a stake in the issue. The organisational field approach has been developed in organisation theory. It is based on the observations that organisational entities may fulfil similar roles, may recognise each other and may engage with each other. Because these actors are involved in a network of organisations, its main premise is that opportunities and limits to individual behaviour will be created, while the network as a whole may handle issues that the actors individually cannot. Both approaches have in common that they take an observable field of institutional life as their starting point. These institutions consist of organisational entities that relate both to an issue and each other. The qualification 'institutional' refers to the fact that participation of the organisations in the issue field is, at least in the short term, rather stable. Another commonality is that both approaches recognise relationships on three levels of analysis.

On the first level, it is considered that the organisational structure of the institutionalised field is structured by the activities of participants in the same dialogue. The activities directed towards the achievement of the issue and the actors' respective organisational aims, including task allocation, responsibilities and coordination, shape the organisational structure and possibilities for action of the issue field. On the second cognitive and normative level, actors in such an institutionalised area are considered 
participants in the same dialogue or discussion, although variations may occur in their commitment to specific perspectives, problem definitions, or strategies to solve them. The third level of analysis regards an institutionalised field as a dynamic identity. Here it is assumed that through their strategic responses towards the issue and each other, the actors are able, to a certain extent, to induce changes in the institutional characteristics of the issue field. It is anticipated that participants in the same dialogue will most likely develop some specific relationships to each other: they will interact, collaborate and form alliances, although it is also possible that (coalitions of) actors develop a more hostile and adversarial relationship.

In our study of the private fair labour governance system we have translated this systemic view into three operational dimensions to evaluate their characteristics:

- The first dimension refers to structural- organisational relationships and focuses on definitions of roles, responsibilities and leadership in the issue area.

- The second dimension refers to normative-cognitive relationships and focuses on the extent to which visions related to the standards for fair labour are shared by the participants in the issue area.

- The third dimension refers to dynamism in the system and focuses on the collaborative-relational capacity of the actors in the field, understood as their inclination to collaborate for concerted change.

Empirically, the boundaries between the three dimensions are not always clear-cut, as some characteristics enforce reaction in other dimensions or integrally span boundaries. The dimensions are meant as a conceptual tool to evaluate system characteristics.

\subsection{Research Methods and Data}

This chapter is based on a literature study, semi- structured in-depth interviews and online desk research of information available in 2013. The literature study comprised literature on partnerships and collaborative arrangements for sustainable development, governance and governance systems, with particular attention given to transnational regulatory arrangements for fair labour. The interviews were conducted with collaborative arrangements of both an intra-sectoral and multi-stakeholder nature. Examining the private governing arrangements as a system includes the setting of boundaries. The criteria for incorporating arrangements into the analysis were that arrangements must: (a) have the improving of fair labour as their main priority; (b) have been explicitly engaged with regulatory activities such as standard setting; and (c) have a transnational scope. A list of arrangements was established based on the literature study and online desk research, which was then complemented with the fair labour 
arrangements mentioned by our interviewees. More than 20 arrangements were recognised to be involved in regulatory activities for fair labour, but only half of these met the criteria of having fair labour as its main concern and having a transnational scope. In total ten transnational private regulatory arrangements were examined, out of which seven interviews were conducted with representatives of the arrangements (BSCI, CCC, FLA, FWF, SAI, WRAP and WRC) and one ILO expert. All of the private arrangements are not-for-profit nongovernmental organisations (NGOs) and all except for the CCC partner with businesses to enhance compliance with fair labour practices.

The following arrangements have been incorporated into the governance system analysis:

- Business Social Compliance Initiative (BSCI), multi-sector focus;

- Clean Clothes Campaign (CCC), focus on the garment industry;

- Electronic Industry Citizenship Coalition (EICC), focus on electronics;

- Ethical Trading Initiative (ETI), multi-sector focus;

- Fair Labor Association (FLA), multi-sector focus;

- Fair Wear Foundation (FWF), focus on the garment industry;

- Global Social Compliance Programme (GSCP), multi-sector focus;

- Social Accountability International (SAI), multi-sector focus;

- Worldwide Responsible Accredited Production (WRAP), focus mainly on the garment industry;

- Worker Rights Consortium (WRC), focus mainly on the garment industry.

While several arrangements focus on multiple sectors and industries, overall, the garment industry and sewn products receive greatest attention by the main arrangements.

In addition to the interviews, the analysis was complemented through online desk research, and the various secondary sources consulted on the arrangements included their websites, codes of conduct, partnership and/or project reports, and annual reports.

The arrangements were introduced from the mid-1990s onwards; with the exception of the CCC, as its establishment can be traced back to 1989, although they only developed a model code in 1998. The arrangement that was initiated most recently has been the GSCP in 2006. This indicates that the private regulatory frameworks on fair labour took off from the mid-1990s and reasonably stabilised around 2006.

\subsection{The Structural-Organisational Dimension}

The structural-organisational dimension of the fair labour system focuses on the manner in which the governance system is structured by the activities of the arrangements. The definitions of roles, responsibilities and leadership in the issue area shape the system 
structure and affect possibilities for action by the arrangements. The characteristics we analysed are the stakeholder representatives included in governance boards, the roles arrangements take regarding businesses, accountability of the arrangements, and views on leadership.

\section{Stakeholder compositions}

The arrangements we studied are governed by different sets of stakeholders. Some are multi-stakeholder, including actors from civil society such as universities and unions, and from the market domain, including companies and industry associations, while others are intra-sectoral, including only civil society or market actors. Independence is reinforced in cases where arrangements have a multi-stakeholder structure as the different actors possess a more representative collection of motivations and a fuller array of complementary competencies. Private actors bring diverse interests and values, expertise and operational capacities together. Among other functions, civil society actors may contribute operational capacities for collecting, disseminating and analysing information, provide input to agenda- setting and policy development processes, assess conditions and monitoring compliance with agreements, and advocate (environmental) justice (Gemmill \& Bamidele-Izu, 2002). Next to economic and management expertise (Van Huijstee, Pollock, Glasbergen, \& Leroy, 2011) business participation is expressed to strengthen the operational capacities for agenda setting, norm promotion and monitoring (Abbott \& Snidal, 2009). While different competencies may be reconciled, the representation of these sectors presents contesting institutional demands, since they are guided by different incongruent core logics (for instance an economic versus a social rationale) (Parker \& Selsky, 2004; Van Huijstee et al., 2011).

A critical example of stakeholder representation is the composition of the governance boards. Members of the governance board have ultimate access to decision-making procedures. Board members are reflective of whose point of view is considered since members of the board of directors act on behalf of the organisation's constituents, whether they are from the state, market domain or civil society. Among other responsibilities, nonprofit board responsibilities are described as deciding on the organisation's mission and purpose, determining whether its programmes are consistent with its mission and monitoring the effectiveness of these programmes, and adhering to legal and ethical standards and norms (Ingram, 2008). Access to decision-making procedures enhances accountability and legitimacy, and may improve compliance and acceptance of the standards. It is argued that the absence of affected societal actors in the decision- making processes not only constitutes a lack of legitimacy but also poses a danger to the effectiveness of the arrangements (Schouten \& Glasbergen, 2011; Zürn, 2004). 
Within the different private standard- setting arrangements, we observe an uneven distribution of types of stakeholders who have access to decision-making in the governance boards. Next to collective representation by businesses, NGOs, unions, universities and colleges, there are also individuals on the boards who function in their own expert capacity. Predominantly represented, however, are business and industry representatives (in eight out of ten arrangements). Throughout all the governance boards, direct representation of workers by unions is minimal (in two out of ten arrangements). Having a multi-stakeholder coalition is, for some of the arrangements, a determining factor for accrediting a sustainable value to negotiating labour rights (for four out of seven interviewed arrangements). A multi-stakeholder input in the governance boards is described as moving towards more sustainable change, and a lack of union representatives on the boards is only by a few deemed to diminish the credibility and legitimacy of the arrangements (for two out of the seven interviewed arrangements). The analysis of governance boards shows that within the private governance system for fair labour, workers' rights are currently more proposed by industry stakeholders and the corporate world than by unions.

\section{Roles}

Civil society is a generic label that covers several disparate and often contradictory and competitive forms of organisation and action (Castells, 2008). NGOs involved in global governance can take a variety of roles, including the mobilisation of public opinion, the representation of the voiceless, and service provisioning by delivering technical expertise on particular topics, as well as participating directly in operational activities, monitoring and assessment, and providing expert advice and analysis (Gemmill \& Bamidele-Izu, 2002). The organisations within the private governance system for fair labour share some characteristics but fulfil diverse roles. This was underscored by the representatives and explained in reactionary, dialectic, but primarily functionalist, terms. Even though it remains indeed ambiguous at whose demand new transnational regulatory institutions are established (Biermann, Pattberg, van Asselt, \& Zelli, 2009), identity formation of organisations may be seen as an inherently social and inter-organisational process, and the creation of new arrangements essentially reactionary to the particular status quo. The representative of the FWF formulated the functionalist argument as follows: "All the organisations have a role, otherwise they would not exist." The representative of the CCC understood the fulfilment of different roles in dialectic terms constituted in a dynamic political arena with purposeful strategies for power. The CCC has a unique position within the private governance system as it does not have corporate members and primarily fulfils a campaigning role by mobilising public opinion and representing the voiceless. The other arrangements are business-NGO partnerships that, as one source of 
income, provide, for instance, expertise, advice, monitoring and assessment based on membership fees. Nonetheless, there are further variations, for instance the WRC that takes the representation of the voiceless as one of their primary roles. Although all arrangements underscore their differences, they are also critical of each other's aims. As will be shown in the next subsections, within the business-NGO arrangements there are many variations in standards and enforcement. While some adhere to stringent standards and discontinue membership in case of noncompliance, other arrangements are toothless and merely provide a global platform for promoting the exchange of knowledge. On a strategic level, this question affects just how the arrangements regard themselves as change agents. Do they fulfil a consultancy role for businesses, or do they perform a more public role? Some of the arrangements are criticised for their impetuses towards industry, while others disapprove of naming and shaming businesses and making public attacks on their operating models. In turn, the more critical and stringent arrangements are critical of the least stringent initiatives, lowering the bar for fair labour standards. The representative of the FLA reflected on the different roles:

Everyone has its role to play and in a spectrum you need the name and shame [arrangements] because they raise a lot of issues, they serve the watchdog function. The threat that they pose forces a lot of companies to get out of their comfort zone and start thinking about social responsibility ... But then you also need [arrangements] where the companies that decide to do something need to go. ... I do get worried though that some of the organisations devalue the currency. ... They make it harder for other groups who are trying to raise standards.

\section{Accountability}

Even though public opinion may at times influence the strategic course of the private arrangements, those based on the monitoring and assessment of businesses are not directly affected in their relationships with businesses. The reasons for this rest on shortcomings in accountability structures. First of all, the arrangements themselves do not have to fear the purchasing power of consumers. The monitoring arrangements do not have consumers as clientele, but businesses. In fact, the more pressure is applied to businesses, the likelier the chance that a business will opt for membership to a certifying or monitoring fair labour arrangement of their choice. Closely connected to the purchasing power argument lies a second argument, which is that the arrangements that fall within the scope of this research do not certify products, and correspondingly do not fear damage to their reputation on defectively certified products. Even accountability for audits is diffuse. For example, with the collapse of the Rana Plaza complex in Bangladesh in April 2013, with a death toll of 1129, BSCI social audits were performed in two of the factories in the complex. The audits did not include building construction or integrity. 
Also in the case of the fire in Ali Enterprises in September 2012 in Pakistan, where nearly 300 workers died, the certification body that issued the certification to the company was accredited by the Social Accountability Accreditation Services (SAAS), an accreditation agency used by both BSCI and SAI. While these and other tragedies have received considerable attention, insufficient private certification practices have received rather limited attention from civil society at large. Other arrangements within the governance system are critical of accreditation and certification practices and comment that more responsibility should be taken (according to three out of the seven interviewed arrangements). There is, however, no mechanism by which arrangements that outsource services are held accountable. In the current configuration of the governance system there are thus several identifiable problems that pertain to its accountability structures.

\section{Ascribed leadership}

Related to the fact that accountability is largely lacking and in the absence of a body that sanctions these organisations, we observe that there is also not one authority that leads or guides the arrangements. The private arrangements consider different public authorities to be relevant and influential for the issue field of fair labour, including: the ILO (e.g. conventions, subdivisions and programmes); the UN (e.g. Guiding Principles on Business and Human Rights as endorsed by the Human Rights Council); the EU (e.g. Corporate Social Responsibility Strategy); and negotiations and agreements made on a national or local level (e.g. the Bangladesh Fire and Safety Protocol). Amongst these, the ILO is considered to be the most authoritative standard-setting body. It serves as a reference point for the arrangements as its conventions, recommendations and jurisprudence are generally appreciated. Some of these works are translated into standards, trainings, and other instruments as employed by the arrangements.

While the former UN Secretary- General's Special Representative for Business and Human Rights, John Gerard Ruggie, has been recognised as having played an influential role, particularly with regard to his proposition of the framework on the UN Guiding Principles on Business and Human Rights in 2008, our research reveals that strong leadership qualities are currently not ascribed to any institution or person. Even though the ILO is considered to be the most authoritative standard- setting body, within the governance system there is not one leading arrangement that shows or sets out how the private arrangements can or should direct their efforts. What's more, due to its tripartite structure, the private arrangements feel that they have very little, if any, influence on the ILO. The ILO does not employ preferential or specifically accommodating services for the private arrangements. However, there are more structural problems that inhibit the ILO from being perceived as a leader by the arrangements. Firstly, the ILO is considered to be almost a victim of its own democracy as a tripartite body. Member states, but also the 
employer and worker federations, can restrict its ability to act. Secondly, because it is a tripartite organisation change occurs slowly and incrementally. Thirdly, there is a heavy focus on the national context, and the tripartite structure is seen to mainly serve the national levels, whereas many of the private arrangements are involved in global supply chain activities.

Overall, the characteristics of the structural-organisational dimension show that the representation of market actors, particularly in relation to the more limited direct representation of workers, represents an uneven distribution of stakeholder representativeness. There is a further divide on the role arrangements take on businesses, from a more supportive and consultative role to an adversarial one. Since the arrangements do not certify commodities they do not fear reputational damage or accountability demands from consumers for ineffective enforcement of private standards. Finally, there are currently no leadership qualities ascribed to any private or public institution.

\subsection{The Normative-Cognitive Dimension}

Although variations may occur in commitment to specific perspectives, problem definitions or strategies to solve them, the normative- cognitive dimension of the fair labour governance system refers to the extent to which visions related to the standards for fair labour are shared by the participants in the issue area. We analysed the provisions in the standards, means of enforcement, and views on public and private responsibility for effective compliance to standards.

\section{Standards}

Standards set by the private arrangements are based on public regulations, primarily those established by ILO conventions, other human rights frameworks, and, in some arrangements, the benchmark of conduct must only be in line with national and local laws. The standards are typically incorporated into codes of conduct, and they stipulate the minimum norms and rules to which the arrangements envision that companies comply with, and on which performance of the supply chains can or must be evaluated. They are written statements in which a commitment to a conduct is expressed. Information about the codes must therefore be communicated externally to become known for businesses, suppliers and consumers. Ordinarily, many codes fall within the realm of general business ethics with no implementation methods, but businesses that adopt codes of conduct by the standard-setting arrangements, adopt them with the intention to apply them transnationally, particularly as sourcing guidelines (Diller, 1999) 
in which the code applies to other enterprises in the value chain which are not directly owned, operated or controlled by the business having adopted the code.

Codes related to labour standards were originally quite diverse, but are considered to have converged around the same ILO core standards and principles at the turn of the 21 st century (O'Rourke, 2003). Even though it is evident that all are inspired by the same core principles, the statements and details incorporated within the provisions vary considerably. In our analysis, several issues concerning the key provisions of the different arrangements come to the fore. Here we provide several examples. On the key issue of child labour, WRAP challenges the minimum age law of the ILO of 15 (unless the legal minimum is 14 which needs to be in accordance with the ILO developing country exceptions) by stipulating the age of 14 as a minimum. Even though the BSCI does refer to the ILO and UN Conventions, the minimum age is omitted from the provision. On the key issue of freedom of association the EICC, GSCP and WRAP refer to 'lawful' rights or the rights in accordance with 'local laws', which restricts the human right to freely associate and bargain collectively. On the key issue of wages, WRAP and the EICC refer to wages in compliance to local laws but leave out any provisions on living expenses, basic needs and discretionary income. The BSCI states that employers are encouraged to provide compensation in cases where the legal wage does not cover living expenses, but this remains provisional. On the issue of hours of work, WRAP ignores the ILO Conventions by referring to a country's law. On the issue of employment relationships, the BSCI, EICC, WRAP and WRC do not have any codes. The analysis not only shows that there is clear diversity in the codes of conduct but also shows there is ambiguity about the ILO being considered as an authoritative model code.

\section{Enforcement mechanisms}

Similar diversity was also found in the enforcement of the standards. Enforcing standards is a means through which the arrangements want to accomplish their goals. Additionally, it also signifies strategic efforts as choices made on the enforcement of standards define how member companies will be treated and how producers in the supply chains will be affected. Systems for implementing and evaluating compliance to codes of conduct are critical to the credibility of the codes endorsed by the standard- setting arrangements (O'Rourke, 2003). Out of the ten standard-setting arrangements in our analysis, seven verify whether businesses implement the respective standards, out of which, three use certification. There is great diversity concerning the actual verification of the implementation of the standards, as arrangements vary on aspects such as who conducts the audits, which aspects of compliance are monitored, how noncomplying members or producers are treated, and whether they make audit results or noncompliant members public. 
Our analysis of the enforcement mechanisms reveals that only the ETI does not require that companies have third-party auditing - that is, audits carried out by independent organisations outside the company and its supply chain to verify whether they meet standards, even though the ETI does make validation visits to verify management performance. All other monitoring organisations do commit businesses to third-party auditing, whether the arrangements coordinate audits themselves or have certification bodies for SA8000 management systems. Auditing of standards related to actual performance requires that companies demonstrate changed practices and have not just put a management system in place (Conroy, 2007). Performance-based standards therefore provide more assurance to businesses down the supply chain and to consumers that a company's fair labour management meets the standard. The FLA, FWF, WRAP and WRC require that auditors visit factories and actually verify standard implementation.

Further distinctions are found regarding noncompliance of members and producers. WRAP is the only arrangement that directly audits producers without necessitating membership involvement of brands. In case of noncompliance they do not certify the factory. The ETI, FLA and SAI terminate brand membership to their organisation in cases of noncompliance. They hold their own members accountable for failing to address noncompliance within their own management system or for failing to terminate relations with a noncomplying producer. The BSCI, FWF and the WRC, on the other hand, assign responsibility for noncompliance at the producing level, and take into consideration whether to continue or discontinue relationships between producer and brand at the brand level. Whether this is out of consideration for brand autonomy or for fear that workers might be worse off without jobs, they ultimately hold producers accountable for noncompliance, and not the brands at the end of the supply chain. Similar strategic considerations can be found in keeping audit results or noncompliant members confidential or making them public. Publicising may be regarded as a punishment as it can have a detrimental effect on business performance and does not improve the situation of workers. Nonetheless, not making results public also has detrimental effects in that unfair labour practices may continue, thus also not improving the situation of the workers.

\section{Views on responsibility}

While the arrangements aspire to improve labour conduct, there is wide acknowledgement that responsibility and capacity to solve the issue is diffuse and rests on everyone, from states, intergovernmental agencies, businesses, trade associations, NGOs and unions, to consumers. None of the arrangements considered their own organisation as bearing the most responsibility in resolving unfair labour conduct. Most often responsibility was placed with businesses and with states. 
Reasons for businesses to carry this responsibility firstly derived from the consideration that labour rights abuses happen specifically because of the way brands and retailers do business. Placing severe price pressures and strict deadlines on manufacturing suppliers necessarily puts a negative burden on labour. Secondly, the solutions to unfair labour practices must be grounded on business principles to be effective. Addressing the business motivations that drive the incentives that sustain unfair labour practices is argued to be more successful in getting rid of the problem. Brands and retailers would need to commit to working with certified manufacturers, and this is projected to create incentives for the rest of the manufacturers.

Ensuring commitment to ethical sourcing through the force of law is the main reason why states are envisioned to regulate the private domain. The failure of business compliance is seen as the responsibility of the state. Many national institutions are considered at a loss due to limited capabilities because global supply chains are transnational. Next to the fact that arrangements consider many states to fail at regulating the labour market, international institutions in turn do not have the ability to regulate the global supply chain. The arrangements, in their own operational capacities, try to force business actors to deliver public goods. Interestingly, the regulatory activities by the private arrangements were placed at an intermediate level between businesses and states, though the responsibility to alleviate unfair labour conduct was ultimately placed at the door of state and business conduct. Overall, the characteristics of the normative-cognitive dimension show that there are different visions of the adaptation of core conventions and principles as set by international institutions, and diverse approaches in enforcement methods. Furthermore, final responsibility to solve unfair labour conduct is primarily given to businesses and public institutions rather than taken by themselves as intermediaries.

\subsection{The Collaborative-Relational Dimension}

The final dimension of the system refers to the collaborative capacity of the actors in the field, understood as their inclination to collaborate for concerted change. This has been examined on two levels of analysis: firstly, the extent to which the private arrangements cooperate with core international institutions; and secondly, how and to what extent the arrangements collaborate with each other.

\section{Relationships between the ILO and private arrangements}

As previously discussed, different international public authorities are considered to be relevant and influential for the work of the private arrangements. Nonetheless, relationships and cooperation between private and public arrangements are seldom 
formalised, nor do they occur habitually. Consultation or collaboration with the ILO is stated to be project driven and not embodying a larger affiliation. Examples provided were consultation and training in the leather sector in Ethiopia by WRAP, consultation and adoption of the fair wage concept by the FLA, or the provision of a neutral chair by the ILO for the steering committee of the Bangladesh Accord to which the CCC and WRC are witness signatories. The Accord on Fire and Building Safety in Bangladesh was designed in 2013 by Bangladeshi and international unions, together with other civil society labour groups, including the WRC and CCC. It was signed by over 50 international brands and retailers, who agreed upon a five- year commitment to invest in safer factories. Among other provisions, the accord includes independent inspections by experts, public reporting, mandatory repairs and renovations financed by brands, and a binding contract to make all commitments enforceable. Public support by the ILO of the Bangladesh Accord is considered by the WRC and CCC to have advanced their efforts. With the exception of one arrangement, the arrangements are not frequently in contact with the ILO, nor do they expect to be. The mandate of the ILO is widely considered to precede engagement with the private arrangements.

\section{Collaboration between the arrangements}

At present, attempts for enduring collaboration have hardly been found within the private governance system. The arrangements collaborate with a small selection of other arrangements, and efforts are initiated on an individual basis depending on ideological and circumstantial reasons. The ideological argument refers to like-mindedness or as one representative (WRC) stated: "we collaborate with organisations we feel make similar commitments and have similar enforceability mechanisms." It was particularly considered that the operating models between industries led arrangements, and organisations without worker representatives were too distinct for real collaborative efforts to take off. Circumstantial motivations refer to factors such as whether arrangements are involved in the same projects, particular countries or regions, brands, factories, or thematic topics such as the living wage concept. Collaboration is particularly valued in cases where duplication of effort is decreased, for example running training on freedom of association or fire and safety. The type of content exchanged is primarily informative, advisory and supportive.

Most of the collaborations are intangible exchanges and take place along informal lines of communication. The only tangible exchanges between the arrangements were noted in those instances where the partners were represented in the governance board, and in cases of joint projects between different standard-setting and monitoring partnerships that are formalised, with, for instance, a memorandum of understanding. From the interviews it became apparent that the latter does not occur often. The most 
common type of collaboration was along informal lines, such as attending consultation rounds convened by one of the arrangements, attending the same seminars or webinars and congresses, and direct lines of personal communication such as email correspondence and telephone conversations.

While collaborative efforts were perceived as valuable and the arrangements were open for more efforts to be undertaken, they recognised that next to a common ideological or circumstantial purpose, two of the biggest constraints were time and being understaffed. This was also reflected in a more strategic attempt at collaboration that had been explored in the past with the initiation of the Joint Initiative on Corporate Accountability and Workers' Rights in 2003, when a total of six arrangements (CCC, ETI, FLA, FWF, SAI, WRC) convened as a first formalised effort between the different organisations to collaborate. Supported by grants from the European Commission and the US State department, the project was initiated to determine whether and how the participating arrangements could enhance efficiency and effectiveness (Derkx \& Glasbergen, 2014). It was an attempt to establish a metagovernance arrangement, or, as it was broadly defined, establishing an 'organisation of self-organisation' (Sørensen, 2006). In an effort to maximise the effectiveness of the regulatory approaches, reduce duplication of efforts, explore possibilities to cooperate and share learning the initiative conducted a 'trial project' in Turkey where they wanted to test various aspects of the collaborative effort. The project ran until 2007 and has not evolved into an active organisational structure or platform in use today. In several studies (Derkx \& Glasbergen, 2014; Glasbergen, 2013) it is explicated that the initiative has been valuable as a learning experience and that it was an important first step towards cooperation. However, it was not very effective in its efforts to change company policy or in achieving actual improvements in the Turkish context. These aggravations spilled over into the convergence element of the collaboration, and also complicated relationships between the Joint Initiative's members. The lack of coordinated effort shows that these hurdles have not been surmounted.

The characteristics of the collaborative-relational dimension show that publicprivate interaction is limited, and although the private arrangements cooperate with each other, this lacks clear coordination and occurs for ideological and circumstantial reasons.

\subsection{Conclusions}

In this chapter we have identified system characteristics of the fair labour governance system which we operationalised on three dimensions. On the structural-organisational dimension, the distribution of representatives across governance boards on the whole includes more industry representation, and the roles the arrangements take on regarding 
businesses varies. There are certain identifiable shortcomings in relation to accountability structures, and there is no leadership in the governance system. On the normativecognitive dimension, many variations exist in the provisions taken up in the standards and in their enforcement. While responsibility to solve unfair labour was considered diffuse, final responsibility to solve unfair labour was not placed with the arrangements in the private governance system, but primarily at state or corporate level. On the collaborative-relational dimension we found that private actors generally have sporadic collaboration with core international labour institutions. While the arrangements share knowledge and expertise to some degree with other arrangements that have similar operational models, the incentive to collaborate is weak, and, as a result, collaboration is largely uncoordinated and limited.

We argue that the fragmentation recognizable on the three dimensions impairs the transformative capacity of the governance system of the fair labour issue field. While there are several arguments for why the existence of diverse regulatory arrangements may be positively assessed, including the potential for innovation and covering niche or different parts of the market, our findings indicate that high levels of fragmentation from a systemic point of view brings limited potential for structural change. Even though the potential for transformative capacity is present as arrangements are, to varying degrees, actively involved with standard setting, monitoring, training and education, systemic change has not occurred. As one representative stated: "Arguably [the industry] is just as bad, just as dangerous as it was 10 years ago when all these programmes had just started." While positive results are noticeable regarding the ground work, particularly in the dissemination of training, implementing complaints mechanisms, and generally in creating awareness about all the different labour rights and conditions, a sense of frustration across the arrangements was noticeable regarding the effectiveness of the work. In particular, the existence of more lax approaches undermines the efforts of more stringent approaches. Whether this contributes to the confusion on the ends of businesses and civil society at large, it certainly offers businesses the opportunity to choose the stringency level of standards and audits.

The new fulfilment of global corporatism raises serious questions about the representativeness of corporatist arrangements, and the extent to which they function as instruments of co-optation rather than representation. One important characteristic that supports this is the predominant representation of industry and corporate interests in decision-making processes and the scarce direct representation of workers. Furthermore, since the distribution of arrangements has reasonably stabilised and remained secure, the incentive to change conduct is low. The predominant focus on the garment sector and sewn products limits the potential for change across sectors. In addition, lacks in accountability structures, particularly for the certifying arrangements, is a system characteristic that sustains the problem of diffuse responsibility. Certification of 
commodities could be one solution. However, regulatory arrangements are currently not able to guarantee a supply chain that is completely fair. As long as the public or private transnational governance system cannot guarantee fair labour nor effectively penalise noncompliance, only individuals will be held accountable and no systemic transformations will occur.

The failure to effectively alleviate fair labour violations on an international level by governments and intergovernmental agencies has not been solved hitherto by the private transnational arrangements in the governance system. This raises questions about the effectiveness of the governance system given that its characteristics do indicate problems related to the fragmentation of the system. Example of this are: the variety amongst the private actors themselves, the lack of accountability and the uncoordinated efforts amongst various arrangements, and weak public-private links. Without more coherence the transformative potential of the arrangements may not be accomplished. More structured intergovernmental support would advance the efforts of the private arrangements, as, in addition to expertise and support, leadership could be provided and authoritative leverage would be brought to the table. A private implementation institution of the ILO could, for instance, by means of authority and capacity lending, fill this governance gap. Without addressing these issues, the transformative capacity of the private fair labour governance system will remain challenging. 



\section{Chapter 3 \\ On the regulatory potential of regional organic standards: Towards harmonization, equivalence, and trade?}

Published as:

Pekdemir, C. (2018). On the regulatory potential of regional organic standards: Towards harmonization, equivalence, and trade? Global Environmental Change, 50, 289-302. doi:10.1016/j.gloenvcha.2018.04.010 



\subsection{Introduction}

Organic production is a highly regulated policy domain. The label 'organic' has increasingly become legally protected, as not only private standards but also public regulations specify the exact requirements for organic production and labelling. Organic regulation is unique among self-regulatory regimes because organic labelling was once the exclusive domain of private organizations, but has since evolved into a regime where the establishment of minimum standards has become the prerogative of public actors in a growing number of countries (Arcuri, 2015). The plethora of available standards, labels, and certifications (e.g., Castka \& Corbett, 2016; Janssen \& Hamm, 2011) has led to a complex and fragmented system of regulations. Of serious concern is that the duplications and overlaps between the systems have led to compliance problems and barriers to trade (Courville, 2006). Consequently, debates in the organic field during the last decade were characterized by the need to harmonize organic standards (Fouilleux \& Loconto, 2017).

In the meantime, the absence of global harmonization has induced governments, traders, and certification institutions to develop complex pathways to facilitate cooperation in trade. These include compliance, equivalence, and mutual recognition based mechanisms (Winickoff \& Klein, 2011). Another pathway that has gained interest from international organizations and developing countries is the regionalization of organic standards. These regional arrangements are public or public-private partnerships within geographical regions with at least two neighboring countries. Through either a common regional standard or the harmonization and recognition of each other's national standards, regionalization is assumed to bring more cohesion - here understood as unity - in the norms and values that underlie organic production and its codification. Regionalization of organic standards thus enables countries to deal with complex regulatory realities (Bowen \& Hoffman, 2015a), which can stimulate intra- and interregional trade.

The European Union's (EU) common framework for organic production is the most notable example of this regionalization as it integrates regulations in its central legislative structure. However, several other regional standards that are not placed in an economicpolitical union with an internal single market have been initiated in the last decade. This phenomenon, including the causes and effects of regionalization of standards, has thus far received scant scholarly attention. Filling this gap, this article will evaluate if regional standards and the system as a whole make the regulatory field of organic production more cohesive, and whether it is conducive to regional and international trade. It will provide an analysis of regional attempts thus far, and identify drivers for regionalization. Then, the ability of regionalization to reduce regulatory fragmentation will be assessed. 
The article first provides an overview of the regulatory field on organic production and places it within the context of fragmentation and cohesion in global governance theory. It will then focus on what regionalization is, and its advantages and disadvantages in relation to organic standards. After an overview of the research methods, a comparative analysis will lay the basis for the discussion and conclusion.

\subsection{The Organic Regulatory Field}

\section{The rise of private and national standards}

The origins of modern organic agriculture can be traced back to the 1920s when initial concern was raised about the direction of industrial agriculture (e.g., Kristiansen, 2006; Lockeretz, 2007). Organic agriculture developed as an alternative form of farming compatible with natural systems. The first organic standard (Demeter) was introduced in 1928. Other informal regulatory tools developed in the 1950s (Courville, 2006), and associations of farmers and consumers started to develop guidelines and standards based on organic principles. From the 1970s onwards, the first private organic labels spread across Europe and the United States. Around this time, organic farmers founded growers' associations with the International Federation of Organic Agriculture Movements (IFOAM) as their transnational umbrella organization (Schmidt, 2011). IFOAM became the main organization to set organic standards, and it issued its 'Basic Standards for Organic Agriculture' in 1980. The need for an independent guarantee of compliance spurred on by consumer demand - increased the amount of private certification bodies (Courville, 2006).

The patchwork of differing organic standards and certifications appeared to be an obstacle to move organic foods into mainstream marketing channels (Ikerd, 2006). This stimulated organic communities to initiate political movements to advance national organic standards. The harmonization of organic standards came on the political agenda in order to stimulate trade based on different national and transnational standards. With the adoption of organic regulation by the EU in 1991, more countries followed suit. At present, there are 87 countries with organic standards, although not all countries have adopted them into national legislation or even have production standards (Huber, Schmid, \& Möller, 2016; Möller \& Huber, 2016). In principle, national organic regulations are binding for domestic producers and for foreign producers interested in entering the market. If national standards are not turned into national legislation or if regulations are not enforced - whether due to a lack of resources or political support - their binding authority is eviscerated. Nonetheless, national standards provide a national definition of organic products and serve as a reference point for certification activities (Huber et al., 2016). In the EU, national certification labels can still be used as long as they comply with 
(supranational) EU regulations. Private organic standards, which are voluntary in nature, also continue to operate in domestic markets but in countries where national standards are in place, a product can only be labelled as organic if the publicly enacted standards are respected (Arcuri, 2015). National and supranational regulations, therefore, function as benchmarks.

\section{International demarcations and transnational guidance on organic regulation}

In addition to private standards and national regulations, there are also various international provisions on organic regulation. These can be categorized in public, private, and public-private sources that are either binding or voluntary. To start off with public sources of law, two legally binding instruments that do not specifically detail organic law but provide the context in which organic regulations are made, are trade agreements and international environmental agreements. The Technical Barriers to Trade (TBT) Agreement and the Agreement on the Application of Sanitary and Phytosanitary (SPS) Measures of the World Trade Organization (WTO) are two trade agreements that are particularly important. The TBT Agreement aims to ensure that technical regulations, standards, and conformity assessment procedures are nondiscriminatory and do not create unnecessary obstacles to trade, while the SPS Agreement sets constraints on Member States' policies relating to food safety and animal and plant health with respect to imported pests and diseases. The purpose of the agreements is to ascertain whether barriers to trade based on health and safety standards should be regarded as compatible or incompatible with trade regulations.

International environmental agreements, on the other hand, generally deal with some aspect of the environment to prevent or manage human impacts on natural resources. The protection and sustainable use of biodiversity and the prevention of land degradation are enshrined in two internationally legally binding treaties, which are the Convention on Biological Diversity (1992) and the Convention to Combat Desertification (1994). All voluntary international instruments on organic agriculture principally include these issues (Morgera, Caro, \& Durán, 2012).

Recommendations for voluntary application are enshrined in the Codex Alimentarius (Codex), a public source first established in 1999 by the Codex Alimentarius Commission of the joint program by the Food and Agriculture Organization of the United Nations (FAO) and the World Health Organization (WHO). The Codex specifically covers guidelines for the production, processing, labelling, and marketing of organically produced foods. The guidelines are intended to facilitate the harmonization of requirements for organic products at the international level, and to provide assistance to governments for developing national regulations (Codex Alimentarius, 2007). 
Transnational voluntary private instruments that provide guidelines to organic regulation and good managerial practices are the Conformity assessment (ISO/IEC 17065: 2012) requirements set by the International Organization for Standardization (ISO), the IFOAM Standard, and other standards set by transnational accreditation and certification bodies, such as the Standard-Setting Code by the ISEAL Alliance. ISO is the main developer of international standards and particularly ISO/IEC 17065 is of importance for organic certification bodies. The standard does not specifically deal with organic regulations but with technical requirements for certification. Certification bodies need to fulfill the described requirements in order to be recognized by ISO as reliable and reputable. The ISO standard allows them to demonstrate their competence and perform against reference standards, such as national or private organic standards. ISO/IEC 17065 accreditation is provided to organic certification bodies by accreditation organizations, such as the International Organic Accreditation Service (IOAS) founded by IFOAM. It is of particular importance for the trade of organic produce, since certain countries only permit the trade of organic products which have been certified by an ISO/IEC 17065 accredited certification body. Through this public-private interplay, voluntary standards can become mandatory, then referred to as legally-mandated private standards (Henson \& Humphrey, 2009).

Differently, the IFOAM Standard can be used by standard setters and certification bodies to certify operators globally. It is intended to enable the trade of organic products between operators certified by different certification bodies (IFOAM, 2014b). The Standard-Setting Code of the ISEAL Alliance defines effective standard-setting processes for social and environmental standards and the ISEAL Alliance has become a global authority regarding the requirements for credible standards and certification systems (Bernstein \& Van der Ven, 2017). Next to that, there are also numerous standards by certification bodies that either focus on organic agriculture or on organic components and ingredients used in products and services (see ecolabelindex.com for further reference on private and public organic standards and labels). Overall, despite all the work on conformity assessment and accreditation of certification bodies, the overall assurance processes of certification schemes exhibit remarkable differences (Castka \& Corbett, 2016) and the public and private divide to accreditation and certification has created tensions and inconsistencies in its global application (see discussion in Fouilleux \& Loconto, 2017). 


\subsection{Fragmentation and Cohesion in the Global Governance of Organic}

A crucial factor fundamentally reconstituting the global public domain has been the inclusion of non-public actors in the transnational area concerned with the production of global public goods (Ruggie, 2004). Scholars have recognized that this reconstitution can result in making regulatory issue fields fragmented (Bernstein \& Ivanova, 2007; Biermann, Pattberg, van Asselt, \& Zelli, 2009) or cohesive (Derkx \& Glasbergen, 2014; Fransen \& Conzelmann, 2014; Ivanova \& Roy, 2007). The concept of fragmentation signifies the diversity, multiplicity, and distribution of regulatory powers of the overall institutional settings of different international and transnational policy domains. Evident from the multilayered regulatory field for organic production (see also Table 3.1), global governance is characterized by the proliferation and diversity of governance actors and mechanisms. Fragmentation can be unconducive to realizing societal goals as it may diffuse, or be counterproductive for, concerted aims and action. The term cohesion functions as its counterpart and the pursuit for cohesion in policy originated in scholarship on public policy and multi-level governance (May, Sapotichne, \& Workman, 2006; Winship, 2006). Partnerships and cooperation can overcome the condition of fragmentation, enhance concerted aims and action, and result in regulatory coherence.

Fragmentation, at least in the sense of co-existence of both public and private regulations, is broadly supported by the organic movement. Where regulations nowadays provide the benchmark for organic production, private standards are lauded for strong stakeholder involvement, leading the way as sources of innovation, local identity, producer and consumer education, improved public trust and market development (Blake, 2009). However, beyond the public and private divide, the fact that standards and regulations and their corresponding assurance systems are diverse has also led to complications. The duplication and overlap of organic standards and regulations has resulted in a complex regulatory system, where integration and coordination between regulatory systems is often lacking. Uneven enforcement, consumer confusion, and fraudulent claims made by farmers attempting to pocket organic price premiums have caused reason for concern (Winickoff \& Klein, 2011). The lack of recognition by national regulations of private multilateral agreements (Bowen, 2003) augments the requisite for certification bodies in particular to get accredited and meet regulatory requirements for each import market (Courville, 2006). This inevitably raises accompanying costs. The increase in regulatory burden generally creates barriers for uptake and compliance with organic standards and certifications, particularly for many smallholders (Gould, 2015). There are, furthermore, also concerns about the limitations of ensuring consistency, legitimacy and stringency in assurance systems, while at the same time it is sought to allow for locally appropriate adaptations (Courville, 2006; Kristiansen, 2006). 
Table 3.1 The regulatoryfield of organic production and trade

\begin{tabular}{|c|c|c|c|}
\hline Level/Source & Public & Public-Private & Private \\
\hline Global & $\begin{array}{l}\text { - International Trade Agreements } \\
\text { (TBT, SPS) } \\
\text { - } \quad \text { Environmental Agreements } \\
\text { (CBD, UNCCD) } \\
-\quad \text { Codex Alimentarius }\end{array}$ & $\begin{array}{ll}- & \text { COROS } \\
- & \text { EquiTool } \\
- & \text { IROCB }\end{array}$ & $\begin{array}{l}\text { e.g.: } \\
-\quad \text { IFOAM Standard } \\
-\quad \text { ISEAL Standard- } \\
\text { Setting Code } \\
-\quad \text { ISO/IEC } \\
\text { 17065:2012 }\end{array}$ \\
\hline Regional & $\begin{array}{l}\text { - } \quad \text { EU: Council Regulation No } \\
\text { 834/2007, Commission Regulations } \\
\text { No } 1235 / 2008 \text { and No 889/2008 } \\
\text { - } \quad \text { Central American Standard } \\
\text { - } \quad \text { ASOA } \\
\text { - } \quad \text { ARS }\end{array}$ & $\begin{array}{ll}- & \text { EAOPS } \\
- & \text { AROS }\end{array}$ & \\
\hline National & $\begin{array}{l}\text { e.g.: } \\
-\quad \text { Japanese Agricultural Organic } \\
\text { Standard }\end{array}$ & $\begin{array}{l}\text { e.g.: } \\
\begin{array}{ll}- & \text { Lao Organic Standards } \\
- & \text { National Standard on }\end{array}\end{array}$ & $\begin{array}{l}\text { e.g.: } \\
-\quad \text { Biogarantie } \\
\text { (Belgian) }\end{array}$ \\
\hline & $\begin{array}{l}\text { - Organic Products Regulations, } \\
2009 \text { (Canada) }\end{array}$ & $\begin{array}{l}\text { Organic Food System } \\
\text { (Indonesia) }\end{array}$ & - $\quad$ Bio Suisse (Swiss) \\
\hline
\end{tabular}

\section{Harmonization and equivalence}

Regulatory coherence in organic has been sought through harmonization and equivalence. Harmonization is a process that aims at the establishment of identical standards, technical regulations, and conformity assessment requirements. Harmonization was first envisioned to develop through the Codex. However, because the main importing countries rely first on national legislation for importing organic products, it has not played a concrete role in harmonizing the different regulations (Fouilleux \& Loconto, 2017). Since conditions for organic agriculture may be detailed for national or local circumstances and practices, harmonization has proven to also be unattainable based on differences between countries relating to stages of development, cultural factors, and geography (Bowen \& Hoffman, 2015a).

Equivalence on the other hand is a process that aims for the acceptance that different standards or technical regulations on the same subject fulfil common objectives. It has been easier to support and utilize than harmonization, because it allows for differences across national and local divides. The EU import regime is the most prominent example of having established equivalency agreements with exporting countries. Besides public equivalence agreements, which have higher diplomatic status in the form, usually, of a treaty (Bowen \& Hoffman, 2015a), equivalence arrangements have also been established between private and public standards (see IFOAM, 2014a).

Several international organizations have stimulated harmonization and equivalence. Organizations of the United Nations included the FAO, WHO, and the United Nations 
Conference on Trade and Development (UNCTAD). From the private sphere, IFOAM has been very influential in normative debates on the content of standards. Because of the multitude of organic standards worldwide and IFOAM's recognition of problems concerning non-credible, inadequately written, and non-transparent standards, it established the IFOAM Family of Standards. It includes all organic standards they officially endorse and is envisioned to facilitate equivalence agreements between organic standards and regulations (IFOAM, 2016a).

The most preeminent initiatives in trying to bring coherence in public and private organic standards resulted from a partnership between IFOAM, UNCTAD, and FAO. First the International Task Force on Harmonization and Equivalence in Organic Agriculture (ITF, 2003-2008) was created with the main objective to stimulate access of developing country producers to international markets and facilitate international trade of organic products. The WTO, and in particular the TBT and SPS rules, served as the general framework to approach the opportunities for harmonization, recognition, equivalence, and other forms of cooperation within and between private organic standards and government regulations on organic agriculture. Equivalence between the existing organic schemes was considered a core solution by the ITF initiative. Two practical tools were developed to offer a means for standardizing equivalence assessment processes: The Guide for Assessing Equivalence of Standards and Technical Regulations (EquiTool), which focuses on production and processing standards, and the International Requirements for Organic Certification Bodies (IROCB), which focuses on the requirements for certification (Bowen \& Hoffman, 2015b). [Although the EquiTool and IROCB are included in Table 3.1, these are practical tools rather than being standards or regulatory agreements]. The successor of the ITF initiative was the Global Organic Market Access (GOMA, 2009-2012), which focused on the practical implementation of the two tools at the level of country and regions. Together with IFOAM, which also had developed tools for assessing equivalence of organic standards, they harmonized the tools into a single one named Common Objectives and Requirements of Organic Standards (COROS). The development of geopolitical regionalization in organic standards refocused the efforts of GOMA. While the tools were initially envisioned to function more for equivalence assessment, they later also served as a benchmark in support of harmonization of standards and technical regulations (Bowen \& Hoffman, 2015b).

Policy-makers have in the meantime also identified mutual recognition agreements and arrangements as particularly conducive to permitting trade. Today, several importing countries, including the EU, the United States and Japan, have bilateral recognition agreements of organic products. These agreements confirm that another country's standards and assurance system are in line with domestic requirements, and that the products certified in those countries can be sold on the national market. These types of agreements are based on technical assessments. However, they are largely also political 
agreements, which for their realization depend on political will and negotiations between the governments involved (Huber, Schmid, \& Mannigel, 2015). Despite strong similarity between regulations (see Seufert, Ramankutty, \& Mayerhofer, 2017), some differences in organic practices point towards the inherent political nature of these standards. For instance, compared to other organic regulations, the EU standard has some unusual exceptions to the prohibition of genetically modified organisms (GMOs), which fail to sufficiently protect operators serving the organic market according to the polluter pays principle. The exceptions are contested within the organic community (IFOAM EU, 2013). Furthermore, even though bilateral mutual recognition agreements start to account for a higher percentage of trade between developed countries, relatively few of these have been signed between developed and developing countries. Bowen and Hoffman (2015a) explain that this is because these agreements require a level of trust in a country's technical competence and its certifying bodies that not many developing countries are likely to be able to provide. As an alternative to bilateral agreements, some countries have sought regional approaches to reach equivalence and trade of organic products.

\subsection{Regionalization of Organic Standards}

Regions have become a major concern of international relations (Fawn, 2009), and while there are ample studies on security and economic integration, most studies of international environmental politics pay little attention to the regional dimension (Balsiger \& Prys, 2014). Fawn explains that although definitions and approaches within the field are contested, there are also commonly used interpretations and observations. First, regionalism usually denotes state-led regional programs whereas regionalization denotes those substantially influenced by private actors. Secondly, a region needs selfdeclarations of its scope and identity. The degree to which it is institutionalized, i.e. the formal procedures and structures that regulate and facilitate the functioning of the region, depend on the nature of the regional project. It equally serves as a means to determine the group's aims and evaluate them and the strength of the grouping in practice. Finally, its practice implies a policy of cooperation and coordination among actors 'within a given region', whereby this coordination in itself can further define the region.

In relation to organic standards, 'regional' or 'local' may generally denote an overseeable geographical region like a district, county or province that might extend across borders (Fuchs \& Hoffmann, 2013). As employed in this article, regional arrangements denote public or public-private partnerships within geographical regions with at least two neighboring countries. Regionalization then might refer the utilization of (1) common organic standards; (2) equivalence mechanisms or regional recognition of organic certification; or may involve and result in (3) regional agreements. Apart from 
rules on production, certification and equivalence, countries may agree to include other elements in regional standards, such as a common label or indicators or harmonized procedures for the registration of organic producers (Morgera et al., 2012).

Although it is uncertain whether current levels of regional cooperation are adequate to address global environmental challenges and whether they contribute to the fragmentation or cohesion of governance (Balsiger \& Prys, 2014), the organic movement calls attention to the benefits of regional cooperation and particularly the regional adaptation of organic standards (e.g., IFOAM, 2014b). Local or regional production can address conditions unique to the region, such as specific climate or labor issues, in a way that a readymade standard could not (Morgera et al., 2012). If supply and demand are regional, it can also reduce accompanying costs of transportation. Also, using surplus produce for home consumption and trade is a more sustainable mode of production from a reproductive angle (Fuchs \& Hoffmann, 2013). In terms of trade, regional organic standards help achieve equivalence and may facilitate trade with countries external from the arrangement (Morgera et al., 2012). Politically, it can foster and stimulate further (intra)regional collaboration and enhance a sense of community.

There are, however, also reasons for skepticism. Regionalization can possibly add another layer to the already complex regulatory framework, which may lead to the further fragmentation of the organic governance framework. Regions might turn into trading blocs, which can lead to diverted trade where non-member countries to the arrangement can be hurt economically or politically. Sovereignty issues may arise as well when countries begin to legislate jointly or delegate power. If the regional organization already harmonizes common trade agreements, the issue likely has been addressed; however, countries that only agree to a common standard need to decide how to recognize equivalence with third countries (Morgera et al., 2012). The conventionalization debate on organic production (see Guthman, 2004; Rosin \& Campbell, 2009) points towards other dilemmas that regional standards pose to ecological farming. The fact that national and regional regulations function as benchmarks for organic standards and as such may promote a shallower form of organic farming, can also stimulate organic production into mass markets and agricultural intensification which poses a threat to ecological farming strategies as issues of cost and efficient production are considered more pertinent.

\subsection{Research Design and Methods}

The following analysis explores all regions that have developed an organic standard, which are: the European Union Regulation (EU), the East African Organic Products Standard (EAOPS), the Pacific Organic Standard (POS), the Central American initiative, the Asia Regional Organic Standard (AROS), the African Regional Standard (ARS), and 
lastly, the Association of Southeast Asian Nations (ASEAN) Standard for Organic Agriculture (ASOA). The cases have been analyzed on several dimensions, including the reasons for the standard initiation, involved stakeholders, and the governance frameworks (see also Table 3.2). After a delineation of each case, a comparison across the contexts on the basis of the governance system approach will answer the question if the standards and the system as a whole make the regulatory field of organic production more cohesive and whether it is conducive to regional and international trade.

Table 3.2 Regional arrangements' characteristics

\begin{tabular}{|c|c|c|c|c|c|c|c|}
\hline & $\mathrm{EU}$ & EAOPS & pOS & $\begin{array}{l}\text { Central American } \\
\text { Initiative }\end{array}$ & AROS & ARS & ASOA \\
\hline Policy approach & Public regulation & $\begin{array}{l}\text { Public-private partnership, } \\
\text { public regualition }\end{array}$ & $\begin{array}{l}\text { Public.private } \\
\text { partnership, standard }\end{array}$ & Public regulation & $\begin{array}{l}\text { Public-private partnership, } \\
\text { standard }\end{array}$ & $\begin{array}{l}\text { Public-private partnesship, } \\
\text { standard }\end{array}$ & $\begin{array}{l}\text { Public regulation. Follow-up on } \\
\text { AROS partrership }\end{array}$ \\
\hline $\begin{array}{l}\text { Regional standard } \\
\text { adopted to } \\
\text { national } \\
\text { legislation }\end{array}$ & Yes, automatically & № & No & No & No & No & No \\
\hline $\begin{array}{l}\text { Other national } \\
\text { organic } \\
\text { regulation in } \\
\text { place (source: } \\
\text { Möller and Huber, } \\
2016)\end{array}$ & $\begin{array}{l}\text { Not necessary due to } \\
\text { supranational EU } \\
\text { regulations }\end{array}$ & $\begin{array}{l}\text { Kenya (1) is in the process of } \\
\text { drafting regulations. All (5) } \\
\text { courtries have a national } \\
\text { standard and legisitation on issues } \\
\text { such as registration, control and } \\
\text { supervision. }\end{array}$ & $\begin{array}{l}3 \text { countries: French } \\
\text { Polynesia, New } \\
\text { Caledenna, Solomon } \\
\text { Islands }\end{array}$ & A.ll 7 countries & $\begin{array}{l}8 \text { countries: China, India, } \\
\text { Indoncsia, Japan, South } \\
\text { Korea, Malaysia, philippines, } \\
\text { Thailand. Nepal (1) is in the } \\
\text { process of drafting } \\
\text { regulations. Bhutan, Hong } \\
\text { Kong, Lasos, Vietnam ( } 4 \text { ) heve } \\
\text { a national standard and } \\
\text { legislation on issues such as } \\
\text { registration, control and } \\
\text { supervision. }\end{array}$ & $\begin{array}{l}1 \text { countryy: Tunisiai. Burkina } \\
\text { Faso, Egypt, Ghana, Kenya, } \\
\text { Rwanda, South Africa, } \\
\text { Tanzania, Uganda, Zambia, } \\
\text { Zimbabwe (10) have a national } \\
\text { standard and legislation on } \\
\text { issues such as registration, } \\
\text { control and supervision. } \\
\end{array}$ & $\begin{array}{l}4 \text { countries: Indonesia, Malaysia, } \\
\text { Philitippines, } h \text { hailand. Brunci } \\
\text { Darissalam, Laos, Vietnam ( } 3 \text { ) } \\
\text { have a national standerd and } \\
\text { legisiation on issues such as } \\
\text { rcgistration, control and } \\
\text { supervision. }\end{array}$ \\
\hline Certification & Yes & Yes & $\begin{array}{l}\text { Yes (through the } \\
\text { Participatory } \\
\text { Guarantee System) }\end{array}$ & $\begin{array}{l}\text { General requirements } \\
\text { available (not in use) }\end{array}$ & № & No & No \\
\hline Label provisions & Yes & Yes & Yes & No & $\begin{array}{l}\text { General requirements } \\
\text { available (not in use) }\end{array}$ & $\begin{array}{l}\text { General requirements avalable } \\
\text { (not in use) }\end{array}$ & $\begin{array}{l}\text { General requirements available } \\
\text { (not in use) }\end{array}$ \\
\hline $\begin{array}{l}\text { Standards focus } \\
\text { areas }\end{array}$ & $\begin{array}{l}\text { Agricultural products, } \\
\text { including aquaculture, } \\
\text { yeast, living o o } \\
\text { unprocessed products, } \\
\text { processed foods }\end{array}$ & $\begin{array}{l}\text { Plant production, animal } \\
\text { husbandry, beekeceing, the } \\
\text { collection of wild products }\end{array}$ & $\begin{array}{l}\text { Plant production, } \\
\text { animal husbandry, } \\
\text { beekeeping, } \\
\text { collection of wild } \\
\text { products and } \\
\text { aquaculture }\end{array}$ & $\begin{array}{l}\text { Plant and animal } \\
\text { products }\end{array}$ & $\begin{array}{l}\text { Plant production and } \\
\text { collection of wild products }\end{array}$ & $\begin{array}{l}\text { Plant production, animal } \\
\text { husbandry, beckecping. } \\
\text { collection of wild products }\end{array}$ & Plant production and wild harvest \\
\hline $\begin{array}{l}\text { Normative } \\
\text { references }\end{array}$ & $\begin{array}{l}\text { Codex (in relation to } \\
\text { equivalency) }\end{array}$ & Codex and IFOAM & Codex and IFOAM & Codex & Codex and IFOAM & Codex and IFOAM & Codex and IFOAM \\
\hline
\end{tabular}

The scale and structure of global contemporary production has contributed to the pivotal role of governance approaches in global value chains. The topic has been central in literature on globalization and global value chains (e.g., Gereffi, Humphrey, \& Sturgeon, 2005; Henderson, Dicken, Hess, Coe, \& Yeung, 2002; Nadvi, 2008). Seen as an interactive process that involves various forms of partnerships (Stoker, 1998), it is associated to the relative decline of national regulatory governance and the growing significance of both international and private actors (Nadvi, 2008). Although the term governance has become a catch-all concept and various typologies exist in different research strands (see Steurer, 2013), it brings the involvement of non-state actors, next to state actors, into the analysis of societal steering. Ultimately, governance is concerned with creating the conditions for ordered rule and collective action (Stoker, 1998). Considering the involvement of a variety of actors, the processes underlying the outputs of governance are therefore of specific 
relevance. Accordingly, governance is here operationalized as describing the patterns that emerge from the activities of social, political, and administrative actors (Jordan, 2008).

The ensuing empirical analysis positions the governance system for regional organic agriculture within this context. In an earlier paper (see Pekdemir, Glasbergen, \& Cörvers, 2015), a systemic approach was developed combining governance systems (as defined by Burns \& Stöhr, 2011a, 2011b; Guéneau, 2007; Jentoft, van Son, \& Bjørkan, 2007) and the closely related organizational field approach (as defined by Dingwerth \& Pattberg, 2009; Machado-da-Silva, Filho, \& Rossoni, 2006; Smith \& Fischlein, 2010). In this paper, this approach is applied to the regional regulatory system for organic production. The approach takes an observable field of institutional life as a starting point for analysis and is concerned with the governability of public issues. Rooted in governance theory, its main premise is that no single organizational entity has the capacity to handle governing challenges effectively. Solutions to problems therefore rest within the network of actors, both public and private, that have a stake in the issue. Relations within this system can be observed from three levels. Firstly, - on the organizational level - the governance system is structured by actors that share a stake in the issue. Possibilities for action are created through the activities the actors undertake and their respective organizational goals, which may or may not be coordinated. Secondly, - on the normative level - although actors in the governance system participate in the same dialogue, differences in ideas and norms may exist. These can relate to how problems are defined and different strategies on how to deal with them. Thirdly, - on the relational level - the governance system is considered to be a dynamic field that is shaped by the power dependence between actors and their strategic responses towards the issue and towards each other. Actors will expectedly develop relations with one another, which may be collaborative and result in partnerships, but may also be adversarial.

Together, the different levels offer an integrative method for analysis from an organizational-level, normative-level, and relational-level perspective (see Fig. 3.1). The operationalization of this framework on the governance system of regional standards will be applied on: (1) the organizational level by examining the stakeholders, the regional framework structure (i.e., certification, labelling), and adoption of standards into national legislative frameworks; (2) the normative level by examining the framing of regionalization, and the level of acceptance of normative organic references; and (3) the relational level by examining intra-regional and inter-regional collaboration, including trade results.

Information about the cases was acquired through desk research and interviews. The examined primary sources included official regulations, project reports, newsletters and websites. In addition, between April 2015 and July 2017, a total of twenty experts were interviewed. The selection criteria for the interviews was that the experts had been involved in the process of establishing a regional standard and/or had worked towards harmonization and equivalence efforts across the different regions. Several of the interviewees had worked on multiple regional efforts, which results in the following 
distribution over the cases: EU (2), EAOPS (3), Central America (3), POS (4), AROS (9), ARS (2), and ASOA (5). Their affiliation can be further categorized as follows: public actors (5 from governments, and 6 from inter-governmental organizations) and private actors (5 from civil society organizations, and 4 from companies). Although the interviewees have here been categorized in terms of the most relevant affiliation with regard to the organic standard, it must be noted that almost half of the interviewees have a dual affiliation regarding their work on organic production (e.g., they are or have been affiliated to an inter-governmental organization and a civil society organization, or affiliated to a civil society organization and a company), which is assumed to also influence their opinions. Seventeen of these were semi-structured in-depth interviews, and three respondents answered interview questions by email. For purposes of quoting, each interviewee has been coded with a unique number. The coding numbers refer to the order in which the interviews were held. Interview questions focused primarily on the topics of the drivers of the regional standard, the processes that underlay its development, the (anticipated) results of the standard, and reflections on the processes and outcomes.

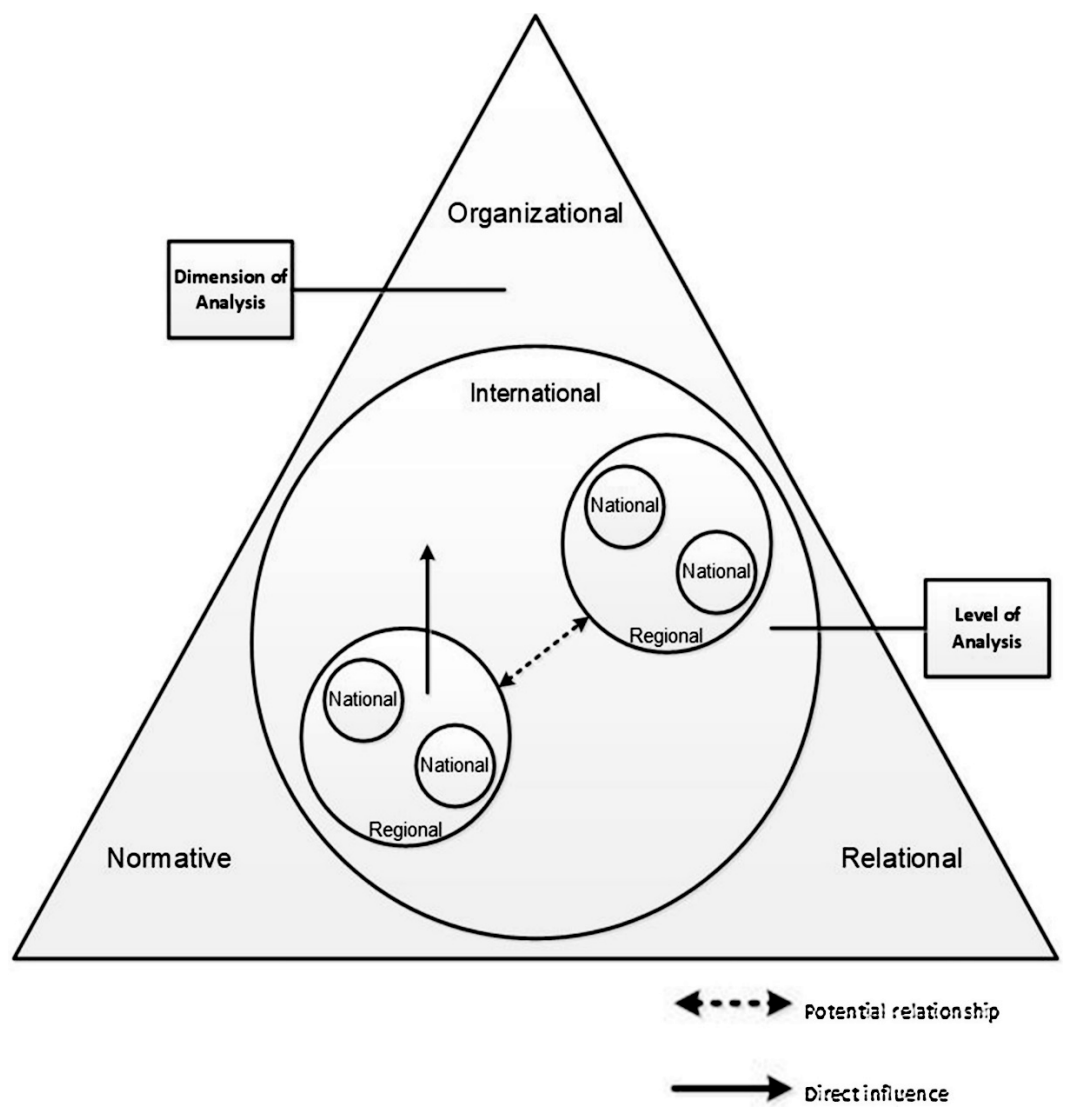

Fig. 3.1 Governance systems framework for regional organic standards 


\subsection{Regional Arrangements}

\section{EU Regulations - from 1991-present}

The increase of organic food and farming in Europe in the mid-80s brought the topic of organic regulations to the attention of European authorities. With many benefits being claimed by organic retailers of organic products and premium prices paid by customers, the European Commission started to consider what controls were necessary to ensure the reliability of organic products for consumers (Schlüter \& Blake, 2009). Right from the early years of the development of the EU regulation, the Commission turned to IFOAM as the primary source of organic expertise. In particular, the IFOAM EU Group is the unified voice of organic stakeholders concerning organic decision-making of the EU. Ever since the early 1990s it has held regular and official meetings with the Commission, but also informal meetings with Commissioners, to discuss progress concerning the regulations and upcoming issues (Schlüter \& Blake, 2009).

In 1991, the European Council of Agricultural Ministers adopted Regulation (EEC) No 2092/91 on organic farming and the labelling of organic farm produce and foods in the context of EU farm policy reform, which came into force in 1993 and became binding for all EU Member States. The EU was the first region in the world to determine a common standard for organic production that would become subject to legal definition and control. A control and labelling system is in place, and the EU organic logo can be used on products that (almost) only contain organic ingredients. National or private logos may simultaneously be used.

The regulation also provides detailed criteria and inspection systems that allow for the import of organic products from non-EU countries. Because imports from outside the EU are a considerable part of the market, the regulation became the benchmark for organic farming in the world as many market actors had to conform to the regulation (Schlüter \& Blake, 2009).

Throughout the years, Commission Regulations were adopted to set requirements for organic animal production (EC No 1804/1999), and implementing rules for imports from third countries (EC No 1235/2008 under EC No 834/2007). Based on the premise that existing regulation could be simplified and improved, and in light of new developments and technical progress, the EU's legal framework on organic production was extended in scope (Fladl \& Hiulot, 2009). In 2007, the Council adopted the new regulation (EC No 834/2007), which came into force in 2009. Resulting from the continuous additions and amendments to European law, the regulation has become extremely long and complex (European Commission, 2014). A revision has been proposed by the European Commission in 2014, which has now been preliminary agreed upon. 


\section{East African Organic Products Standard - from 2007-present}

The United Nations Environment Programme (UNEP) and the UNCTAD selected organic agriculture in 2004 as the focus of joint work. In 2005, they launched the initiative 'Promoting Production and Trading Opportunities for Organic Agricultural Products in East Africa.' The project advanced from and built on the Export Promotion for Organic Agriculture Products for Africa (EPOPA) which started in 1997. Through the EPOPA project national organic agriculture movements emerged. In partnership with IFOAM, a part of the UNEP/UNCTAD project focused on promoting regional cooperation including the development of an East Africa Organic Standard. At the start of the initiative, Kenya, Tanzania and Uganda had different organic standards developed with the support of national organic movements (AgroEco \& Grolink, 2008; Taylor, 2006). Additionally, also several private and international organic standards were used in the region. The proliferation of standards in East Africa mirrored the development of organic standards at the global level, in that they were not harmonized and ran the risk of fragmenting the East African organic market (Twarog, 2011; UNEP, n.d.). This posed significant problems for local organic farmers because they had to meet different requirements to access regional or international markets. Compliance costs were high and complying with one standard meant that they risked being excluded from markets that demanded a different standard. Moreover, the standards were not well adapted to local agro-ecological conditions. Consequently, this also posed problems for producers seeking to target the regional market (UNEP, n.d.). Stakeholders were concerned that this multitude of standards could eventually become a technical barrier to trade within the region and placed unneeded restrictions (Twarog, 2008). The creation of a common standard was envisioned to address these disadvantages. It was also considered that market access for East African organic agricultural products could be improved through successful negotiations with the European Union and other major markets for equivalence or mutual recognition of standards (UNEP, n.d.).

The Regional Standard Technical Working Group was established with the specific mandate to develop an East African organic standard. In 2006, Burundi and Rwanda joined the regional activities (Naqvi, 2009). This group was composed of a cross-section of stakeholders, which included representatives from the participating governments, certification bodies, national organic agricultural movements, the East African Business Council, and facilitators from IFOAM and UNCTAD (Muwanga, 2011). The East African organic standard (EAS 456:2007) was officially adopted in 2007. The EAOPS established a label ("Kilimohai") and the implementation of the standard is carried out by various private certification companies and export outlets. The UNEPUNCTAD project ended in 2010. The standard has been accepted to the IFOAM Family of Standards. Since the East African Community was not a legal entity recognized by the EU to apply for equivalence, 
a certification body applied for equivalence in 2011. The European Commission rejected the application and found the standard inequivalent on several issues including conversion periods and livestock provisions. Experts involved in the East African project reflected that differences were surmountable and were suspicious of underlying motivations by the Commission's rejection. However, they recognized that the certification body did "not follow through very well on the application," and that in the project "more energy should have been spent on just lobbying with the EU." [Interview 16 - EAOPS, private affiliate] The importance of establishing mutual trust for equivalence is also reflected by an expert working for the European Commission, as assurance is needed to "have a very competent authority in front to negotiate [equivalence] and a competent authority responsible for the correct implementation and enforcement of the rules." [Interview 15 - EU, public affiliate]

\section{Pacific Organic Standard - from 2011-present}

The promotion of organic agriculture in the Pacific region eventuated with the recognition of a number of region-wide challenges, including the effects of climate change, the degradation of ecosystems due to unsustainable use of land and marine resources, and the need to generate livelihoods to maintain populations in the islands. It was considered that organic agriculture could contribute to dealing with these challenges (Secretariat of the Pacific Community, 2008). Before the start of the project to develop a region-wide organic standard, there was no legal framework on organic agriculture, a lack of supporting policies and an absence of an overall development strategy under which the main actors could cooperate with each other (Mapusua \& Maccari, 2007).

With the financial support of the International Fund for Agricultural Development (IFAD) and technical assistance of IFOAM, the Pacific Regional Organic Task Force (ROTF) developed the Pacific Organic Standards (POS). The ROTF was a technical group representing all sectors and twenty-two countries and territories of the Pacific Island that were involved in organic. Another group consisted of Pacific leaders, called the Pacific High Level Organics Group (PHLOG), providing high-level political support and advocacy (Mapusua, 2012). The standard was endorsed in 2008 by the PHLOG.

The Secretariat of the Pacific Community (SPC) introduced the Pacific Organic and Ethical Trade Community (POETCom), which developed an organic guarantee and labelling system. In 2013 an export support scheme was implemented as part of the Pacific Organic Guarantee System with a Memorandum of Understanding signed between POETCom and certifying bodies to provide certification services to the Pacific Organic Standard and allowing the commencement of the marketing of a regional brand "Organic Pasifika" (Mapusua, 2016). Although supportive policy frameworks are starting to develop, the POS has not been legally recognized and adopted to national legislation yet 
by any of the countries. An expert involved in the POS reflected that for the adoption of POS into national legislation the respective governments, civil society actors and private enterprises do not collaborate enough "to ensure there is recognition and collaborative support." [Interview 11 - POS, private affiliate]

The POS was accepted by IFOAM into the Family of Standards, and its approval was based on an equivalence assessment against the COROS, which were developed by the ITF. It was also found to be equivalent to the requirements of the EU regulations by the International Organic Accreditation Service (IOAS).

\section{Central American Initiative - approved in 2012}

Impetus for creating a common organic regulation came from authorities from Central American countries of Guatemala, Honduras, El Salvador, Nicaragua, Costa Rica, Panama and the Dominican Republic. The main aims for harmonization were to facilitate intra-regional trade and to allow the countries to negotiate equivalence agreements as a bloc (GOMA, 2012). A regional standard-setting process started in 2004, but stalled by 2007 (Schwindenhammer, 2015). With financial and some technical support of GOMA and operations support by the Inter-American Cooperation on Agriculture (IICA), the project resumed work on the regional standard-setting process (Bowen, 2011). GOMA anticipated that it would have an advisory role in the development process of the standard, but the involved authorities saw the role of GOMA primarily in terms of funding. This resulted in GOMA not being represented during the development meetings, although comments of private sector stakeholders from consultations were taken into account (Bowen, 2013).

The Harmonized Regional Organic Regulation was completed in March 2011, which was officially approved in 2012 by the Central American Agricultural Council. The regulation includes standards for organic production and processing, requirements for conducting organic certification, and a system for supervision of the regulation by the governments (Schwindenhammer, 2015). After finalization, the regional regulation was intended to replace the individual country regulations (GOMA, 2012), but this has not happened to this date. The standard has also not been accepted to the IFOAM Family of Standards. Nonetheless, with the exception of the Dominican Republic, all countries submitted a Central American Technical Regulation on Organic Agricultural Products (RTCA67.06.74:16) to the WTO Secretariat in 2016. This document expands on the organic standard approved in 2012, as it includes provisions for beekeeping and the collection of wild products, as well as provisions for labelling and certification. In case the proposed technical regulation will pass the review stage, the Council of Ministers for Economic Integration (COMIECO) of the SICA will need to ratify the regulation. Once 
the regulation is published in the respective government gazettes, the organic regulation will be binding.

\section{Asia Regional Organic Standard - approved in 2012}

The Asian region hosts a wide range of organic sector development settings and regulatory frameworks, ranging from developing to highly regulated. The market has been growing in the last decade, and while exports remain a dominant feature of sector development in the majority of developing countries, local markets have also emerged (UNCTAD, FAO, \& IFOAM, 2012). Under the auspices of the GOMA Project, a Working Group for Cooperation on Organic Labeling and Trade for Asia was created, which in turn decided to develop the Asia Regional Organic Standards (AROS). The vision was that it should be an inclusive project of all or most countries in the East, South-East, and South Asia regions, and be based on common regional requirements. It was envisioned that the standard would be adopted or adapted as a national standard, above all by countries that had not yet developed their own standard, and that equivalence between organic standards and certification programs within and beyond Asia would be facilitated.

Both public and private stakeholders participated in the initiative. The GOMA-Asia Working Group approved the final draft at its meeting in February 2012. When complied with, the standard enables producers to label their products as organic. The standard does not cover procedures for verification, such as inspection or certification of products. The working group issued a declaration in 2012 calling for such recognition (formally by governments in the region) and recommended that AROS should be adopted as the common standard for the region. It also called for the Association of Southeast Asian Nations (ASEAN) and the South Asian Association for Regional Cooperation to accept AROS as a regionally harmonized organic standard (UNCTAD, 2012). A Chinese expert involved in the AROS project reflected that the standard has not been useful across the entire Asian region, even to the point where it is doubted if government officials have even read the standard: "no-one said that there is a big difference [between AROS and the Chinese national organic standard], so there was no need for them to read it." [Interview 4 - AROS, private affiliate] The standard has been accepted to the IFOAM Family of Standards. Yet, none of the participating countries adopted the standard into national legislation. Nonetheless, the work proved to be the groundwork for the next Asian regional agreement, the ASOA.

\section{African Organic Products Standard - approved in 2013}

The intergovernmental organization for the African Organization for Standardization (ARSO), whose mandate is to develop and harmonize African standards, started an initiative on a common organic standard in 2012. Many different organic standards are 
used in Africa and the purpose of the standard was to have a single organic standard for organic agriculture production, and to further the development of organic production and trade in the African region (ARSO, 2012).

The standard was prepared by the ARSO Technical Harmonization Committee on Agriculture and Food Products (ARSO/THC 1), and participation to the technical committee was open to all African country representatives member to the ARSO, whether from the public or private sphere. At the national level, member states held country consultations during which private stakeholders were consulted. In line with the principles on the African Standards Harmonization Model of ARSO, the EAOPS served as a major source document for the harmonization. The EAOPS standard was not directly adopted and there are differences between the standards (e.g. on the aspect of animal husbandry). Furthermore, the standard was also based on the IFOAM Basic Standards and the Codex (ARSO, 2012). In 2013, the organic products standard (ARS: 751) was approved with consensus.

The standard has, however, not been assessed against the COROS and an application for its evaluation for purposes of inclusion into the IFOAM Family of Standards has not been made. To date, the standard has also not been in use. ARSO, with the support of the African Development Bank and the United Nations Economic Commission for Africa, is currently developing extension material and simplifying provisions in order for requirements and benefits of the standard to be understood by all relevant stakeholders. The standard's conformity assessment system is also being developed, and a verification system is projected to be in place by the end of 2017 .

\section{ASEAN Standard for Organic Agriculture - from 2014-present}

After the AROS was established as a regional benchmark for equivalence, the Task Force on ASEAN Standards for Horticultural Produce established a Special Task Force for further consultation amongst the ASEAN member states, which include Indonesia, Malaysia, the Philippines, Singapore, Thailand, Brunei, Myanmar, Cambodia, Laos, and Vietnam. An expert involved in both the AROS and the ASOA stated that the "AROS was used as a referent [for the ASOA]. But we also worked on modifying it to be suitable to the national standards of ASEAN member states." [Interview 5 - AROS and ASOA, public affiliate] The ASOA is for the most part similar to the AROS, but has been made more specific to the ASEAN conditions. For instance, some items have been agreed to be put on the exclusion list. This includes the use of pig manure as raw material for the production of organic fertilizer, since this is not allowed and considered Haram under Islamic law. The ASOA also expands on the AROS by including provisions on the traceability and recordkeeping of the whole organic operation process. 
Although private stakeholders do have some influence in the form of (informal) consultation, the process is governmentally steered. The ASOA was completed in 2014 (Wai, 2015) and in September 2014 a Strategic Plan of Action of the Task Force was approved by the ASEAN Ministers for Agriculture and Forestry. The main aims of this strategic action plan include the establishment of a common understanding of the organic standard and its requirements. These requirements would then serve as a guide for the authorities in assessing equivalence amongst the member states. The ASOA is a mandatory standard for the ASEAN member states; however, most members still use their own national standards. Some countries do not have a national standard, but it is envisioned that they will adopt the ASOA as a national standard. Countries with a national standard will align it to the ASOA in order to stimulate harmonization and equivalence between member states. Member states are currently in the process of carrying out the strategic plan.

\subsection{Governance System Analysis}

\section{The organizational level}

Although both public and private actors have been crucial for the development of regional standards, the role of public authorities has been quintessential through their categorical involvement in all of the regional governance frameworks. This is unsurprising, as these initiatives transcend geographical borders and jurisdictionally fall within the mandate of public authorities, requiring initially political and then legal endorsement. Their absence or lack of support would seriously imperil the initiatives' operability due to a lack of legal enforceability. Nonetheless, the influence of private actors and public-private partnerships to the initiation and expansion of the regional organic standards has been decisive. The work of IFOAM has been paramount from the start, but after the turn of the 21st century the work of other international organizations, notably UNCTAD, UNEP, FAO and in particular the ITF and GOMA projects, has also been crucial. Recognized as institutional entrepreneurs for organic agriculture standards (Schwindenhammer, 2015), these actors have organized projects and invested issue-specific expertise to the promotion of regional cooperation on harmonization and equivalence. Where governments are characterized by their political and legal authority, the private and public-private actors represent moral and technical authority. First by the credibility they brought to pursue their goals in the field of harmonization and equivalence, and second, by bringing in knowledge-based expertise and funding to support the projects. Underscoring the importance of political and legal authority, the institutionalentrepreneurs always sought the collaboration of public authorities in organic regionalization projects. Four out of the seven regional arrangements were the result of 
public-private partnership, although consultations with private actors have also taken place in the three other arrangements. In five of the arrangements, private actors were in attendance for working groups or technical committee meetings, albeit sometimes as representatives of member state delegations. The formal character of the regional arrangements is predominantly public. Interviewed private stakeholders generally expressed their need to be included (more) in decision-making processes. The lack of competency and know-how by public actors was an often named critique across the cases. One private actor formulated it as follows: "I'm a very strong opponent to theoretical standards making. I always think that standards should be written by practitioners that know what they are talking about." [Interview 16 - EAOPS, private affiliate] Altogether, continued exclusion of civil society can undermine the credibility and legitimacy of institutions governed by member states (Green, 2005).

With the exception of the governance framework of the EU, the regional organic standards are not widely enforced. This appears to stem from two main causes. First, certification and the labelling of products to the standards, the regulatory form of standards (e.g., Bartley, 2011), have not (yet) taken off. The EAOPS and POS have, however, started to introduce certification and labelling, which for the POS was mainly realizable because costs were reduced through the use of Participatory Guarantee System schemes. Such schemes certify producers within locally focused quality assurance systems and are built on a foundation of trust, social networks and knowledge exchange (IFOAM, 2016b). In the case of the POS, certification bodies were also willing to lower their certification fees. Second, the standards are largely not adopted into national regulations, nor are they enforced. Organic regionalization projects do not only require political and legal involvement, but also the development and maintenance of its infrastructures. For instance, legally, public standards need to be adopted into national regulations and enforced, while political commitment to the project by stakeholders needs to be created and maintained. The inadequate allocation of legal, political and funding resources appears to result in ineffective regulation.

\section{The normative level}

The pursuit of regulating organic production by the private sphere stems from environmental and production values underpinning organic farming, whereas public actors have been particularly motivated by safeguarding public interests. To a large degree, these motivations are time and context specific. For example, in Europe, the original incentive for organic regulation came from the organic movement as to provide a more effective basis for enforcing labeling claims, against free-riding and fraud (Gibbon, 2008), which was taken up in the EU regulation as a way to provide fair competition (EEC No 2092/91). In the Pacific, public interests were also paramount as it was envisioned that 
the standard would be a key contributor to the sustenance of culture, improve livelihoods, people's health and the environment, and specifically address the mitigation of negative effects of climate change (Secretariat of the Pacific Community, 2008). Friction between the two spheres can also be seen in the more recent concern by the European organic movement that organic production has allowed some level of GMO contamination. Particularly, a point of criticism from the organic movement is not so much the adaptation of the provisions in the EU organic regulation allowing GMO contamination, but rather the general EU legal framework which is considered to not sufficiently protect organic production from contamination and its consequences (IFOAM EU, 2013).

A prominent incentive shared by the regional arrangements is the facilitation of inter- and intra-regional trade. Arrangements from developing countries specifically envisioned that the regional standards would enable them to negotiate equivalence agreements as a bloc and that it would increase the likelihood of success in negotiations with the EU and other major markets (GOMA, 2012; UNCTAD, 2012; UNEP, n.d.). This anticipation rests mainly on two assumptions. Firstly, harmonized or equivalent regional standards facilitate the recognition and acknowledgement of national standards internal to the agreement. Secondly, the different countries together represent a bigger organic market, which enhances their appeal as a serious trading partner for major markets.

In terms of the production and harvest areas that the standards cover, the arrangements vary from a limited scope on primarily horticulture to the inclusion of provisions on animal husbandry, beekeeping, and the collection of wild products and aquaculture as well. The success of the regional standard is expected to expand the scope of the standard by, on the one hand, leading to market expansion of organic sectors, while on the other hand, encouraging policymakers to regulate more organic sectoral fields. This occurred in the EU, where the organic regulations expanded with rules for organic aquaculture (Regulation 710/2009), whereas the EAOPS has yet to materialize its plans to expand its scope to include aquaculture.

Even though regional standards account to some extent for differences specific to the regional environment and local context, regional standards do stimulate the cohesiveness in terms of the content of the standards across the regions. Several reasons account for this. Above all, in the preparatory stages of the regional standards in developing countries, the Codex guidelines (1999) and IFOAM standard (2005) for organic production and processing served as guidance sources. The so-called institutional entrepreneurs also stimulated the use of these normative references. Furthermore, policy coherence is presumed to enable acceptance of the regional standards by external parties. With the exceptions of the Central American initiative, the ARS, and the newly established ASOA, the standards have undergone equivalence assessments by IFOAM and have been accepted to the IFOAM Family of Standards (IFOAM, 2016a). This 
indicates that although differences between the standards are noticeable, the regulatory field is reaching more cohesion.

\section{The relational level}

Through its organizational structure, intra-regional collaboration evidently intensifies at the preparatory stages as task forces and working groups from different countries are established. Collaboration continues in cases where the standards become operational. Furthermore, regionalization is expected to intensify the intra-regional trade of organic products. Since the countries recognize each other's legal regulatory frameworks, obstacles to trade, in the sense of using other types of certifications and having to deal with import protocols, will be alleviated. Therefore, the introductory texts to the regional organic standards specifically refer to the purpose of facilitating or promoting intraregional trade, or are proposed from a governance framework that explicitly stimulates regional integration. Since four of the standards were adopted in 2012 or more recently, their results are too preliminary to draw strong conclusions in terms of effectiveness for cohesion and trade facilitation. Information on the impact of the standards before 2012 shows mixed results. The organic sector in the EU has risen considerably in the past decade, however, the results in terms of sales and (international) trade is lacking due to insufficient data and official statistics on particularly sales and (international) trade at EU level (European Union, 2016). In East Africa, a baseline report conducted in 2015 on the organic trade and value chain development established that although organic products were not certified nor had the Kilimohai label, considerable trade was taking place across the borders among the organic actors (Ndungu, Unpublished results). It showed the potential for further building of the regional organic market but also identified several barriers per country participating in East African trade, which included, among other issues: border delays and bureaucracy; lack of supplier and market information; and lack of harmonization of pesticide registration. In the 22 Pacific countries and territories, organic trade is reportedly in its infancy, but small quantities of organic products are exported throughout the different markets (Mapusua, 2017). For the regional standards that were developed more recently, impact results are not available to determine intensified trade relations.

Motivations for intra-regional trade were integral to ambitions to trade with major markets. One interviewee explained it as follows: "The testing ground will always be the regional partnership or regional trade. Once it is accepted in the region, you can also sell [on the international market]." [Interview 6 - AROS and ASOA, private affiliate] Although trade with countries from other regions was considered a major stimulus for the initiation of the frameworks, inter-regional collaboration has not lifted off and equivalence with countries outside the region is very limited to non-existent. Not 
adopting organic standards into national regulations has been particularly obstructive in this regard because it does not provide a legal basis for trade with other countries beyond private certification. For equivalence agreements with other countries, however, applications are necessary on country level. A further complication is the preliminary agreement on an overhaul of the existing EU rules which details a move away from equivalence agreements for non-recognized third countries and replace it with a compliance system, which means that private certification bodies in third countries have to comply with EU production and control rules when deciding whether a product to be exported to the EU market is organic or not (Council of the EU, 2017). The option to allow for equivalent production methods in third countries would remain possible under trade agreements (European Parliament, 2017). A consequence of this system, which has been used by all countries with operational organic regulations, is that it replaces the potential for organic trade between countries without trade agreements with a system that creates financial burdens for producers and exporters.

\subsection{Discussion}

To what extent has the regionalization of organic standards contributed to cohesion of regional and global regulation on organic? Before a regional standard is adopted, the content of national standards - if in place - is at minimum mutually recognized, and otherwise harmonized. If on the basis of the regional standard equivalence agreements with countries or other regional standards are established, regionalization significantly contributes to regulatory cohesion on the global level. The Codex and the IFOAM Basic Standard have contributed to cohesion, as the arrangements have underscored them as normative references in the formulation of the regional standards. Functioning as references for the establishment of more specific standards on organic (Schmid et al., 2007), the data show their institutionalization on the regional level. Furthermore, it demonstrates the influence of international and transnational voluntary sources of guidance on organic regulation.

Institutional entrepreneurship has also been significant for processes of institutional change in the regional arrangements (Schwindenhammer, 2015) as for instance the ITF and GOMA initiatives contributed technical and moral authority to several of the regional arrangements. The roles they fulfilled in this regard relates to that of meta-governors (Derkx \& Glasbergen, 2014; Pekdemir, Glasbergen, \& von Gagern, 2016). Specifically, they engaged in framing the global discourse (e.g. promoting harmonization and equivalence through regionalization), capacity building (e.g. providing technical assistance), networking (e.g. involving relevant stakeholders to the regional projects), and 
mainstreaming (e.g. providing normative documents). Advances made in the regional regulatory landscape undoubtedly resulted from their involvement.

The observed normative coherence alone, however, provides insufficient ground for the institutional harmonization of organic standards. If regional standards are not adopted as national regulations and are therefore not enforced, nor used for equivalence arrangements with external countries, they will not provide a sufficient basis for effective inter-regional trade of organic products. The necessary legal, political, and technical infrastructures underlying institutional harmonization would be lacking, resulting in the anticipation by developing countries of equivalence arrangements with big market players to remain unfulfilled. Thus far, a lack of true political and economic integration at the regional level certainly has been conducive to the fact that regional organic standards are not effectively endorsed. In the current governance system for organic trade, import regulations generally do not allow for the recognition of regional standards (Twarog, 2013). In the EU for instance, regions are not part of the so-called third countries whose organic standards are accepted and none of the countries participating in the regional arrangements are part of the EU third country list that are recognized as having equivalent organic production rules and control systems. Paradoxically, without genuine institutionalization within or beyond the regions, regional standards only add to regulatory fragmentation. Inclusion in the IFOAM Family of Standards abates this complication, as it identifies the possibility for equivalence agreements between (regional) standards and regulations.

Contrary to the intentions of the regional arrangements of developing countries, a preliminary agreement has been reached on the European Commission's proposal to move away from equivalence rules, which have proven to be highly contested. Although equivalent production methods in third countries could be recognized under trade agreements, it is arguable in how far the compliance focus contradicts TBT and SPS requirements by the WTO and calls for facilitating harmonization and equivalence of standards that have the same objectives. While trade remains possible under a compliance regime, it undercuts the potential and advantages for trade by means of regionalization. More fundamentally, from the perspective of organic values, regional standards as a governance framework offer an acceptable alternative to compliance regimes. In particular, through regional harmonization and inter-regional equivalence, it allows for variations in local agricultural circumstances, which may emanate from biological, ecological, social, and economic contexts. Nonetheless, the focus of many actors within the regional arrangements reportedly revolves around issues that would permit trade. This supports the theory that the conventionalization and particularly the structure of the standards regime of governance constrain the direction of organic production debates to predominantly trade and market compatible options (Fouilleux \& Loconto, 2017). Trade in turn, puts further pressure towards harmonization which has undesirable 
consequences (Rundgren, 2014). Particularly in relation to the compliance regime, exporters and exporting countries are required to go along with the demands of major markets. Organic standards largely reflect process characteristics, since production and processing principles rather than the attributes perceivable in the product itself are emphasized. Even so, organic standards also reflect both product and process characteristics (Loureiro, McCluskey, \& Mittelhammer, 2001; Nadvi \& Wältring, 2004). Actors along the value chain are apprehensive that the shift from equivalence to a compliance regime implies that the EU regulation is becoming a product standard. Since compliance provides entrance into only one specific market, it burdens particularly farmers with additional certification requirements. In this way, compliance augments regulatory fragmentation through adding a layer of control rules to certification bodies in third countries. As particularly developing country firms and farms are confronted with a variety of both process and products standards, non-compliance will result in exclusion (Nadvi, 2008). Coupled with the fact that environmental problems are often local or regional in scope, the advantages of regional standards disappear.

Although the promise of regional standards for international trade may be shortlived or far-off, efforts have not been in vain as many countries have common or harmonized standards that are applicable to the local and regional conditions. The recent interest in regional organic regulation by Central America and Southeast Asia, two regions committed to further regional integration, may in fact revive the case for regional organic standards. They may prove to be useful in future multilateral agreements, as multilateral processes are currently proposed to address challenges with developing and managing multiple equivalence arrangements (Bowen \& Hoffman, 2015a). A global multilateral system, in which many countries accept the organic regulations of each other based on equivalence of technical regulations and mutual recognition of conformity assessment, would contribute to policy cohesion and international trade of organic production. Each country would only need to be assessed once, and it would not impose different burdens for developed or developing countries. Major organic market players, including the EU and US are at present considering such an agreement. Although promising in its potential, stakeholders outside of this process are wary of possible limitations in the short or long term, which may include lock-in effects and the exclusion of small export markets.

Beyond the regulatory and legal framework that needs to be in place for regional organic trade, or technical discussions concerning mechanisms that permit trade, the findings also underscore the role of trust and reputation in international trade coordination. Indeed, standards are insufficient to overcome quality uncertainties in trade (Bernzen \& Braun, 2014). Formal guidance mechanisms and informal arrangements are both important to reaching agreements. People with organic and alternative movement conventions, which are linked to personal relationships of trust, 
ecological diversity, and social justice (see Raynolds, 2004), operate alongside technocratic and bureaucratic government officials, who do not necessarily share this personal affiliation or have the same level of expert knowledge on organic production. The fact that not many developing countries are able to provide the level of trust in their technical competence and certifying bodies (Bowen \& Hoffman, 2015a) adds to this predicament. It therefore calls for serious and delicate bridging of expectations and in order for trade to commensurate, the role of relationship management, trust building, and partnership more broadly are not to be underestimated.

\section{Conclusion}

This article has examined the regionalization of organic standards as a mode of governance in the quest for cohesion and trade. Based on a governance systems analysis of all the regional arrangements thus far, the findings reveal that on the organizational level, the public-private characteristic of the arrangements has been a key factor for their development. Where governments provided political and legal authority, public and private international organizations and national organic movements represented moral and technical authority. Aside from the EU, the enforcement of the regional standards, however, falls short due to the limited certification and labelling of the regional standards and because regional standards are largely not adopted into enforceable national regulations. On the normative level, public actors framed the pursuit of regionalization in defense of public interests, whereas private actors underscored production values of organic farming. While private values have been more or less constant, public interests have to a large degree been context and time specific. The facilitation of inter- and intraregional trade is an incentive shared by all arrangements. Variations in terms of production and harvesting areas the standards cover are ascribed to the relative success of the standards. While attentive to local and regional conditions, regional standards improve coherence among the content of the standards as similar normative references have been used and promoted by institutional entrepreneurs. On the relational level, stimulating trade in organic products has been a strategic aspect of regional standard development and collaboration. However, comprehensive official statistics on account of all regions is indispensable for corroborating effectiveness and future analysis of organic trade. Nonetheless, it is clear that the often hoped pursuit of inter-regional collaboration and equivalency has not yet been fulfilled.

As a conceptual tool, the governance systems analysis can lay bare the multi-layered governance architecture and interdependencies between different actors and organizations. Alliances, as well as the ways in which actors can hamper each other's activities may come to the fore. In this way, it can be indicative of how a governance system could be efficient or effective, for example by increasing cohesiveness in policies. 
Several observations relating to the role of regional organic standards to reduce regulatory fragmentation and to facilitate cooperation in trade then arise. To start, comparable to private multilateral agreements, regional standards are public and public-private efforts in pursuit of the same reducing the regulatory burden for both producers as well as countries. On a global level, regulatory complexity will be reduced through inter-regional equivalence and multilateral agreements. Their success rests on the commitment and implementation of participating national governments. It is therefore uncertain whether current levels of regional cooperation are adequate to contribute to reduce the fragmentation of governance for organic production. The EU is the most effective in this regard, but remains a unique political entity as it functions similar to states with a legislative, executive and independent judicial branch that can enforce compliance. Evidently, the other regionalization efforts on organic do not carry the same political authority. The commitments of Central America and Southeast Asia to further regional integration are the most promising cases to contribute to cohesion in organic regulation, but whether the same level of regulatory power will be achieved is not certain.

In addition, the ability of powerful actors to define the boundaries of trade practice and constrain the actions of others is evident. In this regard, the recent decision of the EU to enforce a compliance system for non-recognized third countries may also temper the adoption of regional standards seeking equivalency with the EU. While compliance is a widely used system for standards, they add a layer of governance and consequently further fragment the global system as exporters in foreign markets need to comply with these standards. Compared to the regulatory tool of equivalence, it disregards other local conditions in organic production.

Finally, the absence of central coordination offers multiple pathways for future development. Realistic options may include multilateral agreements, whether this will be inclusive or beneficial for less powerful countries remains to be seen. Options for interregional agreements are also viable, and private coordination through for instance the IFOAM Family of Standards could be directive in that. Regional standards in this regard function as a building block. Historically the development of organic standards has been incremental, requiring both political and consumer momentum. If regional standards are adopted as national regulations and enforced, the regulatory potential maystill unfold. If future solutions to fragmentation in organic standards and trade are indeed offered in multilateral agreements, harmonized regional standards constitute compatible regulatory mechanisms. 



\section{Chapter 4}

\section{Private meta-governors and their practices: An inventory of their mechanisms of change}

Published as:

Pekdemir, C., Glasbergen, P., \& von Gagern, S. (2016). Private meta-governors and their practices: An inventory of their mechanisms of change. International Journal of Strategic Business Alliances, 5(2), 133-154. doi:10.1504/IJSBA.2016.079385 


\subsection{Introduction}

Since the mid-1990s, we have seen the emergence of many initiatives by businesses and civil society arrangements, often in the form of collaboration, to induce the sustainability of global value chains. Through standards or more general normative guidance, these private actors have become more and more involved in regulating the behaviour of transnational actors (Pattberg, 2007). The proliferation of these initiatives has brought forward diverse, and oftentimes overlapping, efforts for the voluntary regulation of different international policy domains and transnational issue fields. The result is a very fragmented field of (global) standards, claims and certifications (Derkx \& Glasbergen, 2014).

Although fragmentation may spur competition and innovation, scholars of global governance generally regard it a major concern (Biermann, Pattberg, van Asselt, \& Zelli, 2009). For instance, it can increase conflicts between regulatory schemes, lead to inefficient regulatory competition (Cafaggi, 2016), create confusion among involved stakeholders and consumers (Bitzer \& Glasbergen, 2015), and increase costs for organisations that provide funding to regulators (Fransen, 2011).

This paper focuses on attempts that have been developed to handle this fragmentation, which are generally characterised as meta-governance. Meta-governance has been defined as the 'organisation of self-regulation' (Jessop, 1998), as a way to govern private self-regulation (Kooiman \& Jentoft, 2009; Meuleman, 2006, June; Peters, 2007; Torfing, 2012; Vermeulen, 2015). Through a wide array of guidance mechanisms (Rhodes, 1997), meta-governance addresses fragmentation problems by bringing in more cohesion in the activities and regulatory processes within an issue field.

Meta-governance has often been ascribed to public actors with arguments based upon their centrality in public affairs and their responsibilities for the common good (Bell \& Park, 2006; Christopoulos, Horvath, \& Kull, 2012; Parkins, 2008; Whitehead, 2003). However, in more recent studies, private meta-governance has also become a subject of investigation of governance scholars (Bitzer, Glasbergen, \& Leroy, 2012; Cafaggi, 2016; Derkx \& Glasbergen, 2014; Fransen, 2015; Glasbergen, 2011). Rather than requiring actors to accept substantive norms in advance, from above, and on behalf of a specific organisation (e.g. a firm) or an imagined collectivity (e.g. the nation), private metagovernance is concerned with solving fragmentation problems on the basis of a commitment to a continuing dialogue. This dialogue is assumed to establish the grounds for negotiated consent, resource sharing and concerted action (Jessop, 2011).

Like public meta-governance, private meta-governance is inherently political. The different stakeholders involved may have different priorities, which leads them to different diagnoses of regulatory challenges and to support different meta-governance solutions (Fransen, 2015). While the term meta-governance is used to denote a higher level of decision-making, including the development of an institutional design and 
behavioural rules for partnering (Beisheim \& Simon, 2015), the reciprocal and negotiated character of private meta-governance (Jessop, 2011) also make it easily subjected to influence and power plays.

This paper aims to further contribute to our knowledge about specific private metagovernance practices. Research until now mainly studied the potentials and limitations of private meta-governance as a particular mode of governing. However, little is known about how meta-governors fulfil their roles in terms of the activities they employ.

To answer the question in what ways private meta-governors fulfil meta-governance roles and to what extent their efforts reduce fragmentation, we developed a framework representing potential mechanisms of change. These are confronted with the practices of three meta-governors that have the ambition to become a key actor for the advancement of sustainable production in a global value chain: the sustainable fisheries partnership (SFP), the Common Code for Coffee Community Association (4C) and the World Cocoa Foundation (WCF).

The next section unfolds the repertoire of potential activities of meta-governors ordered in four categories, based on a literature study. The resulting framework is applied in a study of the three meta-governor arrangements in the following sections. The last section reflects on our findings in terms of their fulfilment of meta-governance mechanisms, and in terms of handling fragmentation in their issue field.

\subsection{Meta-Governors Potential Repertoire of Change Mechanisms}

Meta-governors aim to bring more cohesion into their issue fields in various ways. Based on a literature study on (private) meta-organisations and meta-governance, we categorised the different meta-governance activities into four mechanisms: (re)framing the (global) discourse, capacity building, networking and mainstreaming. In the following subsections, each mechanism and the different types of activities that comprise them are separately delineated. An overview is included in Table 1. The boundaries between the different mechanisms are not always clear-cut, because some activities may enforce reaction in other mechanisms or generally span boundaries. The mechanisms are meant as conceptual tools to define the different meta-governance processes employable by governance actors. 
Table 4.1 Meta-governance mechanisms and associated activities

\begin{tabular}{lll}
\hline Mechanism & Activities & References in literature (e.g.) \\
\hline (re)Framing the & Agenda setting & Derkx and Glasbergen (2014), Torfing (2012) \\
(global) discourse & Establishing discursive power & Kooiman and Jentoft (2009) \\
& Setting terms of global debate & Glasbergen (2011) \\
& Producing new knowledge & Glasbergen (2011) \\
Capacity building & Providing rules for governance & Beisheim and Simon (2015), Jessop (1997, \\
& & 1998) \\
& Provision of information and & Ahrne and Brunsson (2008), Beisheim and \\
& knowledge & Simon (2015) \\
& Advance chain-wide competency & Beisheim and Simon (2015), Fransen (2015), \\
& & Torfing et al. (2012) \\
& Inclusion of (new) actors into the & Beisheim and Simon (2015), Glasbergen (2011), \\
& network & Jessop (2009) \\
& Connecting initiatives and identifyingAhrne and Brunsson (2008), Cafaggi (2016) \\
& opportunities for collaboration & \\
& Intermediating & Fransen (2015) \\
& Identity formation & Ahrne and Brunsson (2008) \\
& Standard setting & Fransen (2015), Glasbergen (2011) \\
& Supporting harmonisation & Cafaggi (2016), Derkx and Glasbergen (2014), \\
& & Jessop (1997) \\
Lainstreaming & Bitzer, Glasbergen and Leroy (2012) \\
& &
\end{tabular}

\section{(Re)framing the (global) discourse}

The mechanism of framing the discourse consists of activities that are directed towards shaping the dominant political and normative discourses of the issue field. Framing activities can determine or contribute to the specification of problem-definitions, the terms and norms surrounding the sustainability discourse and the ways to solve the problems in an issue field. Among other things, meta-governors can regulate or attempt to control which issues and options can be included in the system (Torfing, 2012). Processes of framing are continuous efforts, and new findings and insights may contribute to reframing the discourse. Several activities are discernible within this mechanism, namely, agenda setting, establishing discursive power, setting the terms of the global debate and producing new knowledge.

Meta-governors function as deliberative sense-making enterprises, where common views on issues are shaped and on which convergence can be pursued (Derkx \& Glasbergen, 2014). Examples of the different ways in which meta-governors can be involved in agenda setting is by influencing which issues members do and do not discuss, deciding on what is needed for sustainable change in the issue field, setting priorities for on-site implementation and creating willingness to work on them. 
Discursive power can be established by shaping and disseminating politically relevant values, norms, theories and stories. Although these may often remain implicit, they underpin governance practice. According to Kooiman and Jentoft (2009), metagovernance particularly ensues when norms, principles and values are discussed, formulated and applied in governing processes.

Meta-governors do not only set the agenda with members and partners directly, but in effect also (attempt to) influence a wider audience and shape the terms of the global debate. For instance, this can take place by discussing (novel) public and/or private regulations with reference to the meta-governor's frame. Next to that, the standards set by the meta-governor can also serve as a role model for other regulatory forms of private global governance (Glasbergen, 2011).

A meta-governor can also (re)frame the global discourse by producing new knowledge. Non-governmental organisations and businesses can broaden the information base (Glasbergen, 2011), and professional knowledge and research can be acquired on, for instance, local circumstances, applicable technical standards and implementation conditions.

\section{Capacity building}

The mechanism of capacity building involves activities aimed to improve the capacities of meta-governors' members and partners for sustainable change. The main distinguishable activities are as follows: providing rules for governance, provision of information and knowledge and advance chain-wide competency.

Activities aimed at capacity building can firstly be realised by establishing interorganisational expectations and rules (Jessop, 1998) through which governance partners can pursue their aims. For instance, power can be delegated to some members, through which existing strengths may be capitalised. Meta-governors can also mediate among parties that are in dispute and may serve as a 'court of appeal' (Jessop, 1997). Formalised and binding rules of conduct may also require particular activities by members and partners (Beisheim \& Simon, 2015).

Activities can also be aimed at the provision of information and knowledge. Metagovernors can collect information and research, provide access to information and disseminate knowledge and research. Members may add to the information pool and provide information to each other (Ahrne \& Brunsson, 2008).

Chain-wide competency, understood as the competencies of various actors within value chains from producers to retailers, can be strengthened by meta-governors by, for example, facilitating technical and peer support, reviews and internal conformity assessments. Assessments can be made on the impact and performance of the system and its partners (Torfing, Peters, Pierre, \& Sørensen, 2012). The provision of capital can also 
allow partners to access third-party funds (Beisheim \& Simon, 2015). Producer capacity may be built through trainings and on-site assistance. Providing market information to producers can lead to economic empowerment. Furthermore, institutional structures can be established where voiceless or weaker actors are provided a forum and may for instance take part in decision-making.

\section{Networking}

The mechanism of networking refers to the processes that link various actors in an issue field. Networking can be realised in existing institutionalised forums, in more loosely structured forums and projects, or in informal conversations. By seeking to enforce coordination and coherence of the actors involved (Peters, 2007), networking activities aim at constructing a sphere where collaboration can turn into shared visions on goals to induce change in the issue field. The various activities of networking are as follows: inclusion of (new) actors into the network, connecting initiatives and identifying opportunities for collaboration, intermediating and identity formation.

Activities aimed at networking by the meta-governor will firstly be concerned with efforts to include (all) the relevant stakeholders through membership or partnership to the meta-organisation. Networking is not a neutral process: it often includes subjective selectivity of, among other things, actors, interests, spatio-temporal horizons, alliances, strategies, tactics and practical contexts (Jessop, 2009). For instance, inclusion of both North and South actors can be considered a criterion for success (Glasbergen, 2011).

Meta-governors can engage in activities that connect initiatives and identify opportunities for collaboration; for instance, the meta-governor may serve as an umbrella organisation and a focal point for all the initiatives. It may offer an arena where actors can meet and facilitate interaction and increase cooperation among each other. It may devise a form of collaboration but also competition among members (Ahrne \& Brunsson, 2008).

Closely connected to the previous activity of networking is the intermediary role of the meta-governor. Through mediation, or 'brokering' (Bitzer et al., 2012), linkages can be established between suppliers and buyers through which market access can be created, or supply chain access can be secured (Fransen, 2015).

Identity formation can also be an essential element of networking activities, here understood as close similarity or affinity with the meta-governor by virtue of being a member. Through membership or partnership, member identities may be created, reinforced or at least confirmed among its members. Being associated with the metagovernor may in turn provide members a convincing case for identity, status and legitimacy within their environment (Ahrne \& Brunsson, 2008). 


\section{Mainstreaming}

The mechanism of mainstreaming describes those activities that aim at acceptance, inclusion and harmonisation of the meta-governor's normative and regulatory framework, or those it supports. Meta-governors can promote regulatory coherence and convergence (Derkx \& Glasbergen, 2014) both on policy and operational levels. The activities directly pertaining to mainstreaming are as follows: standard setting, supporting harmonisation and lobbying.

Meta-governors are rife with recommendations, guidelines, policies, benchmarking, rankings, codes of practice and the like (Ahrne \& Brunsson, 2008). The activity of standard setting can involve a recommendation, or the development of specific standards. The latter is done, for example, by establishing a sector-wide minimum standard, or by selecting an existing one such as the gold standard.

Activities may also pertain to enhancing harmonisation of different governance mechanisms and regimes (Cafaggi, 2016; Jessop, 1997). This may also concern standards, which means that processes of verification, certification and understandings of sustainability are similar or comparable in different standards. In addition, meta-governors may also support equivalence, a formal recognition of the criteria and requirements of different standards (Marx \& Wouters, 2015), as fulfilling common objectives.

Another activity the meta-governor can undertake is lobbying (Bitzer et al., 2012). On behalf of its members and partners, the meta-governor can act as a representative and advocate in the relevant forums and discussions, for instance, in trade and policy domains.

\subsection{Research Methods}

This article is based on a literature study, semi-structured in-depth interviews and online desk research. The literature study served as the basis for the conceptual framework, which was developed by categorising the mechanisms of (private) meta-governance. Subsequently, case studies were sought to apply the framework on. The criteria for incorporating meta-governors into the analysis were that arrangements must:

1. be civil society organisations

2. have the improvement in sustainable development in value chains in their respective sector as their main priority

3. have an ambition for concerted action for sustainable change

4. exercise their raison d'être by having members and partners from other organisations active in the same sector

5. have a transnational scope. 
The characteristic that sets meta-governors apart from more common standard setting NGOs for sustainable value chains is their ambition for concerted action from member and partner organisations that may or may not already have private standards and other partnerships for sustainability in place.

The five criteria led us to the recognition of three different arrangements across sectors. While scholars have recognised multiple meta-governors in same issue fields (Fransen, 2015; Williams \& Rushton, 2011), we opted for a cross-case analysis to yield knowledge from individual cases, and to inform on the similarities and differences across cases. The case studies selected were the SFP, 4C and WCF. These arrangements function along the lines of supply chain governance of fisheries, coffee and cocoa supplies, respectively, and serve as representative case studies for commodities of transnational supply chain governance in which sustainability issues have gained prominence. Although the terms meta-governance or meta-governor are not used by the arrangements, given their ambition, the 4C and WCF have previously been identified as meta-governors in scholarly work (Bitzer et al., 2012; Fransen, 2015). SFP is similar in its ambition.

The purposive sampling of the meta-governors was complemented with snowball sampling of potential members (actors who have a membership with the meta-governor) and partners (actors who collaborate or attend meetings organised by the meta-governor) for the execution of semi-structured interviews. Since the three arrangements are not all membership organisations, for purposes of consistency members will henceforth also be referred to as partners. One meta-governor strictly controlled public relations about the arrangement, which rendered attempts to contact potential partners and members outside of the involvement of the meta-governor fruitless. Between June 2013 and October 2014, 16 semi-structured in-depth interviews were held, and an additional five respondents answered interview questions by email. The total of 21 respondents consisted of interviews with representatives of the three meta-governors, and with six of their partners. These can be categorised as follows: civil society organisations (9), companies (6), state-owned enterprises (2) and intergovernmental organisation (1).

The interviews included questions regarding the context and background for the initiation of the meta-governor; the different activities the arrangements undertake with consideration to mechanisms of framing the discourse, capacity building, networking and mainstreaming; the influence the organisations are perceived to have by stakeholders in the relevant sectors; and organisational arrangements and ideational perspectives to further understandings on the effectuation of mechanisms. In addition to the interviews, the analysis was complemented through desk research, and the various secondary sources consulted included websites, newsletters, partnership and/or project reports, documents and annual reports. 


\subsection{Introduction of the Cases}

The three case studies are introduced below. The descriptions delineate why these arrangements have been established, what their missions and goals are, and the issuespecific challenges they need to address.

\section{Sustainable fisheries partnership}

The SFP (www.sustainablefish.org) is a business-focused civil society arrangement that was initiated in 2006 to solve sustainability problems in the seafood sector, including the fisheries sector and aquaculture. The arrangement is not involved in standard setting, but within the seafood sector there are multiple, often-competing market-based approaches. Early examples include single species eco-labels and seafood guides, while more recent initiatives (Marine Stewardship Council, Global Aquaculture Alliance, Global Good Agricultural Practice, Friend of the Sea, Aquaculture Stewardship Council) operate at the global level and target multiple environmental problems including overfishing and bycatch (Kalfagianni \& Pattberg, 2013). The reason for SFP's initiation lies in the problems that remained unsolved. Firstly, interviewees pointed towards the problem that most governance actors make insufficient differentiations between fishes and regions, thereby being largely inconsiderate of specific sustainability challenges. Secondly, for an efficient and responsible fisheries management, information on fish population dynamics is needed but often not available (Gagern \& van den Bergh, 2013). Finally, market-based initiatives often concentrate their activities either on wild fisheries or on aquaculture, whereas decoupling is problematic due to the interconnectedness of the two chains. With a mission to catalyse global seafood supply chains in rebuilding depleted fish stocks and reducing the environmental impacts of fishing and fish farming, SFP addresses the aforementioned issues in several ways. For example, SFP maintains an extensive and publicly accessible database of fisheries named FishSource (www.fishsource.com), which contains assessments of sustainability and improvement needs. The FisheriesWiki website (www.fisherieswiki.org) offers experts and analysts the chance to contribute materials on various aspects of fisheries, and functions both as an online contributor network and a common shared database. SFP Metrics, a software package linked to FishSource, can advise corporate partners about the sustainability status of the fish they are ordering. SFP also works on fisheries and aquaculture through improvement projects, in which relevant stakeholders in supply chains collaborate to influence policies and management practices, and improve the sustainability of fishing and fish farming operations. The arrangement does not campaign or provide eco-labels, but instead aims to reduce the barriers to action by industry. 


\section{Common Code for Coffee Community Association}

The 4C (www.4c-coffeeassociation.org) is a multi-stakeholder organisation. After the coffee crisis of 2001-2002, the organisation was established in 2003 to address the main sustainability issues affecting the coffee sector. In its ambition for concerted action, the arrangement aims to provide a platform for all actors committed to addressing these issues in a pre-competitive manner. $4 \mathrm{C}$ is one initiative amongst others, as with the liberalisation of the coffee markets in the late 1980s, numerous private and public-private initiatives tried to balance the de-regulation with private regulation. Certification schemes were initiated, for instance, by Fairtrade, International Federation of Organic Agriculture Movements, UTZ Certified and Rainforest Alliance. Partnerships between NGOs and trade and industry emerged. From 2004 onwards, more initiatives developed, including other intersectoral partnerships. More members of civil society started to change their strategy from campaigning against companies to cooperating. Yet, strong competition between the standard setters led to compliance problems for producers, confusion for consumers and competition between partnerships and members of the supply chain who rely on sustainability standards (Bitzer, 2012). The mission of 4C is to achieve $100 \%$ coffee sector compliance with at least baseline sustainability standards. To meet this goal, the organisation advances sustainability by setting and maintaining the $4 \mathrm{C}$ Code of Conduct, which is a set of baseline standards to start producers on the path to sustainable production; providing access to tools and information for coffee farmers for implementation; setting rules and a verification system; actively promoting sustainability standards and initiatives in the market to create greater value for verified/certified coffees; and providing an open and dynamic platform for exchange where stakeholders can work together. In this role, the $4 \mathrm{C}$ organises forums or workshops on a regular basis and helps setting up joint projects between different stakeholders to tackle particular sustainability issues.

\section{World Cocoa Foundation}

The WCF (http://worldcocoafoundation.org) promotes a sustainable cocoa economy through economic and social development and environmental stewardship in cocoagrowing communities. Founded in 2000, the WCF is an international membership organisation and embodies more than a 100 partner companies, representing $80 \%$ of the global corporate market. Membership is open to manufacturers and cocoa processors, supply chain managers, ports, allied industries and trade associations. WCF is an arrangement that was part of the shift that took off from public to private and publicprivate initiatives for cocoa in the late 1990s. WCF works through partnerships that bring together donors, industry members, producing country governments, research institutes and NGOs to achieve its goals. It also organises twice-yearly partnership meetings where these actors and development agencies convene. Through these efforts, WCF strives for 
concerted action in the cocoa sector. Since 2005, other multi-stakeholder collaborations emerged including a wide range of stakeholders (Bitzer et al., 2012). Currently, different initiatives strive for sustainability in the cocoa chain. These include stakeholder organisations for producing and consuming countries, traders, processors and manufacturers, the value chain and other international multi-stakeholder organisations for economic, social and/or environmental sustainability (including WCF, International Cocoa Initiative, Roundtable for a Sustainable Cocoa Economy; TCC, 2008), and global standard setting and certification organisations (e.g. Fairtrade, Organic, Rainforest Alliance, UTZ Certified). Although WCF is not a certifying body, the arrangement considers that their sustainability principles and goals have much in common with those of transaction-oriented product certification systems. WCF specifically tries to bridge the needs of cocoa farmers with those of the cocoa industry and the environment. To achieve its goals, the organisation focuses among other things on building partnerships with cocoa farmers, origin governments and environmental organisations; supporting and applying demand-led research that improves crop yield and quality; supporting training and education that improves well-being of cocoa-farming families.

\subsection{The Practice of the Meta-Governors and its Application to the Conceptual Model}

Our analysis of the cases shows that the arrangements employ a wide array of metagovernance mechanisms, albeit often in different ways and to varying degrees. In the following, characteristic examples have been chosen to illustrate their specific operationalisation and these are summarised in Table 4.2. 


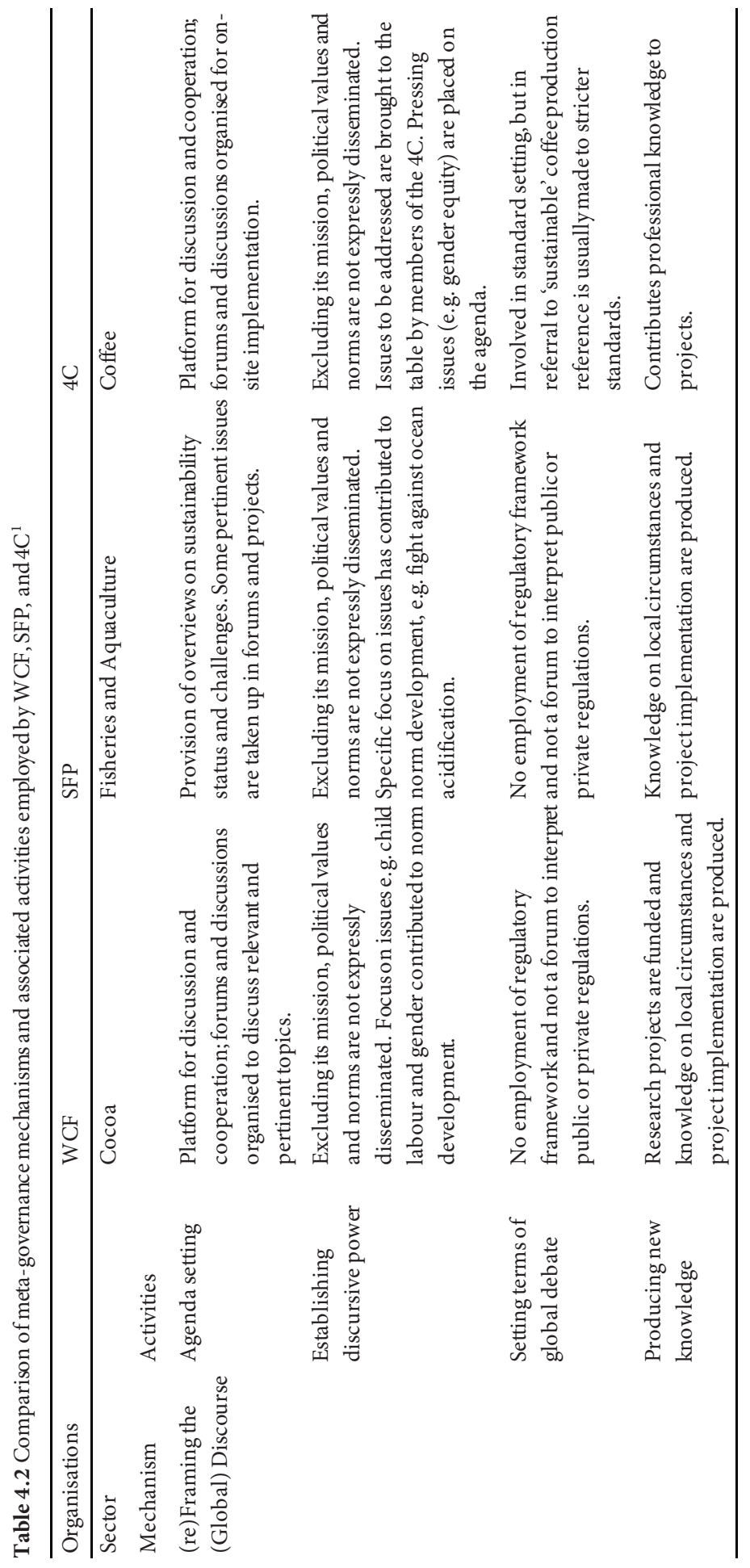

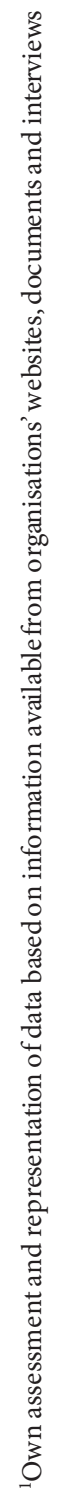




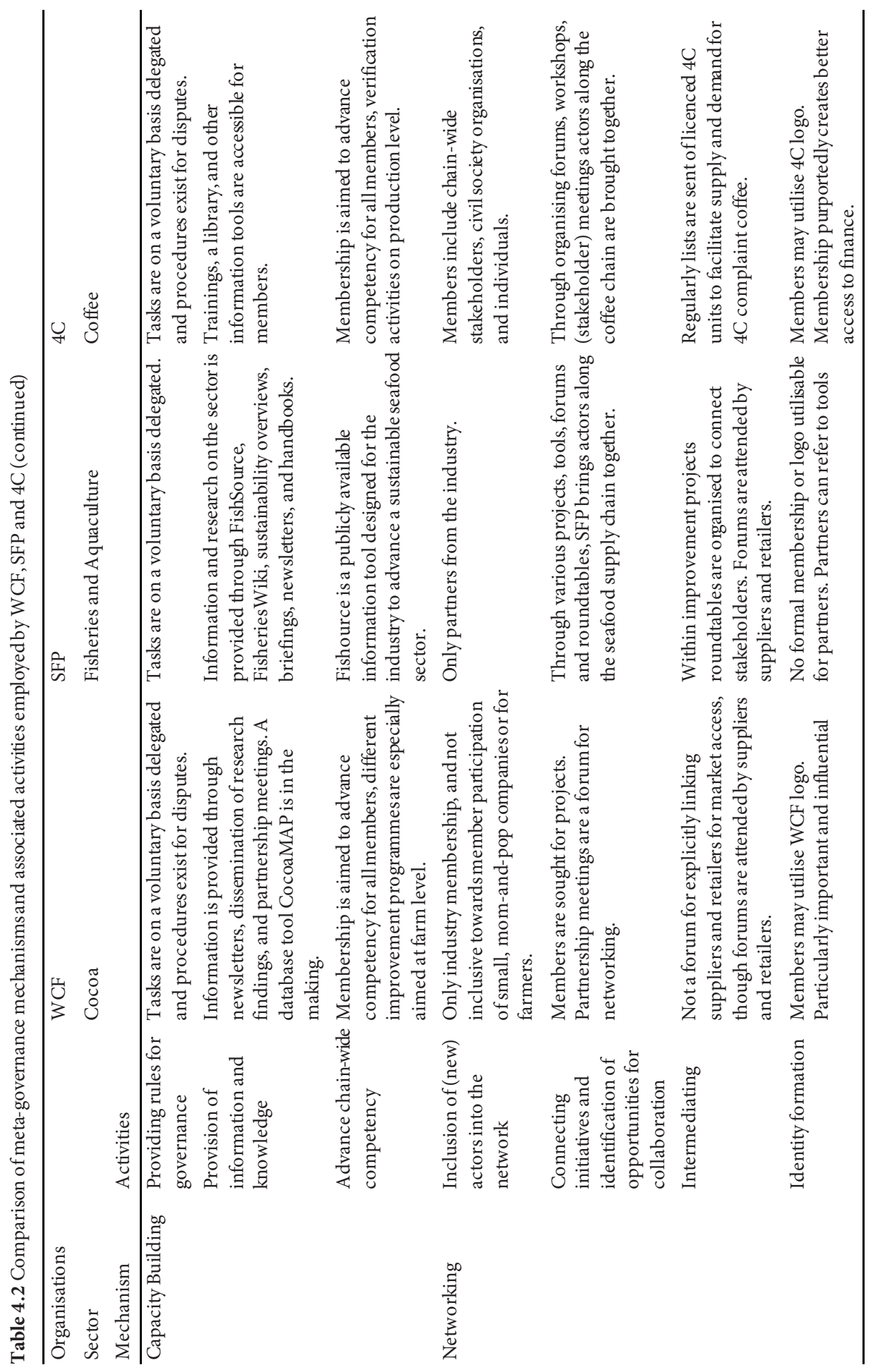




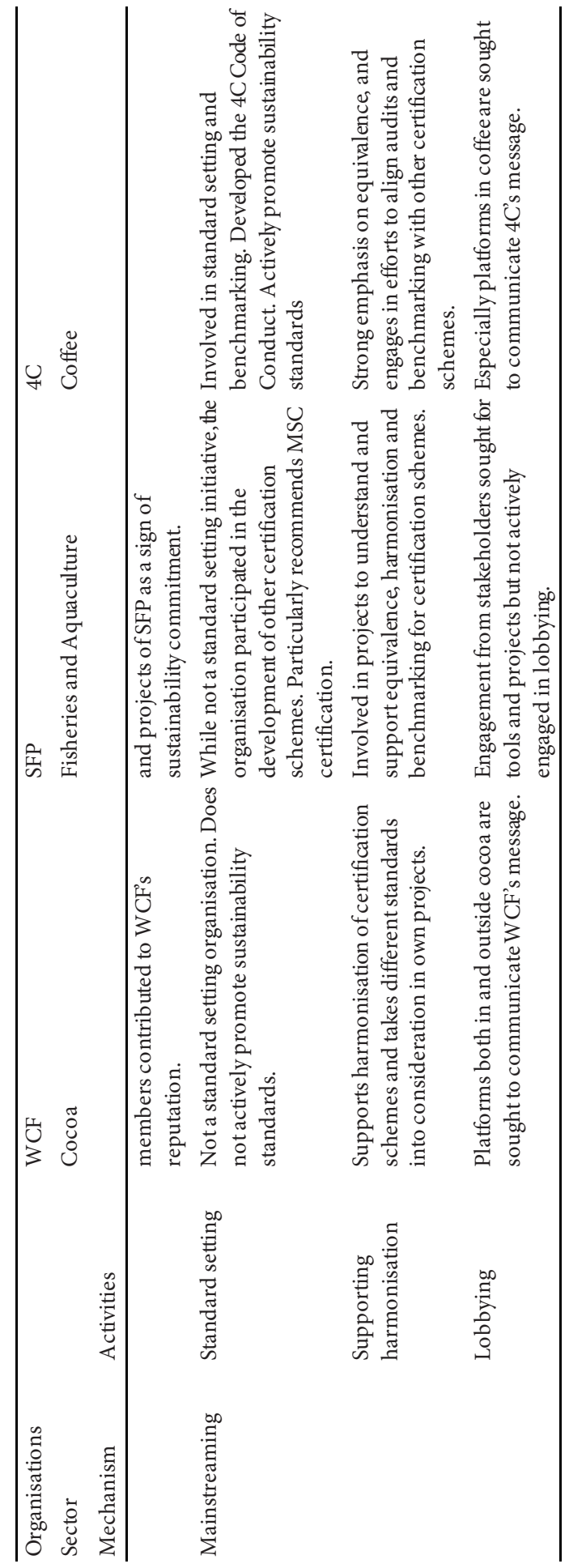




\section{Framing the global discourse}

The arrangements influence the dominant political and normative discourse in their efforts to regulate and control the issue fields. Serving as a platform for discussion and cooperation, 4C and WCF engage in activities that set the agenda on what is needed for sustainable change. Actors along the chain discuss pressing sustainability issues in stakeholder and partnership meetings. Although SFP is not a forum for discussion, all three organisations set priorities for on-site implementation by organising forums, workshops and/or projects regarding some of these challenges. SFP, for instance, sets the agenda for responsible management of mixed-trawl fisheries in Southeast Asia, where mixed-trawl fisheries are common practice but certification is often problematic, because standards such as MSC and IFFO's Responsible Sourcing standard focus on single fish fisheries. In partnership with IFFO, SFP started discussions with scientists and industry representatives on possibilities for responsible management of mixed-trawl fisheries to develop a tool to drive improvement in this area.

More than propagating and disseminating explicit political values and norms on sustainability issues, the arrangements establish discursive power in an indirect manner primarily by taking up issues they consider unvalued. For the SFP, the discourse on sustainable marine management serves as an example. Together with the National Fisheries Conservation Center, it initiated the 'Global Ocean Health Program', where scientists and carbon experts disclosed problems and potential solutions to producers, vessel owners, policy makers, citizens and industry participants (SFP, n.d.-b). The fight against ocean acidification became a relevant norm for actors along the chain. Personal communications with stakeholders reveal that SFP's discursive power mainly works in the industry, and that the scientific community and other stakeholders do not necessarily take notice of SFP's endeavour. 4C includes so-called 'topics of interest' into the agenda of its meetings, such as gender equity in the coffee sector. WCF also takes up sustainability values and norms as gender empowerment.

The extent to which the arrangements are able to set the terms of the global debate varies but is marginal, as none of the arrangements is leading in discussing public and/or private regulatory interpretation, nor serve as a regulatory role model in their respective sectors. Interviewed partners referred to SFP as an independent expert that has been able to include new aspects regarding issues such as sustainable feed, best practices of

by-catch, regional farm management and trawled fisheries. Where SFP specifically endorses MSC certification, WCF takes a neutral stance towards certifications. 4C has a baseline standard and does not serve as a role model for other regulatory forms of governance in the coffee sector.

All three arrangements produce new knowledge, by bringing particularly professional knowledge into the (mainstream) discussion. Distinctive in its sector is SFP's 
focus on local fish stock because of its knowledge regarding differences of species in different regions. Moreover, all arrangements base their information on scientific findings. SFP provides a database within which scientists can develop fish-profiles and has a research and data division for maintaining FishSource and the information base FisheriesWiki. WCF funds research and collaborates regularly in research roundtables where research outcomes and needs are discussed. $4 \mathrm{C}$ involves scientists in forums and as members.

\section{Capacitybuilding}

All arrangements seek to build and improve the capacity of their members and partners for sustainable change. The organisations have general rules for governance and delegate tasks to members and partners involved to make projects (largely) self-supporting. SFP has changed its role from implementing to steering improvement processes and focuses on providing guidance, advice and tools to actors interested in improvement projects. WCF also delegates tasks, and while members may lend their expertise to projects, they are primarily funding partners. $4 \mathrm{C}$ has increasingly delegated tasks to other actors in the chain. An example of this is the 'Training of Trainers workshops' where participants learn how to conduct farmer trainings. Different from SFP, 4C and WCF are membership driven and also have systems for conflict and dispute settlements in place. While both focus on finding amicable solutions, $4 \mathrm{C}$ recommends settlements and has a mediation panel to solve enduring disputes. At WCF, taskforces can be created to determine the differences that lead to conflict.

Although all arrangements make information and knowledge available in the respective sectors, SFP specifically focuses on information dissemination. SFP collects information, conducts research and makes it publicly available. FishSource summarises fisheries experts' information on fish stocks and sustainability statuses. SFP also developed tools where buyers can measure their sustainability progress. These provide only a rough guide to how individual fisheries are performing, and SFP does not define a level of sustainable fish stock but provides information on how international standards would rate the fisheries (FishSource, n.d.; SFP, 2010). A point of criticism raised by an interviewee is that some of the data in FishSource are not up-to-date, but are accepted by its users because there are no lot of specific information available beyond it. This shows the significance and also the responsibility of such efforts.

Common Code for Coffee Community Association provides information and knowledge with trainings, illustrated guides for illiterates, a 4C Tool Library that includes training manuals and other information tools. WCF brings topics to the attention of their members through research updates, newsletters and partnership meetings. Its most current initiative under development, CocoaMAP (Cocoa Measurement and Progress), is 
aimed at measuring and reporting progress towards sustainability in the cocoa value chain. WCF is currently developing a framework for a shared Key Performance Indicators tool, data collection tools and online dashboard to assist member companies, governments and others to better measure, understand and manage their investments in sustainability at the farm level through aggregated information (WCF, 2012a).

Whether initiated or facilitated by the arrangements, all partners are invited to participate in different improvement projects. SFP projects mainly assess the improvement needs of fisheries, develop work plans and educate on how to catch trawled fish sustainably. With the publicly available database FishSource, SFP aims to reduce the barrier for industry and other interested actors for a sustainable seafood sector. $4 \mathrm{C}$ offers on-site assistance with trainings for farmers. While, for instance, roaster-members have to commit to buy increasing amounts of $4 \mathrm{C}$ compliant coffee over time, buyer-members of $4 \mathrm{C}$ need to make long-term contracts with $4 \mathrm{C}$ compliant coffee sellers, which can stabilise the producer's environment. The $4 \mathrm{C}$ unit system also helps industry members, because it enhances transparency and traceability of the coffee (Kuit, Rijn, \& Jansen, 2010), which is the basis for responsible procurement policies. WCF seeks to improve chain-wide competencies through, for example, the CocoaMAP initiative, but the different programs endorsed by WCF are commonly aimed at the farm level.

Generally, the work of the arrangements progressively reaches more of the stakeholders at the bottom of the value chains. With its baseline standard, $4 \mathrm{C}$ reached more than over 300,000 farmers and 900,000 workers in producing countries with an increase in 4C Units from 178 in 2012 to 263 in 2013 (4C Association, 2014). SFP has developed and/or facilitated more than 40 fisheries improvement projects and has aquaculture improvement projects running in three Asian countries (SFP, n.d.-a). WCF has reached over 540,000 farmers through its different programmes (WCF, n.d.-a). One of the main limitations of all three initiatives is the lack of evidence for an improved financial situation of producers through the activities. As profitability is a key for sustainability (Ibnu, Glasbergen, Offermans, \& Arifin, 2015) for all actors along the supply chain, the connection must be recognised and aspired.

\section{Networking}

The arrangements link various actors in one issue field through networking. Throughout the years, the arrangements have expanded their network of partners. $4 \mathrm{C}$ is the most inclusive organisation of all, with partners covering all parts of the chain, including farmers and other private standard setting organisations. Small-scale producers can enter the network with relatively low implementation costs and efforts in implementing the $4 \mathrm{C}$ code of conduct. SFP and WCF are less inclusive, because they focus on partner companies. WCF also does not include small (mom-and-pop) companies or farmers as members. 
However, WCF does represent $80 \%$ of the global corporate market on cocoa, therefore encompassing a large number of member companies (WCF, 2012b). WCF considers that having an established pool of member companies attract new members, because older members reach out to interested companies. Also partnerships entice companies to apply for membership, of which particularly the Bill \& Melinda Gates Foundation is considered to have raised the profile of WCF and attracted other companies to join WCF.

A possible challenge for all three arrangements is to expand their networks further. According to an interviewee, separating 4C's function as a platform from its standardisation function would be valuable as it could lead to the inclusion of standard setters that do not support 4C's baseline code and industry players who are already committed to other non-member standards. According to both SFP and WCF partner interviewees, the arrangements were advised to include (more) small-scale fishermen, farmers or their representatives into the decision-making. Such participation was deemed as possibly increasing the effectiveness of networking activities, and providing more legitimacy to decision-making processes.

The arrangements serve as a platform for cooperation and joint action. Through various forums, projects, tools and roundtables, they bring together actors from the supply chains, scientific bodies and institutes, and local, regional and international institutions and organisations. WCF informs members about specific projects and gauges interest for sponsorship. Stakeholders from the cocoa industry come to WCF partnership meetings, including businesses throughout the chain but also civil society actors. SFP convenes an alliance of producers, processors, suppliers and buyers for improvement projects. To avoid overlap with other initiatives, SFP first considers and recommends existing initiatives, including certifications, to buyers. SFP also aligns efforts with other initiatives. With America's Monterey Bay Aquarium, for instance, it shares the information system used to evaluate the sustainability status of seafood sources. In forums of $4 \mathrm{C}$, stakeholders discuss sustainability challenges, identify possible solutions, share knowledge on best practices and ideas for future cooperation.

Out of the three arrangements, only $4 \mathrm{C}$ functions as an intermediary as it institutes linkages between supplier and buyers. The arrangement regularly sends a list of licensed 4C units to all members to facilitate supply and demand for 4C compliant coffee. WCF and SFP only function indirectly as intermediaries with projects and forums providing stakeholders along the chain with the possibility to create new markets. In addition, SFP organises 'Fisheries Forums' where retailers get the opportunity not only to speak to suppliers, but also to business 'competitors' about experiences with fisheries improvement projects, challenges of aquaculture and specific sustainability requirements. Thereby, they can develop relationships and start new projects, creating market opportunities for fisheries and guaranteeing future supply for retailer (Bush, Toonen, Oosterveer, \& Mol, 2013). 
Particularly, WCF and 4C lend their identity to members and partners as their logos are utilised in demonstration of allegiance and membership to the organisations. According to a representative of $4 \mathrm{C}, 4 \mathrm{C}$ membership creates better access to finance some financial loans. Through important and influential partners (e.g. Bill \& Melinda Gates foundation, governments), WCF has received a respectable reputation which in turn is important to partner companies as it may influence their customers.

\section{Mainstreaming}

The arrangements are involved in mainstreaming activities when they aim at acceptance, inclusion and/or harmonisation of the meta-governor's own normative and regulatory framework or those it supports. From the three cases, only $4 \mathrm{C}$ sets standards and verifies compliance. It considers its baseline code as a literal baseline and recommends further improvement. 4C helps verified producers to step-up to other, more stringent, standards. An assessment of the compatibility of the standards is made, after which farmers are informed on consequent steps. 4C's pre-competitive character has attracted standards setters criticising the 4C code to apply for membership (like UTZ in 2011 and Fairtrade in 2012). In 2013, the $4 \mathrm{C}$ tripled its volumes in compliant coffee, with a total volume of over 39 million bags of coffee (4C Association, 2014), making it one of the most purchased verified coffees. Particularly, the benchmarking practices with UTZ and RA have led to strong increase in $4 \mathrm{C}$ compliant coffee produce. Nonetheless, according to an interviewee, this does not create additional sustainable coffee production, because farmers involved in benchmarking are already certified by stricter standards.

Sustainable fisheries partnership developed six stages for fishery improvement projects, the final optional step being MSC certification. Referring to MSC certification as the most robust and rigorous seafood eco-label, MSC serves as the basis for FishSource scores. According to another fisheries standard setter, other standards also receive increased awareness of industry through SFP improvement projects, reports, forums and briefings. Because of its expertise and influence in the sector, SFP participated in the development of ASC and GAA standards. While SFP does not set standards and does not oblige partners to certification, it does support stringent standards. WCF does not have standards on sustainable cocoa production and takes a neutral stance towards certification.

All three arrangements support harmonisation of standards. 4C's code was developed after an assessment of existing standards to avoid differences in auditing and identify overlap. As a member of the International Social and Environmental Accreditation and Labelling Alliance, a non-governmental membership organisation for multi-stakeholder arrangements committed to making sustainability standards systems more effective and more widely adopted, 4C had to strengthen its efforts towards consistency between standards in the coffee sector. $4 \mathrm{C}$ enhanced efforts to align audits and benchmarking with 
other standards to avoid multiple audits and provided already certified producers access to $4 \mathrm{C}$ markets. This enables certified producers to apply for a $4 \mathrm{C}$ license without additional costs or efforts. SFP initiated a project to understand equivalencies and potential for benchmarking and harmonisation of three different aquaculture standard setters. Within the project, different tilapia farms in several countries were compared on aquaculture certification schemes, and according to interviewees feedback has been incorporated in newer versions of the standards. WCF also supports harmonisation of standards and certification schemes and with the initiation of the CocoaMAP tool, the arrangement has made efforts to compare indicators and measurement methodologies from different cocoa certification schemes (WCF, n.d.-b). Even so, WCF regards certification to be a part of a companies' competitive pole which it does not want to interfere with.

All arrangements are involved in lobbying, and particularly 4C and WCF seek platforms outside their respective sectors to communicate their message. WCF, for instance, sought partnership opportunities with origin country governments, the World Economic Forum and inter-American development bank on agricultural development. The CocoaAction project initiated in 2014 is an unprecedented project for productivity enhancing and community development interventions of the cocoa sectors, for which the governments of Ghana and Côte d'Ivoire have formally endorsed the project as industry's aligned effort to support their national coca sustainability plans (WCF, 2015).

\subsection{Conclusion}

The case studies elucidate that private governance arrangements employ all metagovernance mechanisms for sustainable change, albeit to a limited degree. Besides casespecific differences, which will be discussed shortly hereafter, the arrangements are particularly suited for activities geared towards process management strategies, activating actors and resources, and arranging and facilitating interactions amongst stakeholders. Meta-governors particularly create associational value through the mechanisms of networking, by engaging in collaborative relationships (Austin \& Seitanidi, 2012). In addition to having been able to attract key multi-national corporations, the arrangements have increased their number of partners over time. This is an accomplishment as each of their sectors are rife with different institutions and standard setters for sustainability in their value chains (e.g., for cocoa, fisheries and aquaculture, and coffee, respectively Bitzer et al., 2012; Kalfagianni \& Pattberg, 2013; Reinecke, Manning, \& von Hagen, 2012). The pre-competitive space allows businesses and other actors to meet, share, learn and support each other through the different forums and projects. Working relationships

should however not be idealised, as interviewees point out that antitrust lawyers may be present at meetings and conflicts do occur. Furthermore, various stakeholders from all 
domains and across the sectors are reached through partnership meetings and symposia. By providing platforms and spaces for engagement, the meta-governors serve as facilitators for sustainable development.

A second mechanism, the private meta-governors lend themselves most to, is capacity building. The collaborative value that arises from this is mainly resource complementarity, in that access is created to resources that most partners do not possess (Austin \& Seitanidi, 2012). The arrangements produce new and, above all, professional information for uptake in the industry. Besides knowledge production, the efforts are also aimed at knowledge transfer. The distribution and accessibility of the information to partners are seen as part of the solution to sustainability problems within the chains.

The potential for mainstreaming is largely unfulfilled. Specifically, while there is support for shared content and harmonisation of standards by all arrangements, they do not employ (stringent) regulatory frameworks. The formulation of issue-specific problems and possible solutions are often negotiated, and goal congruence is sought rather than obligating stringent cognitive-normative and regulatory frameworks. SFP and WCF were not developed to set clear and hard-cut sustainability criteria, and 4C standards are one of the least stringent in its issue field (Pierrot, Giovannucci, \& Kasterine, 2011). This supports the proposition that the meta-governance proposed by private actors is more concerned with dialogue and achieving negotiated consent than reaching (other) goals (Jessop, 2011). This suggests that membership and reach of the meta-governors in their respective issue-fields is inversely related with stringency on sustainability standards. This would be in line with empirical transnational governance research where higher stringency tends to be associated with rather limited uptake (Kalfagianni \& Pattberg, 2013; Kolk, 2013).

The reciprocal relationship between the arrangements and their partners also limits private meta-governance potential for framing the global discourse, particularly in its main focus on those issues that lie at the heart of protecting industry interests (e.g. productivity concerns). Standards, policies and strategic direction are not merely imposed, but are to differing degrees collaboratively thought and carried out. Although such conditions are central to participatory policy-making along sustainable lines (Meadowcroft, 2007), it makes private meta-governance very vulnerable to the representation of established interests. Particularly in arrangements without multistakeholder and democratic governance boards, it weakens claims of representativeness and legitimacy. The influence of key multi-nationals on meta-governors should not be undervalued, as some of the key industry member companies (for WCF) have assumed prominent roles in terms of initiation, implementation and funding (Bitzer, 2012).

The case studies have also revealed that the mechanisms for change are used in different ways and to varying degrees. Taking the mechanism of networking as an example, the arrangements have different attitudes on the topics of inclusiveness of civil society 
organisations, and in how far the arrangements intermediate in connecting suppliers to retailers. Linking this to the characteristics of the issue-specific fields, we consider two causes to underlie such differences. The first is functional, and relates to perceived sustainability problems that cause dysfunction and need being addressed. For instance, if an arrangement considers a lack of information as the main cause of unsustainability, offered solutions and practices are likely to be geared towards alleviation of this problem. The second is ideational, and relates to normative viewpoints. To extent the previous example, if a corporate social responsibility approach is taken to the problem of information deficit on the side of sourcing businesses, the focus will expectedly centre on industry actors which are projected to source sustainably when information is available.

The arrangements are furthermore not reducing fragmentation in the sense that partners (of WCF and 4C) also are part of (other) standard setting sustainability initiatives. Many of the meta-governor partners only see a (small) part of their value chains covered, because the meta-governors are focused on specific issue fields and lead firms often make use of value chains across sectors. This supports the view that private meta-governance is geared towards domain-specific objectives and are limited in scope (Steurer, 2013). In addition, as partnerships are also voluntary, this poses a constant threat of businesses leaving the meta-governance arrangement. Furthermore, the metagovernors under study largely remain governance actors horizontally next to other initiatives, and in this sense even reproduce the problems of self-organised governance it is supposed to address (Fransen, 2015). Overlapping membership across different initiatives, one form of fragmentation of governance systems is consequently not reduced by the arrangements.

This analysis shows that private uptake of meta-governance mechanisms for change particularly relate to networking and capacity building, and are mostly geared towards process management strategies, activating actors and resources, and arranging and facilitating interactions amongst stakeholders. Lacking in command and control authority and abilities, business-oriented voluntary arrangements create a tension between strong sustainability approaches, which may include stringent sustainability standards on the one hand, and participation on the other. As private meta-governors manoeuvre within this context, it curbs the operationalisation of change mechanisms. Even so, stringency of regulatory frameworks is not necessarily positively correlated to the effectiveness of meta-governance (Cafaggi, 2016). Refraining from further discussion on stringency or effectiveness, this study leads us to recognise that private metagovernance can be strengthened in their efforts to frame the global sustainability discourse and through further mainstreaming of (stricter) sustainability goals. Further research may investigate the current transformations in an analytical and critical sense, and especially evaluate its relative performanc 


\section{Chapter 5}

The quest for cohesion in global governance: An exploration of tensions in the global governance of organic production, and labour rights 



\subsection{Introduction}

In governance concerning the production of global goods, for instance of garments and foods in global value chains, there are various sources of authority and power (Meadowcroft, 2007). Next to mandatory laws and regulations by public actors, also more flexible and voluntary forms of regulation and implementation are offered by private actors (e.g., Abbott, 2012; Bartley, 2011). The entirety of formal and informal rules is considered a highly disaggregated and only a minimally coordinated system of governance (Rosenau, 2003). This phenomenon has led to the observation that many policy domains are characterised by fragmentation (Biermann, Pattberg, van Asselt, \& Zelli, 2009). The concept of fragmentation denotes the diversity, multiplicity, divergence and distribution of regulatory powers in the overall institutional settings and resulting policies of different international and transnational policy domains (Pekdemir, 2018). In this way, the concept of fragmentation denotes a particular state of affairs of governance systems.

Fragmentation can be regarded as positive. It may for instance lead to multiple routes of intervention on the same policy issue. If diverse actors are involved, the issue can be addressed not only in multiple but also in different ways, as each actor has its own interests, values, and competencies (Derkx \& Glasbergen, 2014). It may also lead to regulatory innovation, for instance when governance arrangements can learn from one another (Cafaggi, 2016). It can furthermore allow for the adjustment of standards and procedures to local and regional circumstances (Abbott \& Snidal, 2009; Pekdemir, 2018). Fragmentation may however be problematic if it impedes the effectiveness of governance of a policy issue. For instance, when the capacity of governments or international organisations are weakened in their desired effects (Ivanova \& Roy, 2007) or more generally, if it constrains the efficient and effective realisation of generally accepted public values (Derkx \& Glasbergen, 2014).

To counter negative effects of fragmentation, initiatives and policy efforts have been developed to induce more regulatory cohesion. These efforts attempt to change the fragmented state of affairs from the understanding that a certain level of cohesion is necessary to achieve shared values. Examples of these are metagovernance initiatives (Fransen, 2015; Pekdemir, Glasbergen, \& von Gagern, 2016) and regional standards (Pekdemir, 2018). Certain tensions however emerge through the quest for cohesion. We postulate that these tensions are 1) dependent on the system characteristics of fragmentation of an issue field and 2) dependent on the ways in which cohesion is sought.

This paper seeks to examine these tensions in two distinct issue areas, namely the global governance of labour rights and organic production. In the field of labour rights, fragmentation leads to the inadequate protection of workers' rights. In the governance of organic production, fragmentation has led to insecurity about the trustworthiness of organic products and to difficulties in market access. In this paper, we investigate what 
tensions emerge in the quest for cohesion in these two governance systems and what their causes are. After a delineation of the research methods, the global governance systems of the two cases will be introduced. The subsequent sections explore several tensions for each issue field. In conclusion, some final considerations regarding the tensions that emerge out of the quest for more cohesion are discussed.

\subsection{Research Methods}

The analysis is based on desk-research and in-depth interviews with experts. The exploration is grounded in governance theory and the operational definition of global governance used in this paper, which was also corresponded to the experts, specifically refers to all processes of governing, whether undertaken by governments, businesses, or civil society actors. The two issue fields, the global governance of labour rights and organic production, serve as cases to explore the tensions from efforts to foster cohesion. The comparison will function as an inductive exploration by bringing into focus the contrasts as well as similarities between the cases. The issue fields are grounded in different historical contexts and are concerned with different topics. Nonetheless, both governance domains are concerned with the production of goods in global value chains. As part of concept-formation for governance theory, the comparative method may offer an understanding into generalities across different contexts.

In this study, we draw on forty-six experts that were interviewed between May 2013 and October 2017. Twenty-four experts with experience in policy-making and evaluation in global labour rights were interviewed on the topic of global labour governance. Through purposeful sampling, information-rich experts were identified and snowball sampling was used to get into contact with other experts from the network of the respondents. The distribution of affiliations is as follows: public actors (4 from intergovernmental organisations), private actors ( 3 from companies, 2 from employer's organisations, 1 from a worker's organisation, 8 from non-governmental organisations), and 6 from academia and/or research institutes. Concurrent, twenty-two experts with experience in policy-making and evaluation in organic production were interviewed on the topic of global governance for organic production. A similar approach to sampling was used as on the topic of labour governance. The affiliations of the experts on organic production is as follows: public actors (5 from governments, and 7 from intergovernmental organisations), and private actors ( 5 from companies, and 5 from civil society organisations).

The experts have here been grouped in terms of the most relevant affiliation or primary occupation. This categorisation does however not sufficiently capture the different experiences and richness in affiliations the experts have in global governance. 
To illustrate, in the field of labour governance, some experts from academia or research institutes have extensive working backgrounds in intergovernmental organisations or workers' organisations. In the field of organic production, some experts are for instance affiliated to a civil society organisation and a company.

Questions revolved around different drivers of global governance, as well as an inquiry into perceptions of the global governance system. Characteristics of the governance system, including understandings of important and powerful actors in the field, the similarities and differences in the norms and standards, and the level of collaboration between different organisations of the two governance systems were inquired. In addition, visions for the future were explored with experts, and questions addressed what would be needed to get to a desired future for the governance issue, including: i) actions, ii) actors of change, iii) agents making the realisation difficult, iv) values underlying its accomplishment.

Through desk research, public documents of organisations - including white papers, manifestos, and project reports - were examined. The two-day symposium organised by the ILO, The Future of Work We Want: A Global Dialogue, on 6 and 7 April 2017 provided further input. The software program MAXQDA facilitated the analysis of the interviews manuscripts. Segments of the transcripts were categorised and provided with codes as a way to facilitate the analysis. In this paper, those segments that specifically relate to tensions in fragmentation and cohesion will be elaborated. For this purpose, quotes have been used relatively sparingly as a way to illustrate findings and provide perspectives to the overall narrative. Each expert has been coded with a unique number and the coding numbers in-text refer to the order in which the interviews were held.

\subsection{Case Studies}

\section{Labour rights}

For an important part, labour rights protection rests on a public approach as labour regulations are largely enacted by states. Nonetheless, in many accounts of the origins and operation of labour law, other actors are regarded to play a significant role too (Arthurs, 2011). This is primarily on account of the tripartite constituency of the International Labour Organization (ILO), which was established in 1919 with the aim of developing international policies and norms on labour related issues. As a tripartite cross-sector arrangement, the ILO brings together governments, employers and workers of 187 member states. The ILO takes a central role in international labour governance. It sets standards, develops policies, and devises programs in promotion of decent work (ILO, n.d.). ILO conventions, recommendations, and protocols - sometimes also referred to as international labour standards (La Hovary, 2018) - have conventionally been regarded 
as the primary sources of international labour standards (e.g., Hendrickx, Marx, Rayp, \& Wouters, 2016). Significant shortcomings within the international labour domain are related to the implementation capacity and enforcement of standards. Weak enforcement mechanisms of the ILO (Elliott, 2000), and the absence of an international court trying multinational corporations can be considered testimony to this.

In light of continued violations of labour rights and consumer protests, private fair labour arrangements have been initiated in the last several decades. Different from the ILO, they directly address businesses. While they base their work on ILO norms and standards, there is a variety in these initiatives and standards themselves. While their objectives are related, they have divided the issue field in different fractions through their sectoral (e.g. garment), country (e.g. Bangladesh), or thematic (e.g. fire and building) focus. Furthermore, they also compete for market share of businesses. Regardless of whether they are considered effective, they only account for the fraction of the issue field, which is tied to specific company clients and the sectoral focus. Private arrangements have a stake in the labour rights domain for their continued existence. Attempts to bring in more cohesion amongst the private arrangements through metagovernance in the past have failed (Derkx \& Glasbergen, 2014).

Not only private arrangements have increasingly assumed responsibility for the protection of global labour rights, other intergovernmental and even economic institutions engage in global standard and norm setting as well. The term global labour governance has therefore become increasingly relevant in debates about globalisation and labour standards (Hassel, 2008; Meardi \& Marginson, 2014). At the same time, an understanding has arisen that the shift from international to transnational labour protection has resulted in fragmentation (Blackett \& Trebilcock, 2015; Hepple, 2005; Zumbansen, 2006). The new actors add to the regulatory complexity of the governance system and in effect create more fragmentation. The global character of labour law is characterised as a form of multi-level governance, as it includes regulations and standards on the transnational, international, regional, national, and even the shop level. It is signified by complexity, diversity, and asymmetries across time and space (Blackett \& Trebilcock, 2015). Sources of law are questioned in terms of their authority and legitimacy (e.g., La Hovary, 2015), which have alerted practitioners and academics alike.

\section{Organic production}

Standards for organic production grew out of private initiatives. The Demeter standard was the first to be introduced in 1928, which was developed to grow farm produce based on a biodynamic value system. From the 1950s onwards, associations of farmers and consumers started developing guidelines and standards based on organic principles (Courville, 2006). From the 1970s, private organic labels spread across Europe and the 
United States. The International Federation of Organic Agriculture Movements (IFOAM) was founded around this era by growers' associations as their transnational roof organisation (Schmidt, 2011). IFOAM has maintained its central character within the governance system for organic production and lobbies for the organic movement. It has various regional offices throughout the world and engages in partnerships with developments agencies and donors. IFOAM issued its 'Basic Standards for Organic Agriculture' in 1980, which has been subject to change over the years. Through the worldwide uptake by both public and private actors of the standard (Pekdemir, 2018) it is regarded a gold standard.

The rise of organic standards also increased the number of private certification bodies due to needs for independent guarantee of compliance to organic standards (Courville, 2006). The different organic standards and certifications appeared to be an obstacle to move organic foods into the mainstream food marketing channels (Ikerd, 2006). The organic movement itself initiated political movements for public regulations. In the European context, this was specifically motivated to offer a more effective basis for enforcing labelling claims, countering free-riding and fraud (Gibbon, 2008). It particularly requested the European Commission to use its competence for legislative initiative to define organic labelling requirements (Schmidt, 2011).

While several states in the United States had adopted organic legislation in the 1970s, Denmark was the first country to adopt comprehensive legislation on organic farming in 1987. Present day, 87 countries have organic standards (Willer \& Lernoud, 2018), quite a number of them in (mandatory) regulation. Next to national standards, private standards continue to be used in markets across the world. The plethora of available standards, labels, and certifications, however, has led to a complex and fragmented regulatory system. Governments, traders, and certification bodies have developed complex pathways to facilitate trade in this context. Moreover, the continued proliferation of standards is considered to be a challenge for the organic market (Sahota, 2018). There is however a continuing process of seeking equivalence and harmonisation by both public initiatives and IFOAM as a way to improve coherence amongst standards. These come in the forms of regional standards, organic trade agreements, and the IFOAM Family of Standards (Bowen \& Holmes, 2013; IFOAM, 2016; Pekdemir, 2018).

\section{Overview of case characteristics}

In table 5.1, an overview is provided of characteristics of the two issue fields. The table captures relevant characteristics discussed in the previous case study sections, but also includes governance system characteristics to further contextualise the cases and facilitate a meaningful elaboration and comparison arising from tensions in efforts to strengthen cohesion in the discussion and conclusion. 
Table 5.1 Characteristics of the two issue fields

\begin{tabular}{|c|c|c|}
\hline & Labour rights & Organic production \\
\hline Issue origins & $\begin{array}{l}\text { Started as a public issue in face of bad } \\
\text { working conditions during the ind ustrial } \\
\text { revolution }\end{array}$ & $\begin{array}{l}\text { Started in the private sphere as an alternative } \\
\text { way of farming against conventional and } \\
\text { industrialised farming methods }\end{array}$ \\
\hline \multirow[t]{2}{*}{$\begin{array}{l}\text { Governance } \\
\text { approach origins }\end{array}$} & \multicolumn{2}{|c|}{$\begin{array}{l}\text { From national origins to early internationalIn early } 20^{\text {th }} \text { century, pioneers focused on } \\
\text { focus through the creation of the ILO in individual and local implementation } \\
1919\end{array}$} \\
\hline & Top-down & Bottom-up \\
\hline Actors origins & $\begin{array}{l}\text { ILO's tripartite structure brought together } \\
\text { representatives of governments, employers } \\
\text { and workers }\end{array}$ & $\begin{array}{l}\text { Practitioners of scientific and farming } \\
\text { backgrounds }\end{array}$ \\
\hline $\begin{array}{l}\text { Rights-based } \\
\text { approach }\end{array}$ & Human right, 'group right' & Individual liberty \\
\hline $\begin{array}{l}\text { Modus operandi } \\
\text { civil society }\end{array}$ & Scandals, advocacy groups, tackling abuses & $\begin{array}{l}\text { Advocacy groups, alternative life style, world- } \\
\text { view }\end{array}$ \\
\hline Actors present-da & $\begin{array}{l}\text { y Many actors involved in global governance } \\
\text { including governments, intergovernmental } \\
\text { organisations, workers' organisations, } \\
\text { employers' organisations, certification } \\
\text { schemes and businesses }\end{array}$ & $\begin{array}{l}\text { e,Although influence of industry non- } \\
1 \text { negligible, main actors are farmer's } \\
\text { organisations, governments and certification } \\
\text { schemes }\end{array}$ \\
\hline & $\begin{array}{l}\text { Authority of international labour law and } \\
\text { enforcement of rights dispersed }\end{array}$ & $\begin{array}{l}\text { Authority of standards and enforcement } \\
\text { structures clear }\end{array}$ \\
\hline $\begin{array}{l}\text { Sustainability } \\
\text { discourse }\end{array}$ & $\begin{array}{l}\text { Development, human rights, part of the } \\
\text { sustainable development goals (SDGs) } \\
\text { discourse }\end{array}$ & $\begin{array}{l}\text { Sustainable agriculture including } \\
\text { environmental stewardship and principles of } \\
\text { health and fairness, indirectly part of the } \\
\text { SDG's discourse }\end{array}$ \\
\hline
\end{tabular}

\subsection{Tensions}

\section{Labour rights}

\section{Tension: Regulatory uncertainty}

A first tension is visible between different forms of public regulation. Besides the ILO and private arrangements, other public international actors have increasingly started to define and adopt labour policies (e.g. International Monetary Fund (IMF), World Bank, Organisation for Economic Co-operation and Development (OECD), and the European Union (EU)). Labour provisions have also become more commonplace in trade agreements. However, policies and provisions are not always formulated in accordance with ILO standards (see Agust, Ebert, \& Le Clerq, 2014; Ebert, 2014, 2018; ILO, 2017), creating regulatory uncertainty. A case in point are trade agreements, of which in 2016 
there were a reported 77 trade agreements with labour provisions that in total cover 136 economies (ILO, 2016). The provisions take different forms. While the majority of trade agreements with labour provisions refer to the ILO and the core labour rights, there are more than a few trade agreements that do not (ILO, 2017). Furthermore, some agreements take a more promotional approach based on dialogue and cooperation rather than being hard clauses (Marx, Brando, \& Lein, 2017). Moreover, many of the trade agreements do not refer to the ILO Conventions, but rather to ILO's 1998 Declaration. The content of the Declaration is not as specific compared to the ILO Conventions (Alston, 2004), which results in a risk of legal uncertainty and an application of these labour provisions that is in fact inconsistent with the application of the ILO supervisory machinery itself (Agust et al., 2014).

Experts operating in the legal domain considered the existence of dissimilar and conflicting standards obstructive in getting a complete picture of all relevant and applicable laws, regulations, and standards that are operative in transnational labour law. Public organisations were also accused of sustaining this lack of harmonisation. Experts remarked in this context:

Sometimes you get the impression that the ILO is just doing something, the OECD another thing, and the other UN bodies and the European Commission, and so on ... without having the complete picture of what is going on in other bodies. [Interview 18, advisor]

... [They should be] harnessing much more the ILO's knowledge about employment and labour issues then they often do. Often it is very striking to see what work the [World] Bank, or the OECD, or even the IMF do in regards to labour standards, and what kind of statements they issue. Recognising that there is of course the ILO agency at the international level with the largest expertise. But ... for some reason [they are] not really referring to that expertise, just coming up with their own vision of certain things and that is unfortunate from many perspectives. [Interview 19, researcher]

\section{Tension: The limitations of the ILO in promoting cohesion}

A second tension that is observed are certain limitations of the ILO in promoting cohesion, both in relation to the internal as well as external functioning of the ILO and its constituents. The ILO is by and large considered the most central and influential organisation for the global governance of labour rights. There is however also wide acceptance that coherence in norms and standards is a difficult task for the ILO to realise. Internally, the tripartite character of the ILO has many merits as well as disadvantages (see La Hovary, 2015). In reaching agreement on standards, the differences in perspectives of ILO constituents is a democratic value underlying the arrangement. That agreement is 
difficult or at times impossible to reach, is part of the bargain. However, the discussions among workers and the employers have been regarded as becoming tenser, even hostile, over the past decades. Particularly the clash between employers and workers during the International Labour Conference in 2012 is considered substantial in this regard (see La Hovary, 2015, 2018; Maupain, 2013). Here employers challenged that the right of strike was protected by Convention 87 on Freedom of Association. Furthermore, they also questioned the authority of ILO's most important quasi-judicial body (the Committee of Experts on the Application of Convention Recommendations) to interpret a right when it is not explicit in a convention. The crisis is considered to not only having shaken the very foundations of tripartism, but also having revealed a much deeper dissatisfaction with international labour standards and their supervision (La Hovary, 2015). It also enticed questions whether all the tripartite constituents share a sufficient willingness for changes that would improve the effectiveness and coherence of the supervisory system (Maupain, 2013).

The topic of external cohesion and the failure to achieving it strikes right at the heart of enduring labour violations and limits in sanctioning thereof. This inability contributes to regulatory uncertainty. The topic of coherence on labour standards concerns the ILO, not in the least because other policies and standards often allure to ILO standards while not necessarily conforming to relevant or most recent conventions (e.g., ILO, 2016; Pekdemir, Glasbergen, \& Cörvers, 2015). High-level officials from the ILO have expressed the urgent need for closer cooperation and coherence between the ILO, the IMF and the EU (Mola, 2016). This is for instance reflected in a formal declaration that came out of the European Regional Meeting of the ILO in 2013. Here a means of action for the ILO was identified to promote synergies and policy coherence with international and regional organisations and institutions, namely the IMF, OECD, the World Bank, the EU and the Eurasian Economic Commission, through fora such as the G20 (ILO, 2013). In the meantime, further calls have been made that serious consideration should be given to the ways in which the ILO could regulate the use and appropriation of its standards by private actors, so that it contributes rather than undermines ILO's efforts to advance States' legislation and implementation (Maupain, 2015).

\section{Tension: Limitations in the responsiveness of the ILO}

A third tension is observed in the responsiveness of the ILO to global challenges. To start with, breaches of ILO labour standards are not penalised with any real sanctions except for global criticism. In this respect, the ILO is often perceived as toothless. Beyond this, there is also an argument of timeliness which arguably applies to labour regulations in general which are often considered to be catching-up on developments in the world of work, or as an interviewee noted "labour legislation is an instrument of protection [and] will always follow the development of industry". [interview 20, researcher] 
An interesting case in point is the issue of the changing character of production and employment. There are extensive studies on the future of work (see Balliester \& Elsheikhi, 2018) which for a large part also deal with the issue of the changing character of production and employment and the accompanying role of technology and innovation. The 'modernisation' or 'future' debate is regarded to have pushed labour law into a sort of regulatory crisis (Hendrickx, 2018), and responding to the challenges ahead is on the top of the minds of the experts interviewed. These trends transcend national boundaries and according to many necessitate its governance on a global level. In run-up to its centenary mark, the ILO launched the 'Future of Work' initiative and provided a platform to discuss these and other issues affecting the world of work in the future. In the meantime, however, the largely unregulated matters challenge the ILO and its constituents for an appropriate response. Regulatory responses to precarious work as represented by Uber and the like are starting to come from local and national jurisdictions (McGaughey, 2018).

The urgency of tackling the precarious working conditions as presented by companies such as Uber and Deliveroo was widely held by the experts, nonetheless, there was also worry that the responsiveness of the ILO to these developments may take too long. An important reason for this lies in the ILOs tripartite functioning. In general, the reaction of the ILO was regarded as "being limited by [it's] slowest tripartite member". [interview 10, researcher] It was also viewed "that anything that comes out of the ILO has to be a negotiated comprise which supresses most key issues in conflict". [interview 11, researcher] As another interviewee stated:

The employers and workers sometimes will block each other ... a freezing of positions that makes it impossible for the secretariat to put forward certain ideas that might have merit. But they do not even come forward because the secretariat knows: "No, no, no. Either the employers or the workers will kill this". [Interview 21 , consultant]

\section{Organic production}

\section{Tension: Generalising organic farming conditions and organic values}

A first tension is that generalising farming conditions is to some extent at odds with organic values. Organic products have entered the mainstream as the global market continues to grow and consumer demand is further increasing. According to the market research company Ecovia Intelligence, the sales of organic food and drinks are reported to have increased from less than 15 billion to almost 90 billion US dollars over the past two decades (as cited in Willer \& Lernoud, 2018). The scaling-up of organic production, particularly by the large-scale agro-food industry, is considered to water down organic 
standards and is contradictory with some of the core values of organic farming (e.g. the practice of organic monoculture versus conserving biodiversity). The weakening of organic standards by industrial interests has comprised a critical part of scholarly work on organic governance (e.g., Guthman, 2004; Mutersbaugh, 2005). The political economy of organic products is important, as the large-scale agro-food industry has the power in overtaking and watering down what is considered "natural" in organic production (DuPuis \& Gillon, 2009).

Although core organic values are to a certain extent unfixed (Alrøe \& Kristensen, 2004) and contested (De Wit \& Verhoog, 2007), different values and interests at the core of the organic movement as opposed to the large-scale agro-food industry are evident. For the latter, keeping production costs low is key to the success at the conventional retailers' aisle. While premiums may still be pocketed, the price needs to be competitive. From the organic movement, there is a call to keep the prices of organic produce fair throughout the whole value chain. In order for the marketplace for organic products not to become further distorted, it is argued that both the positive and negative externalities need to be reflected in the price as to fairly account for the costs and benefits to the environment, biodiversity, human health, society and culture of any production system and farming method (Arbenz, Gould, \& Stopes, 2016). Particularly the push for monoculture farming of organic produce, as opposed to crop rotation, is critically divergent from organic values as upheld by the organic movement. The positive role of crop rotation and the role it has on biological diversity in enhancing agricultural sustainability is well established (Bezdicek \& Granatstein, 1989). Crop rotation is considered a critical feature of all organic cropping systems because it provides the principal mechanism for building healthy soils, a major way to control pests, and a variety of other benefits (Mohler, 2009). The clear deviation in values and interests is considered to hinder the potential for agreement with the industry or, to paraphrase one expert: the proposal of monoculture renders the discussion on the sustainability of organic production and standards meaningless. [interview 1, coordinator]

\section{Tension: Trustworthiness, overregulation and uniformity}

A second tension is that the quest for reliability in organic production and labelling leads to inefficiency. In order to guarantee the trustworthiness of the organic sector, regulation on organic production is enacted by various governments. In these countries, products can generally only be labelled as organic if the public standards are respected (Arcuri, 2015). Private organic standards also continue to operate in domestic markets. National organic regulations function as benchmarks because in case a private label wants to claim it has been produced according to organic standards, it must first conform to the production methods from the public organic regulation. 
While the system of assurance and verification is intended to enhance the level of trust in organic products, it conversely places a degree of distrust at the level of producers. Criticism against the certification system is that it impedes dedicated farmers, bullies them with rules and regulations that pose additional administrative burdens. While the organic sector is plagued by fraudulent labelling (USDA, n.d.), the trust that both consumers and farmers seek poses a quandary in protecting the organic sector while maintaining the integrity of organic farmers. This system also runs the risk of overregulating, as for instance the level of detail within provisions can become restrictive to organic certifications. Organic farming originated from various innovative farmers worldwide, and regulation is considered to hamper innovation and experimentation (Vogl, Kilcher, \& Schmidt, 2005). In this context, one expert stated the following:

While you could say that the EU regulation is a kind of floor on which you can add on, the problem is that the regulation is deeply detailed and so restrictive [for] practices. It limits innovation a lot. I mean, if you want to use a new method, or new input, or something that has not been used before, the process to get that one approved in the EU regulation is enormous. (...) incremental development is not possible with EU regulation in mind. So, it is not only about that it is too low, or not good enough, it's as much that it is really trying to put in organic in extreme detail. And people are not happy with that. [Interview 16, consultant]

While the organic market is attracting more retailers and consumers, it risks losing the legitimacy of well-established organic stakeholders. This also came to the fore in the interviews. For instance, the Swedish organic Krav label, which entered the organic market in 1985, contemplated in 2017 whether to detach or decouple themselves from the EU regulation. Having a reported 98 percent awareness level of the label among Swedish consumers (KRAV, 2018), the label felt it was capable to not certify its products as organic as certain farming practices would not be allowed under the new EU regulation. If this had been opted for, efforts of the organisation would have been put in educating consumers on what the standard would exactly entail.

\section{Tension: Equivalence case of the strongest economies}

A third tension is that equivalence between organic regulations is a privilege benefitting the strongest economies. Equivalence has been identified as an important mechanism to overcome challenges that the various standards on organic production pose for trade. Both governments and IFOAM seek ways through which equivalence can be established. Although the EU, North American countries, and Japan have established trade and equivalency agreements, producers outside the "trading blocs" have to consider several certifications to access different export markets (Sahota, 2018). Adversely however, out of the at least 2.7 million organic producers in 2016, more than $87 \%$ are from developing 
countries and emerging countries (Willer \& Lernoud, 2018). Multiple certifications pose a regulatory burden, and creates barriers for uptake and compliance particularly for many smallholders (Gould, 2015). For instance, an Indonesian organic coffee producer would have to adopt the EU regulations, National Organic Program of the U.S. Department of Agriculture, and Japanese Agricultural Standard to access markets in Europe, the United States, and Japan respectively (Sahota, 2018). The EU currently has recognised thirteen non-EU countries, so-called 'third' countries, as having equivalent organic production rules and control systems (listed in Annex III to Regulation (EC) No 1235/2008). Out of these five countries are from the Global South.

As from 1 January 2021, the new EU regulation will go into effect which will replace the system of equivalence with a compliance system. This means that private certification bodies in third countries have to comply with EU production and control rules when deciding whether a product exported to the EU market is organic or not (Council of the EU, 2017). Equivalence would only be allowed for third countries as part of a trade agreement (European Parliament, 2017). Currently, out of the various countries having reciprocal equivalence agreements, only one Global South country (Tunisia) has a reciprocal arrangement with the EU.

Due to its merits, equivalence is however also considered a strategic option for countries of the Global South (Pekdemir, 2018). Several regional standards have been initiated by more than 50 countries from the Global South. Through a common regional standard or the harmonisation and recognition of each other's national standards, regionalisation is assumed to bring more cohesion in the codification of organic production and stimulating trade between countries. Some regional standards have been recognised by the IFOAM Family of Standards as being equivalent to the IFOAM Basic Standard (Bowen \& Holmes, 2013; IFOAM, 2016; Pekdemir, 2018). Possibilities to enter the markets of countries however, is still through complying with the standards of the strongest economies engaging in organic production. This then begs the question why a farmer or producer exporting to two or more countries with an equivalence agreement would need to go through the system of assurance separately for each market. This is essentially not only an inefficient system for organic farmers and producers, but also an exclusionary one.

\subsection{Discussion and Conclusion}

In global governance, fragmentation is dysfunctional when it impedes the adequate realisation of policy goals. It is therefore valuable to understand the nature and the causes underlying fragmentation. To this end, we interviewed actors from various societal domains who showed many commonalities in terms of their perceptions of the specific 
governance systems. In this study, we observe that certain tensions emerge through quests for cohesion. We postulate that these tensions are dependent on the system characteristics of fragmentation of an issue field, as well as being dependent on the ways in which cohesion is sought. In this way, the approach taken in this study is aligned with calls in scholarly work proposing to analyse the drivers, causes and consequences of fragmentation, and move beyond debating the merits or demerits of different types and degrees of fragmentation in normative terms (Gupta, Pistorius, \& Vijge, 2016; Zelli \& van Asselt, 2013).

In terms of system characteristics of fragmentation, we identify that the approach to the protection of workers through labour standards lies for a large part in the public sphere. Many standard setting private arrangements have been initiated in the past decades, which have divided the issue fields in fractions. Furthermore, also public intergovernmental organisations and international finance institutions have started to take up on labour provisions. One of the results of the fragmented and multi-layered regulatory field of fair labour is that it causes regulatory uncertainty. This falls in a larger debate, where there is arguably large agreement on the very broad concepts and norms concerning labour standards. Disagreement predominantly exists on how those norms are best realised and the necessary governance tools that should accompany them. To exemplify, there is increasing consensus that workers should earn a living wage. Consensus however lacks on critical questions of calculating the wage and the distributional question of which actor(s) take responsibility for realising that norm within the value chain. As such, it is subject to political considerations (Parker, Arrowsmith, Fells, \& Prowse, 2016). Actors are looking for a meta-governance role to be fulfilled, but the ILO is not able to deliver the level of cohesiveness that is sought. The ILO is confined in its role, and among other issues, its tripartite character and lag in responsiveness are considered impeding factors.

In the issue field of organic production, ways are sought which permit the diversity in standards. From the organic movement, there is an imperative to do this based on organic principles, which do not only do justice to organic values but also to the variety of actors within the issue field. Approaches are sought that also offer opportunities to (smallholder) farmers. The way in which organic farming conditions are generalised through mainstreaming is however at odds with organic principles. It has given rise to the conventionalisation hypothesis (see Guthman, 2004; Rosin \& Campbell, 2009), which purports that organic farming is becoming a marginally modified model of conventional agriculture (Best, 2008). National regulations also pose another predicament to organic stakeholders through defining boundaries. When conflicts over these boundaries arise, the legitimacy of the market can be threatened (DuPuis \& Block, 2008). In a study on the organic market as a mode of governance in the United States, DuPuis and Gillon (2009) observe that the extent to which an alternative market expands is largely dependent on 
whether or not buyers and sellers find them worth participating in. While the organic market is attracting more retailers and consumers, it risks losing the legitimacy of wellestablished organic stakeholders as the example of the Swedish organic Krav label illustrates. Furthermore, we have argued in this paper that regulatory responses to guarantee trustworthiness can be regarded as inefficient and favourable to Northern markets.

Just as the causes underlying fragmentation are different in the two issue fields, so are the solutions that are offered to counter fragmentation. They each bring forth their own set of problems. In labour rights, the rapprochement of organisations and countries to labour standards through for instance various economic instruments can be considered a positive development (Zandvliet \& van der Heijden, 2015). From a coherence point of view, various standards and policies are becoming normatively aligned as standards from both public and private actors allude to ILO standards. The way in which standards are referred to and given effect are important in this regard. Private arrangements divide the field of protection in fractions. As the example of trade agreements revealed, the provisions take many different forms (ILO, 2016) which poses inconsistencies with the application of the ILO supervisory machinery (Agust et al., 2014). Since fragmentation continues the inadequate protection of workers' rights, harmonisation is recognised to be a more desirable mechanism for cohesion. If there is acceptance that the ILO is the most central and authoritative organisation, then the standards and policies developed by other public or private arrangements should be literally in line with ILO standards. For this to occur, strategic interaction and particularly the strengthening of collaborations between standard setting arrangements warrants focus.

In the governance of organic production, fragmentation initially led to insecurity about the trustworthiness of organic products and to difficulties in market access. While historically, the push against fraudulent claims and for organic regulations came from the organic movement, existing regulations paradoxically pose new concerns to the governance of organic production. First, there is the question how organic principles can be protected from watering down by standards that were once created to protect the integrity of organic values. Second, like a straightjacket, regulations are considered to confine and restrict organic standards that are more innovative and experimental in nature. Globalised value chains and the appeal of furthering trade may give the impression that identical standards, and therefore production methods, are preferable. Diversity does however not seem reconcilable with harmonisation of organic standards. Besides hampering innovative and experimental approaches, local and regional conditions in organic production run the risk of being disregarded. As this compromises an important element of organic production, in this field equivalence of standards are a preferred mechanism for policy coherence. It not only resolves issues of fragmentation, but also mitigates problems that regulatory measures have created in terms of trade. If the 
basis on which equivalency is based is reputable, the integrity of organic standards and principles can be maintained. Access to external markets can also be provided to actors that currently have less advantageous conditions for doing so in the current regulatory system. While strategic interactions take place, they are still largely excluding Southern actors and smaller markets.

Concluding, the focus on tensions informs the discussion on fragmentation and cohesion in several novel ways. First, in the quest for cohesion, it is of importance what type of intervention is proposed. Sometimes, policies aimed at strengthening a policy goal (e.g. labour provisions in trade agreements) sort an opposite effect through further fragmenting the issue field. Second, mechanisms for cohesion offer policy choices that are not only instrumental but normative as well, as they carry a particular vision for reaching cohesion. A choice for a certain policy mechanism has consequences. For instance, equivalence allows for more diversity in standards and therefore in practices, whereas harmonisation strives for unity in standards and as a result in practices as well. Third, the choice for a policy mechanism can be informed by the functionality for a particular issue field, namely, whether the consequences are suited to solve the problems associated with fragmentation in the issue field. For instance, what is the extent to which equivalence in labour standards can univocally protect labour rights of workers around the globe? If harmonisation serves the purpose of protecting labour rights better, what differences amongst governance actors and their standards would need to be overcome? These types of questions then lead to a fourth point, in that they call for a deliberative process amongst governance actors as a way of informing policymaking. Various tensions that arise through the quest for cohesion in governance systems stem from nonalignment between actors and their respective standards and expectations. Both cases, the global governance of labour rights and organic production, show that for achieving policy cohesion, there is ample room to seek partnerships and strengthen collaborative efforts. 



\section{Chapter 6 \\ Conclusion and reflection}

There are certain ideas of uniformity, which sometimes strike great geniuses ... but infallibly make an impression on little souls. They discover therein a kind of perfection, because it is impossible for them not to discover it; the same weights in the police, the same measures in commerce, the same laws in the state, the same religion in all its parts. But is this always right, and without exception? Is the evil of changing always less than that of suffering? And does not a greatness of genius consist rather in distinguishing between those cases in which uniformity is requisite, and those in which there is a necessity for differences?... If the people observe the laws, what signifies it whether these laws are the same?

Montesquieu, 1748

The Spirit of Laws (p. 378)

Navigating between fragmentation and cohesion: An exploration of tensions and policy mechanisms for cohesion in global governance for sustainability. [Manuscript in preparation based on chapters 1,5 , and 6] 



\subsection{Introduction}

Just as Montesquieu postulated in 1748, not all laws have to be uniform. Not even in contemporary times which, compared to the times in which The Spirit of Laws was written, have undergone immense processes of globalisation and are characterised by the interaction and integration of people, organisations, and indeed, laws and regulations as well. An important element of Montesquieu's argument for non-uniformity lies in the supposition that laws are observed. Laws are, however, not always present. Even in case of existence, they are not necessarily enacted or observed. Furthermore, how should one identify those cases in which uniformity is requisite and those cases in which there is a necessity for differences? Within the context of this dissertation, this concluding chapter sets forth the argument that a valid and logical approach for defining whether uniformity or differences are required rests on its evaluation. Three specific characteristics and the way they interlink are important in this appraisal, namely the topic and issue at hand, the governance context, and the consequences of (non-) uniformity. This argument will be elaborated in the remainder of this concluding chapter.

This dissertation started with the observation that issue areas concerned with sustainable practice are characterised by a growing number of standards and regulations. Particularly around the production of global public goods (Ruggie, 2004), the new global public domain has been subject to contending centres of economic and political power (Gereffi, Humphrey, \& Sturgeon, 2005). Many elements of the regulatory process have been transferred to both public and private actors in global governance, on topics as diverse as human rights, the environment, health, trade and finance.

In consequence, global governance for sustainable development is considered as having various sources of authority and power (Meadowcroft, 2007). Next to mandatory laws and regulations also more flexible and voluntary forms of regulation and implementation are offered (e.g., Abbott, 2012; Bartley, 2011). This phenomenon has led to the observation that many policy domains in international relations are characterised by fragmentation (Biermann, Pattberg, van Asselt, \& Zelli, 2009). Fragmentation is regarded as problematic when the capacity of governments or international organisations is weakened in their desired effects (Ivanova \& Roy, 2007) or more generally, if it constrains the efficient and effective realisation of generally accepted public values (Derkx \& Glasbergen, 2014).

The changes in global governance and the accompanying growth in regulatory complexity also spurred the quest for cohesion, sometimes also referred to as 'convergence' (e.g., Vogel \& Kagan, 2002). Initiatives for cohesion and the development of common global standards have brought the interests of public and private interests together in areas such as environmental, labour and social issues (Nadvi, 2008). Cohesion 
in regulations is considered favourable in the production for global public goods, for instance when standards, certification requirements and mutual recognition agreements converge in global value chains (OECD, 2013).

Characteristics of fragmentation and cohesion can be observed in many different issue areas of sustainable development. Issue fields are rooted in specific institutional contexts. For this reason, many governance approaches have developed in distinctive ways. The governance systems of some issue areas appear to have more regulatory cohesion, whereas other issue areas appear fragmented. It is assumed that some governance systems are more conducive to realise sustainable change than others are. However, elaborate explorations why this is the case were identified to be lacking, and the formulated research questions intend to fill this knowledge gap. Several case studies were examined in order to answer the following research questions:

i. What tensions between fragmentation and cohesion manifest themselves in various global governance systems?

ii. How do these tensions influence the governance capacity of these systems?

iii. What attempts have been made to handle these tensions and how are they able to contribute to the governance capacity?

This concluding chapter will first provide a brief overview of the different cases and specify the research methodology that is applied toward the study of fragmentation and cohesion. The three subsequent sections provide an answer to one research question respectively. In the section that follows, the implications of the key findings are addressed. In the last section, some final reflections and outlooks for further research are elaborated. 


\subsection{The Various Approaches to Theorizing Fragmentation and Cohesion}

In this dissertation, the concept of fragmentation signifies the diversity, multiplicity, and distribution of regulatory powers of the overall institutional settings of different international and transnational policy domains. The term cohesion functions as its counterpart, and regulatory coherence is understood as a system of governance in which policies are aligned resulting in concerted aims and actions. In absence of a nonfragmented, universal, and coordinated system of global governance structured around coherent sets of rules, full coherence on the global level is considered a theoretical construct. The pursuit for alignment as a way to create policy coherence has been analysed through the notions of harmonisation, equivalence, and metagovernance.

In the first case study on private fair labour arrangements (chapter 2), dimensions along which fragmentation and cohesion of governance systems can be studied have been identified. This resulted in a conceptual framework, which advances that relations within governance systems can be observed from three levels, namely the organisational, normative, and relational level. On the organisational level, the governance system is regarded as structured by the activities and respective organisational goals of actors who share a stake in the issue. This structuration may or may not be coordinated. On the normative level, the governance system is composed of ideas and norms that the different actors hold. Differences in these may exist, and can transpire in the way problems are defined and the strategies proposed to deal with them. On the relational level, the governance system is shaped by the power dependence between actors and strategic responses to the issue and each other. In this dynamic field, relations may develop into collaborations and partnerships, but may as well be adversarial. The conceptual framework served as an analytical basis to understand the regulatory system of global labour rights. Based on an investigation of the private transnational arrangements for fair labour, the fragmentation recognisable on the three dimensions were considered to impair the transformative capacity of the governance system of the fair labour issue field.

The second case (chapter 3) analysed the regionalisation of standards on organic production as a way in which public and private actors aim to bring more cohesion in the governance system on the global level. By examining all the existing initiatives from across the world, it evaluates if the promise of regionalisation can make the regulatory field of organic standards more cohesive and whether it is conducive for regional and international trade. Regionalisation as a system of governance is considered to contribute to normative coherence within the issue field while allowing for the regional adaptation - which in principle is considered a merit in the world of organic production. In this chapter, it is argued that ineffective enforcement and inadequate allocation of legal, 
political, and funding resources seriously imperil the institutional alignment necessary for international trade purposes.

The third case study (chapter 4) explored the concept of metagovernance as a way to bring more cohesion in governance systems on the global level. Based on a literature study on meta-organisations and meta-governance, a conceptual framework was developed with the potential repertoire of change mechanisms. The different metagovernance activities were categorised into four mechanisms: (re)framing the (global) discourse, capacity building, networking and mainstreaming. The practices of private governance arrangements having the ambition to be key for the advancement of sustainable production in three diverse global value chains were analysed in terms of these mechanisms. From the analysis, it became apparent that the mechanisms for change are used in different ways and to varying degrees across the different case studies. Generally, the private uptake of meta-governance mechanisms for change are considered to relate to networking and capacity building. These are mostly geared towards process management strategies, activating actors and resources, and arranging and facilitating interactions amongst stakeholders. It was found that private metagovernors could be strengthened in their efforts to frame the global sustainability discourse and mainstreaming of sustainability goals.

The fourth case study (chapter 5) examined the ways in which tensions in global governance systems manifest themselves through the quest for cohesion. In this chapter, it is postulated that the emerging tensions are dependent on the system characteristics of fragmentation in an issue field. Furthermore, these tensions are considered shaped by the ways in which cohesion is sought. By examining the global governance of labour rights and the global governance of organic production, it is found that a cause for these tensions emerging out of a quest for cohesion, ironically, stem from non-alignment itself as particularly strategic coordination between actors is often lacking. Both case studies illustrate that for achieving policy cohesion, whether in the form of equivalency or harmonisation, there is ample room to seek partnerships and strengthen collaborative efforts. It is concluded that collaborative roadmaps for cohesion in the global governance of production of global goods should not be treated alike, and require an issue based analysis for collaborative roadmaps to be functional for the governance systems itself.

\section{What tensions between fragmentation and cohesion manifest themselves in various global governance systems?}

The results of the various cases uncover that tensions between fragmentation and cohesion of global governance systems manifests themselves in several ways. The first tension area relates to the difficulties encountered in the relational aspect of governance in the transnational sphere. Specifically, while there is an understanding that 
collaboration and partnership can be beneficial, the governance arrangements have difficulties in arranging and maintaining collaborative efforts that can sustain and amplify their own working methods. Here several examples are provided from the various cases that exemplify this case in point. The case of private fair labour arrangements elucidated that for the main private governance arrangements operating in standard setting for fair labour, a governmentally funded joint initiative was organised in 2003 to explore whether efficiency and effectiveness could be realised. In a trial project in a producing country, the arrangements explored whether fragmentation could be reduced by, for instance, eliminating and reducing the duplication of efforts. Cohesion was specifically sought through identifying where collaboration between the arrangements could be strengthened. The pilot turned out to be unsuccessful and aggravations spilled over to the convergence element of the collaboration. Although the working methods are quite similar, up until this day, the fragmentation between private fair labour arrangements continues to exist. In addition, the case study on tensions in global governance systems revealed that public international institutions in labour governance also underscore the need for collaboration. While the International Labour Organization (ILO) is considered the most central institution on this topic, the usages of different labour provisions in standards has led to regulatory uncertainty. Closer cooperation and working towards synergies and policy coherence with international and regional organisations and institutions has been identified by the ILO as granting further attention. Another example was discussed in the case on regional standards for organic production. While several regional standards have been established which aspire to function as a common standard, its effectuation poses difficulties for most regional standards. While the intra-regional elements of the partnerships can be described to be successful from a relational and collaborative point of view, the inter-regional collaborative element that is to be negotiated and applied beyond the region, a crucial element in setting up an international trade agreement, has proven hitherto to be a bridge too far.

This ties in with another tension area between fragmentation and cohesion, namely, despite the quest for cohesion across the issue fields, the approach to achieving policy coherence is by and far not a settled issue amongst actors operating in them. As a result, the different working methods of the governance actors and their preferred ways for realising coherence is sometimes not only a non-shared endeavour, the preferred working methods also sustain or deepen the fragmented character of governance systems. This became evident in the case on regional standards for organic production. Particularly, compliance with organic standards is the main method set by governance actors. Equivalence is a method that permits the recognition of different standards fulfilling common objectives. In the field of organic production, this means that differences in standards across national and local divides can be allowed. While many countries have engaged in regional organic 
standards, most of these standards are not operational. Furthermore, only a handful of countries recognise each other's organic standards as equivalent.

Another tension area between fragmentation and cohesion can be observed between inclinations toward either global or local methods. To continue the previous example, the case on regional standards for organic production and the case on tensions in the global governance systems elucidated that globalisation has been a major factor behind the internationalisation of organic standards. The globalisation of supply chains has accompanied an increase in the volumes of trade of organic produce. The global trade in organic is considered both a reason for the increase in organic standards, as well as a catalyst for harmonising standards. However, within the organic movement, a counter reaction to the interdependent and integrated global supply chains and food systems is present. The value of local or regional organic food systems is underscored which refers to the method of food production and distribution that is geographically localised. Standards that are local in scope, such as national or regional standards, are considered to allow for variations that are relevant in terms of local practices and circumstances. Also in the field of labour rights, which has been discussed in the case on private fair labour arrangements and the case on tensions in the global governance systems, local approaches received support in the wake of the Rana Plaza commercial building collapse in Bangladesh, where many working in deplorable circumstances for international brands lost their lives. The Accord on Fire and Building Safety in Bangladesh and the Alliance for Bangladesh Worker Safety, the two western buyers' platforms working to improve workplace safety in Bangladesh readymade garment sector, are both local and thematic in their approach. These examples show that while an overarching, normative application of standards is often desired on the global level by transnational actors, these same actors stress the importance of the adaptation of standards to local characteristics as a way to safeguard their applicability and effectiveness.

\section{How do these tensions influence the governance capacity of these systems?}

Governance capacity was construed as an evaluative concept encompassing several elements. Beyond the applicability of the concept to the transnational and international sphere, we distinguished defining characteristics of governance capacity as the ability to contribute to policies, to implement policies, to put in certain resources, to achieve certain outcomes, and linked to the latter, the criterion of success. The influence of the tensions on the governance capacity of arrangements has been discussed in several ways throughout this dissertation. A general observation is that in most parts of the world, many transnational arrangements are tolerated to contribute and implement policies. An efficient and effective realisation of goals within issue fields are hard to achieve due to insufficiencies in (sharing) resources and concerted actions. 
In the field of labour rights, while there is largely a desire for cooperation between the governance arrangements, the international and transnational system is largely characterised by the lack thereof, whether within the public and private domains themselves, or across it. In the development and implementation of policies, arrangements largely focus on their own resources and capabilities as a way to contribute primarily to the social value for individuals, organisations and societies. For private labour arrangements, the inability or unwillingness to cooperate has divided the issue field in different fractions through their focus on particular sectors. Furthermore, they also compete for market share of businesses and the arrangements make a case for their relevance and impact within the labour rights domain for their continued existence. Regardless of whether they are considered effective, each arrangement only accounts for a fraction of the issue field, which is tied to specific company clients and the sectoral foci. In an analysis of public international actors, it was found that next to the ILO other international actors have increasingly started to define and adopt labour policies. However, formulations and reference to normative standards in provisions and policies differ, resulting from a reported lack of synergies for policy coherence. One of the main conclusions of the case on private fair labour arrangements and the case on tensions in global governance systems was that the characteristics of the governance system as a whole point to problems related to the fragmentation of the system. In this regard, the variety amongst the actors themselves, the lack of accountability, the uncoordinated efforts amongst various arrangements, and the weak links between and across the public and private divide, were all signified as unconducive to induce the envisioned changes.

The field of organic production is also a field that is rife of standards and many actors are involved with drafting and implementing standards and regulations. The case on private fair labour arrangements showed that resources and capabilities are shared in regional arrangements for standard setting. Also in terms of alignment between standards, two normative standards - one from the public and another one from the private sphere were considered to contribute to the regional standards development. The organic farmers' roof association puts in quite a lot of its efforts to policy development and implementation. In the private sphere, diversity in standards is valued in so far as they are recognised to be in line with organic values. This can also be seen reflected in the endorsement of equivalency. In this regard, standards can be specifically adapted to the local context. The approach of public arrangements differs. Next to having organic regulations, major organic markets and developed nations have a strong implementing capacity. The approach to other major developed markets is cooperative. While major markets engage in equivalence agreements, other actors have to conform to the compliance regime. For developing countries, we observe that the development and implementation capacity of countries may vary significantly from country to country. Equivalency is aspired, but is not a reality for most countries. As a system of governance then, the issue-field of organic 
production has many elements of collaborations and partnerships between both public and private actors. The governance system as a whole however, cannot be described as cohesive due to the excluding characteristics of major public actors. Also discussed in the case on tensions in global governance systems, there is not a negotiated view on how to go forward in terms of the regulatory approach to cohesion, and actors go about exploring the avenues most beneficial for them in terms of international trade. In terms of successfulness, the regulation of organic production shows successful as well as unsuccessful characteristics. The degree to which the sector is protected from fraudulent claims can be marked as quite effective. However, regulatory complexity and concerns of Southern inclusivity remain to be challenges for the overall sector.

\section{What attemptshave been made to handle these tensions and how are they able to contribute to the governance capacity?}

Various attempts have been undertaken by both public and private actors to handle the tensions arising from particularly fragmented state of governance affairs. In the empirical chapters, different approaches to reaching policy coherence were examined namely equivalence, harmonisation, common standard adoption, and metagovernance.

Under the equivalence model, actors accept each other's standards as if they are the same. Differences in provisions and variations in formulations are allowed. For this reason, the purpose of equivalence lies within its functionality. In standards for organic production, the European Union for instance has both unilateral as well as reciprocal equivalency agreements. One standard may be used as a normative standard which other standards need to be equivalent with. The International Federation of Organic Agricultural Movements' Family of Standards is an example of such an equivalency network framework. Although currently only a theoretical construct, multilateral processes are at present propositioned by major developed markets to address challenges with developing and managing multiple equivalence arrangements (see Figure 6.1 for an overview of the policy coherence mechanisms). With harmonisation, actors bring different standards in line with one common standard or regulatory framework. This way, a system of standards operates efficiently without inconsistencies or inequalities. With adopting a common standard, actors agree that one standard applies to all parties. In principle, there is not a necessity to duplicate the standard. Regional standards for organic production are examples of common standards. Metagovernance can bring in more cohesion in the activities and regulatory processes within an issue field through a wide array of guidance mechanisms. Metagovernors can therefore employ any of the policy coherence mechanisms previously described. The International Social and Environmental Accreditation and Labelling Alliance (ISEAL), which is recognised by 
scholars as a sustainability metagovernor, endorses the ISEAL's Credibility Principles, which for instance works according to the harmonisation mechanism.

The way in which policy mechanisms contribute to governance capacity are multiple. First, they offer a means in which expectations of actors concerning policy coherence can be managed. Once an approach is agreed upon, it furthermore offers a way in which the governance system can be structured. In that sense, the policy mechanisms are indicative of strategic relationships. Very simply put, in a bilateral equivalency agreement there is a basis of reciprocity in terms of demands, expectations, and benefits. While these elements may of course be present in unilateral equivalence agreements, they are not reciprocative. This ties in with another observation, which is that the policy mechanisms and the agreements struck reveal where power lies. To stay with the example of equivalence, power lies with those actors with whom equivalence agreements want to be struck with and those who are part of reciprocal equivalency agreements.

Analogously, the way a metagovernance organisation employs mechanisms for policy coherence discloses the governance capacity that the metagovernor itself has, as well as that of its members. For instance, with the harmonisation model of ISEAL's Credibility Standards, standards endorsed by other actors need to comply with certain principles of ISEAL to be regarded a sustainability standard. As a metagovernor, it employs a regulatory mode to its members. In a typology of interplay management, Oberthür (2009) distinguishes between two modes of interplay management, namely regulatory and enabling. ISEAL employs the former mode through its employment of a more hierarchical, regulatory, and top-down approach to its normative standard. However, the Sustainable Fisheries Partnership recommends the Marine Stewardship Council as a common standard, but does not mandate or enforce this. As the case on private metagovernance has demonstrated, the private arrangements investigated offer many different activities through which concerted aims and actions could be sought, and these activities lay mainly in networking and capacity building. This working method resonates with the enabling mode of interplay management, as its governance approach is non-hierarchical, communicative, voluntary, and enabling. If no other policy mechanism is offered for policy coherence by a metagovernance organisation, it signals that in terms of governance capacity, the organisations lack regulatory power and are therefore too weak to be considered governors. Therefore, in this concluding chapter we propose that besides employing a variety of the mechanisms of change as detailed in the case on tensions in global governance systems, metagovernors should employ one of the policy cohesion mechanisms, whether equivalence, harmonisation, or a common standard in order to be considered a metagovernor. In effect, this would contribute to the governance capacity of metagovernance arrangements and potentially to the governance system as a whole. 


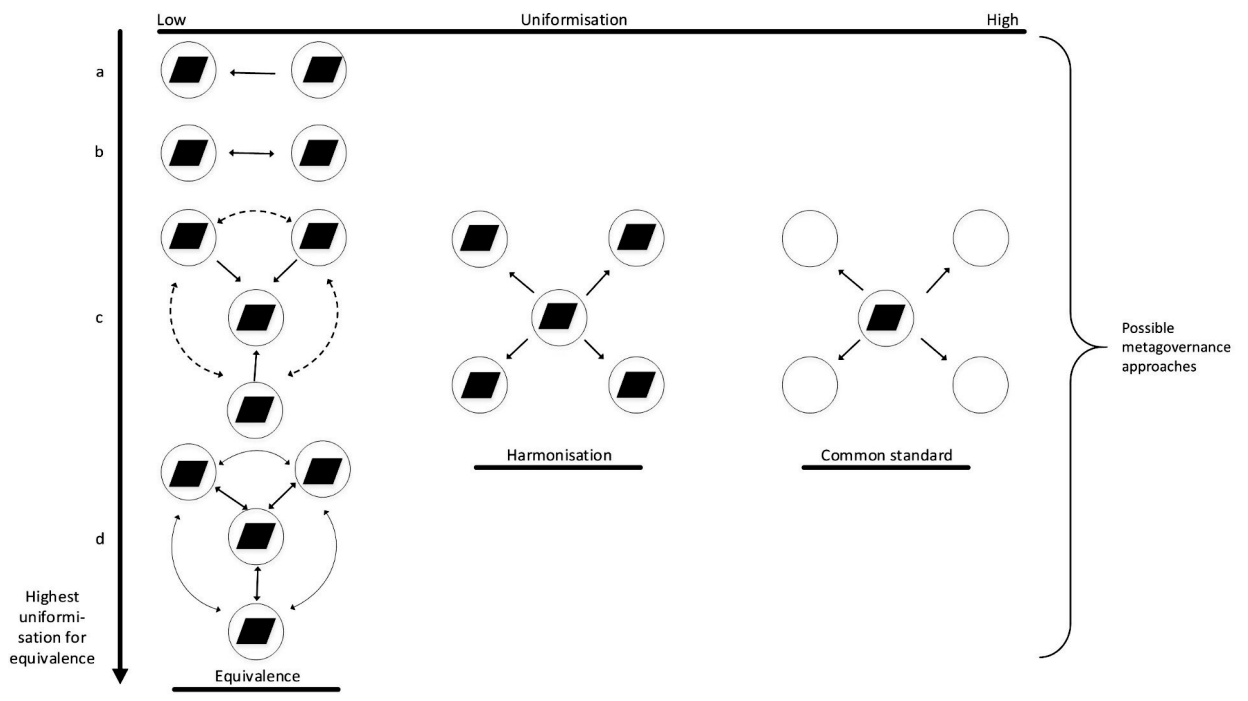

Figure 6.1 Mechanisms for policy cohesion

\subsection{Implications of Key Findings}

The manifestations of fragmentation and cohesion and the associated tensions deriving from them have been explored and contextualised through several case studies in this dissertation. It is our understanding that the main observations, analyses, and insights have an extendibility to other issue areas of global governance as well. Regardless of the level or the degree to which there is fragmentation within diverse issue fields in the production of global goods, fragmentation is omnipresent in global governance. Can we even expect that the diversity of actors engaged with the global governance of the production of global goods (including companies, civil society organisations, and polity in different cultures) would aspire the same? What is regarded as sustainable is often dependent on geographic, spatial, temporal matters. Even in cases where there is wide consensus on what is sustainable, trajectories for development may differ. There is value in diversity of actors and governance approaches to sustainable development, and in this particular sense, to fragmentation as well.

Fragmentation becomes problematic when the issues of sustainability and development become unmanageable. The concepts of fragmentation and cohesion within this study have been regarded normatively in so far that fragmentation was understood as being unconducive to realising societal goals as it may diffuse, or be counterproductive for, concerted aims and action. Contrarily, efforts for cohesion have been understood positively in so far that partnerships and cooperation can overcome the condition of 
fragmentation, enhance concerted aims and action, and result in regulatory coherence. When previously established values codified in laws and regulations are obscured or infringed upon, it is of crucial importance to understand the drivers and the accompanying agendas attached to them. While policy cohesion may be desired, the level and the extent to which will need to be determined. This can aid in the agenda to distinguish associated management efforts which tackle fragmentation (Zelli \& van Asselt, 2013). It is central then to navigate between fragmentation and cohesion in order to deal effectively with diversity and the tensions this poses on the governability of sustainable development. While universal coordination may be lacking, central and authoritative actors can take a key role in fostering policy coherence.

Three approaches may be instructive in navigating between fragmentation and cohesion. First, fragmentation can be approached as an organisational problem. In this approach, it is not only important to identify actors and their responsibilities, but also to suggest where responsibilities lie, or shift, redistribute, and reorganise responsibilities. Second, fragmentation can be approached as a problem emanating from normative issues. A general normative framework may be required. In case this is present, not only more stringent or encompassing standards can be called for, but also a normative framework on the mechanism of policy coherence. Third, fragmentation can be approached as a relational problem. Collaborations and interactions between governance actors need to be fostered. Interplay management then becomes an important concept in this regard, which refers to the conscious efforts by any relevant actors or group of actors, regardless of form and forum, to address institutional interaction and its effects (Oberthür \& Stokke, 2011). Each of these approaches may however bring forth tensions, such as those relating to legitimacy and accountability (see e.g., Biermann \& Gupta, 2011). Nonetheless, for steering societies across the world towards sustainable trajectories, systemic transformation remains one of the biggest governance challenges of our times.

\subsection{Reflections and Outlook}

Just as the quote of Montesquieu inferred, it might be tempting to think that uniformity is desirable. In this dissertation, we particularly nuance the intuitive assumption that a higher level of uniformity in policy cohesion strategies is preferable. On basis of the research findings of this dissertation, we argue that the type of cohesion that should be sought depends on the characteristics of underlying fragmentation and the issue at stake. The case study on regional standards for organic production demonstrated that diversity is arguably a valued characteristic for the standards system. For this reason, equivalence as a mechanism for policy coherence is a suitable system. However, for labour rights, harmonisation or a common standard of core labour standards is preferable as regulatory 
fragmentation leads to the continued violation of labour rights. The obscuring of normative standards in other regulations and policies rekindles the ineffective labour rights protection system. Within the context of governance for sustainable development, little is known about the advantages and disadvantages of the policy mechanisms for policy cohesion. In what ways can the policy mechanisms be of use within different issue fields, and what would be their advantages and disadvantages? Since this avenue in research is largely unexplored, these questions merit further academic and policyoriented research.

Furthermore, in interviewing governance actors on the various cases, some visions for the future were explored with experts. Specifically, interview questions explored what would be needed to get a desired future for a relevant governance issue, and included questions on the actions, actors of change, agents making the realisation difficult, and values underlying its accomplishment. These types of questions link very well with foresight studies. As different national and international, public and private organisations have the task or ambition to explore the long term (see e.g., van Asselt, van 't Klooster, van Notten, \& Smits, 2010), foresight studies on policy coherence approaches with relevant stakeholders could provide a concrete step toward defining a shared future. Through developing futures according to the different policy coherence mechanisms, scenario exercises may for instance contribute to evaluating whether policies approaches are robust, whether there would be consensus or conflict between the various perspectives in policy coherence approaches, and to the identification of possible solutions in case of conflict and explore various options available.

Lastly, the 2030 Agenda for Sustainable Development by the United Nations, which is pursued by the Sustainable Development Goals - successor to the Millennium Development Goals - is the most recent universally acclaimed normative agenda. While countries remain the ultimate addressees, the inclusion of partnerships as a development goal is considered part and parcel for the realisation of the rest of the normative agenda. In order to contribute to the same policy agenda, whether now or in the future, the search for policy coherence by governance actors will remain of eminent relevance. In a world critically divided on many issues, it is our hope that this dissertation can contribute to the search of suitable governance approaches for sustainable development. 


\section{References}

4C Association. (2014). Propogating a sutainable coffee community. Annual report 2013. Retrieved from Global Coffee Platform website: https://www.globalcoffeeplatform.org/assets/files/Documents/Reports-Brochures /4C_AnnualReport2013_web_small.pdf

Abbott, K. W. (2012). Engaging the public and the private in global sustainability governance. International Affairs, 88(3), 543-564. doi:10.1111/j.1468-2346.2012.01088.x

Abbott, K. W., \& Snidal, D. (2009a). The governance triangle: Regulatory standards institutions and the shadow of the state. In W. Mattli \& N. Woods (Eds.), The politics of global regulation (pp. 44-99). New Jersey: Princeton University Press.

Abbott, K. W., \& Snidal, D. (2009b). Strengthening international regulation through transnational new governance: Overcoming the orchestration deficit. Vanderbilt Journal of Transnational Law, 42(2), 501-578.

AgroEco, \& Grolink. (2008). Organic Exports - A Way to a Better Life? Export Promotion of Organic Products from Africa. Retrieved from Grolink website: http://www.grolink.se/epopa/Publications/Epopa-end-book.pdf

Agust, P., Ebert, F. C., \& Le Clerq, D. (2014). Labour provisions in free trade agreements: Fostering their consistency with the ILO standards system. ILO background paper social dimensions of free trade agreements. Retrieved from International Labour Organization website: http://www.ilo.org/wcmsp5/groups/public/--dgreports/---inst/documents/genericdocument/wcms_237940.pdf

Ahrne, G., \& Brunsson, N. (2008). Meta-organizations. Cheltenham, UK: Edward Elgar Publishing Limited.

Alrøe, H. F., \& Kristensen, E. S. (2004). Why have basic principles for organic agriculture? And what kind of principles should they be? Ecology\& Farming, 36, 27-30.

Alston, P. (2004). 'Core labour standards' and the transformation of the international labour rights regime. European Journal of International Law, 15(3), 457-521. doi:10.1093/ejil/15.3.457

Andenas, M., \& Andersen, C. B. (2011). Preface: Theory and practice of harmonisation. In M. Andenas \& C. B. Andersen (Eds.), Theory and practice of harmonisation (pp. xi-xiv). Cheltenham, UK: Edward Elgar Publishing Limited.

Andenas, M., Andersen, C. B., \& Ashcroft, R. (2011). Towards a theory of harmonisation. In M. Andenas\& C. B. Andersen (Eds.), Theory and practice of harmonisation (pp. 572-594). Cheltenham, UK: Edward Elgar Publishing Limited.

Andreadakis, S. (2011). Regulatory competition or harmonisation: The dilemma, the alternatives and the prospect of reflexive harmonisation In M. Andenas \& C. B. Andersen (Eds.), Theory and practice of harmonisation (pp. 52-64). Cheltenham, UK: Edward Elgar Publishing Limited.

Andresen, S. (2001). Global environmental governance: UN fragmentation and co-ordination. In O. S. Stokke \& Ø. B. Thommessen (Eds.), Yearbook of international co-operation on environment and development 2001/2002 (pp. 19-26). London: Earthscan Publications.

Ansell, C., \& Gash, A. (2008). Collaborative governance in theory and practice. Journal of Public Administration Research and Theory, 18(4), 543-571. doi:10.1093/jopart/mum032

Arbenz, M., Gould, D., \& Stopes, C. (2016). Organic 3.0 - for truly sustainable farming and consumption. Bonn: IFOAM Organics International and SOAAN.

Arcuri, A. (2015). The transformation of organic regulation: The ambiguous effects of publicization. Regulation \& Governance, 9(2), 144-159. doi:10.1111/rego.12066

ARSO. (2012). ARS 751: Organic products standard. Retrieved from the Internet Archive website: https://archive.org/stream/ars.751.2012/ars.751.2012_djvu.txt

Arthurs, H. (2011). Labour law after labour. In G. Davidov \& B. Langille (Eds.), The Idea of Labour Law (pp. 1329). New York: Oxford University Press Inc. 
Auld, G. (2014). Confronting trade-offs and interactive effects in the choice of policy focus: Specialized versus comprehensive private governance. Regulation \& Governance, 8(1), 126-148. doi:10.1111/rego. 12034

Austin, J. E., \& Seitanidi, M. M. (2012). Collaborative value creation: A review of partnering between nonprofits and businesses: Part I. Value creation spectrum and collaboration stages. Nonprofit and Voluntary Sector Quarterly, 41(5), 726-758. doi:10.1177/0899764012450777

Balliester, T., \& Elsheikhi, A. (2018). The future of work: A literature review (Working Paper No. 29). Retrieved from International Labour Organization website: https://www.ilo.org/wcmsp5/groups/public/---dgreports/ ---inst/documents/publication/wcms_625866.pdf

Balsiger, J., \& Prys, M. (2014). Regional agreements in international environmental politics. International Environmental Agreements, 16(2), 239-260. doi:10.1007/s10784-014-9256-3

Barrientos, S., \& Smith, S. (2007). Do workers benefit from ethical trade? Assessing codes of labour practicein global production systems. Third World Quarterly, 28(4), 713-729. doi:10.2307/20454958

Bartley, T. (2007). Institutional emergence in an era of globalization: The rise of transnational private regulation of labor and environmental conditions. American Journal of Sociology, 113(2), 297-351. doi:10.1086/518871

Bartley, T. (2011). Certification as a mode of social regulation. In D. Levi-Faur (Ed.), Handbook on the politics of regulation (pp. 441-452). Cheltenham, UK: Edward Elgar Publishing Limited.

Baser, H., \& Morgan, P. (2008). Capacity, change and performance study report (Discussion Paper 59B). Retrieved from European Centre for Development Policy Management website: http://ecdpm.org/publications/capacitychange-performance-study-report/

Beisheim, M., \& Simon, N. (2015). Meta-governance of partnerships for sustainable development. Actors' perspectives on how the UN could improve partnerships' governance services in areas of limited statehood (Working Paper Series No. 68). Retrieved from Collaborative Research Center website: http://www.sffgovernance.de/en

Bell, S., \& Park, A. (2006). The problematic metagovernance of networks: Water reform in New South Wales. Journal of Public Policy, 26(1), 63-83. doi:10.2307/4007811

Bellamy, R., \& Palumbo, A. (Eds.). (2010). From Government to Governance. Farnham: Ashgate.

Benvenisti, E., \& Downs, G. W. (2007). The empire's new clothes: Political economy and the fragmentationof international law. Stanford Law Review, 60(2), 595-631.

Berliner, D., \& Prakash, A. (2012). From norms to programs: The United Nations Global Compact and global governance. Regulation \& Governance, 6(2), 149-166. doi:10.1111/j.1748-5991.2012.01130.x

Bernstein, S., \& Ivanova, M. (2007). Institutional fragmentation and normative compromise in global environmental governance: What prospect for re-embedding? In S. Bernstein \& L. W. Pauly (Eds.), Global liberalism and political order: Towards a new grand compromise? (pp. 161-186). Albany: SUNY Press.

Bernstein, S., \& Van der Ven, H. (2017). Best practices in global governance. Review of International Studies, 43(3), 534-556. doi:10.1017/S0260210516000425

Bernzen, A., \& Braun, B. (2014). Conventions in cross-border trade coordination: The case of organic food imports to Germany and Australia. Environment and Planning A, 46(5), 1244-1262. doi:10.1068/a46275

Bertels, S., \& Peloza, J. (2008). Running just to stand still? Managing CSR reputation in an era of ratcheting expectations. Corporate Reputation Review, 11(1), 56-72. doi:10.1057/crr.2008.1

Best, H. (2008). Organic agriculture and the conventionalization hypothesis: A case study from West Germany. Agriculture and Human Values, 25(1), 95-106. doi:10.1007/s10460-007-9073-1

Bezdicek, D. F., \& Granatstein, D. (1989). Crop rotation efficiencies and biological diversity in farming systems. American Journal of Alternative Agriculture, 4(3-4), 111-119. doi:10.1017/S0889189300002927

Bhatia, K. L. (2010). Textbook on legal language and legal writing. New Delhi: Universal Law Publishing Co. Pvt Ltd.

Biermann, F., \& Gupta, A. (2011). Accountability and legitimacy in earth system governance: A research framework. Ecological Economics, 70(11), 1856-1864. doi:10.1016/j.ecolecon.2011.04.008

Biermann, F., Pattberg, P., van Asselt, H., \& Zelli, F. (2009). The fragmentation of global governance architectures: A framework for analysis. Global Environmental Politics, 9(4), 14-40. doi:10.1162/glep.2009.9.4.14 
Biermann, F., Stevens, C., Bernstein, S., Gupta, A., Kabiri, N., Kanie, N., . . Young, O. R. (2014). Integrating Governance into the Sustainable Development Goals (Policy Brief No. 3). Retrieved from United Nations University Collections webiste: https://collections.unu.edu/eserv/UNU:1825/Post2015_UNU-IAS_ PolicyBrief3.pdf

Bitzer, V. (2010). Partnering for change in chains: On the capacity of partnerships to promote sustainable change in global agricultural commodity chains (Doctoral dissertation, Universiteit Utrecht). Retrieved from http://dspace.library.uu.nl/bitstream/handle/1874/197673/bitzer.pdf?sequence $=1$

Bitzer, V. (2012). Partnering for change in chains: The capacity of partnerships to promote sustainable change in global agrifood chains. International Food and Agribusiness Management Review, 15(B Special Issue), 13-38.

Bitzer, V., \& Glasbergen, P. (2015). Business-NGO partnershipsin global value chains: part of the solution or part of the problem of sustainable change? Current Opinion in Environmental Sustainability, 12, 35-40. doi: 10.1016/j.cosust.2014.08.012

Bitzer, V., Glasbergen, P., \& Leroy, P. (2012). Partnerships of a feather flock together? An analysis of the emergence of networks of partnerships in the global cocoa sector. Global Networks, 12(3), 355-374. doi:10.1111/j.1471-0374.2011.00359.x

Blackett, A., \& Trebilcock, A. (Eds.).(2015). Research handbook on transnational labour law. Cheltenham, UK: Edward Elgar Publishing Limited.

Blake, F. (2009). Overview of the new regulations - and the implications for organic food and farming. 2.2 General analysis of the new regulation. In C. Mikkelsen \& M. Schlüter (Eds.), The new EU regulation for organic food and farming: (EC) No 834/2007. Background, assessment, interpretation (pp. 18-21). Retrieved from the IFOAM EU Group website: http://www.ifoam-eu.org/sites/default/files/page/files/ifoameu_ reg_organic_regulation_dossier_2009_en.pdf

Bowen, D. (2003). International harmonisation of organic standards and guarantee systems. In OECD (Ed.), Organic agriculture: Sustainability, markets and policies (pp. 199-202). Wallingford, UK: CABI Publishing, CAB International.

Bowen, D. (2011). Reducing barriers to international trade: The story of the Global Organic Market Access project. Ecology and Farming, 5, 8-11.

Bowen, D. (2013). Review of key systemic issues and findings resulting from activities of the International Task Force on Harmonization and Equivalence in Organic Agriculture (ITF) and the Global Organic Market Access (GOMA) project (Discussion Paper No.2). Retrieved from United Nations Forum on Sustainability Standards website:https://unfss.files.wordpress.com/2013/02/unfss_dp_itfgoma_v2.pdf

Bowen, D., \& Hoffman, U. (2015a). Plurilateral regulatory cooperation on organic agriculture and trade (Discussion Paper No. 5). Retrieved from United Nations Forum on Sustainability Standards website: https://unfss.files.wordpress.com/2013/02/unfss_5-_pluri_regulatory_cooperation-final_apr_2015.pdf

Bowen, D., \& Hoffman, U. (2015b). Public-private collaboration on policy, standards, regulations and trade facilitation for organic agriculture (Discussion Paper No. 4). Retrieved from United Nations Forum on Sustainability Standards website: https://unfss.files.wordpress.com/2013/02/unfss_4-final_-publicprivate_collaboration_apr_2015.pdf

Bowen, D., \& Holmes, M. (2013). Bilateral equivalence arrangements on trade of organic products: A review of processes leading to arrangements between Canada and United States, Canada and European Union and European Union and United States. UNCTAD, FAO and IFOAM, retrieved from Food and Agriculture Organization of the United Nations website: http://www.fao.org/docrep/017/aq205e/aq205e.pdf

Brown Weiss, E. (1993). International environmental law: Contemporary issues and the emergence of a new world order. Georgetown Law Journal, 81(3), 675-710.

Burke, J. (2013, December 8). Bangladesh factory fires: fashion industry's latest crisis. The Guardian. Retrieved from http://www.theguardian.com

Burns, T. R., \& Stöhr, C. (2011a). The architecture and transformation of governance systems: Power, knowledge, and conflict. Human Systems Management, 30(4), 173-194. doi:10.3233/hsm-2011-0751 
Burns, T. R., \& Stöhr, C. (2011b). Power, knowledge, and conflict in the shaping of commons governance. The case of EU Baltic fisheries. International Journal of the Commons, 5(2), 233-258. doi:10.18352/ijc.260

Bush, S. R., Toonen, H., Oosterveer, P., \& Mol, A. P. (2013). The 'devils triangle'of MSC certification: Balancing credibility, accessibility and continuous improvement. Marine Policy, 37, 288-293.

Cafaggi, F. (2016). Transnational private regulation. Regulating private regulators. In S. Cassese (Ed.), Research handbook on global administrative law (pp. 212-241). Cheltenham, UK: Edward Elgar Publishing Limited.

Castells, M. (2008). The new public sphere: Global civil society, communication networks, and global governance. The ANNALS of the American Academy of Political and Social Science, 616(1), 78-93. doi:10.1177/0002716207311877

Castka, P., \& Corbett, C. J. (2016). Governance of eco-labels: Expert opinion and media coverage. Journal of Business Ethics, 135(2), 309-326. doi:10.1007/s10551-014-2474-3

Christopoulos, S., Horvath, B., \& Kull, M. (2012). Advancing the governance of cross-sectoral policies for sustainable development: A metagovernance perspective. Public Administration and Development, 32(3), 305-323. doi:10.1002/pad.1629

Codex Alimentarius. (2007). Organically Produced Foods ( $3^{\text {rd }}$ ed.). Retrieved from Food and Agriculture Organization of the United Nations website: ftp://ftp.fao.org/docrep/fao/010/a1385e/a1385e00.pdf

Conroy, M. E. (2007). Branded! How the 'Certification Revolution' Is Transforming Global Corporations. Canada: New Society Publishers.

Council of the EU. (2017, June 28). Green light to new European rules on organic farming [Press release]. Retrieved from https://www.consilium.europa.eu/en/press/press-releases/2017/06/28/rules-organic-farming/

Courville, S. (2006). Organic standards and certification. In P. Kristiansen, A. Taji, \& J. Reganold (Eds.), Organic agriculture: A global perspective (pp. 201-219). Collingwood: CSIRO Publishing.

De Wit, J., \& Verhoog, H. (2007). Organic values and the conventionalization of organic agriculture. NJAS Wageningen Journal of Life Sciences, 54(4), 449-462. doi:10.1016/S1573-5214(07)80015-7

Derkx, B. (2011). Metagovernance in the realm of private of sustainability standards setting (Master's thesis, Universiteit Utrecht). Retrieved fromhttps://dspace.library.uu.nl/handle/1874/200277

Derkx, B., \& Glasbergen, P. (2014). Elaborating global private meta-governance: An inventory in the realm of voluntary sustainability standards. Global Environmental Change, 27, 41-50. doi: 10.1016/j.gloenvcha.2014.04.016

Diller, J. (1999). A social conscience in the global marketplace? Labour dimensions of codes of conduct, social labelling and investor initiatives. International Labour Review, 138(2), 99-129. doi:10.1111/j.1564 913X.1999.tb00062.x

Dingwerth, K., \& Pattberg, P. (2009). World politics and organizational fields: The case of transnational sustainability governance. European Journal of International Relations, 15(4), 707-743. doi:10.117// 1354066109345056

Donahue, A. M. (2000). Equivalence: Not quite close enough for the international harmonization of environmental standards. Environmental Law, 30(2), 363-386.

DuPuis, E. M., \& Block, D. (2008). Sustainability and scale: US milk-market orders as relocalization policy. Environment and Planning A, 40(8), 1987-2005. doi:10.1068/a39250

DuPuis, E. M., \& Gillon, S. (2009). Alternative modes of governance: Organic as civic engagement. Agriculture and Human Values, 26(1), 43-56. doi:10.1007/s10460-008-9180-7

Ebert, F. C. (2014). The integration of labour standards concernsinto the environmental and social policy of the International Finance Corporation. Verfassung und Recht in Übersee / Law and Politics in Africa, Asia and Latin America, 47(2), 229-249. doi:10.5771/0506-7286-2014-2-229

Ebert, F. C. (2018). Labour standards and the World Bank. Analysing the potential of safeguard policies for protecting workers. In H. Gött (Ed.), Labour standards in international economic law (pp. 273-304). Cham: Springer International Publishing.

Elliott, K. A. (2000). The ILOand enforcement of core labor standards. International Economics Policy Briefs(006), 1-7. 
Enriquez, E., \& Centeno, M. A. (2012). State capacity: Utilization, durability, and the role of wealth vs. history. International and Multidisciplinary Journal of Social Sciences, 1(2), 130-162. doi:10.4471/rimcis.2012.07

European Commission. (2014). Organic farming policy: The historical background. Retrieved from http://ec.europa.eu/agriculture/organic/eu-policy/eu-legislation/historical-background/index_en.htm

European Parliament. (2017). QઐA on the informal agreement on reform of EU organic food rules (Reference No:20170627BKG78420). Retrieved from http://www.europarl.europa.eu/pdfs/news/expert/background/ 20170627BKG78420/20170627BKG78420_en.pdf

European Union. (2016). Facts and figures on organic agriculture in the European Union. Retrieved from European Commission website: https://ec.europa.eu/agriculture/organic/sites/orgfarming/files/docs/ pages/014_en.pdf

European Union. (n.d.). The EU motto. Retrieved from https://europa.eu/european-union/abouteu/symbols/motto_en

Fawn, R. (2009). 'Regions' and their study: Wherefrom, what for and whereto? Review of International Studies, 35, 5-34. doi: 10.2307/20542776

FishSource. (n.d.). Does FishSource define sustainability?Retrieved from https://www.fishsource.org/how/scores Fladl, M., \& Hiulot, J. F. (2009). Overview of the new regulations - and the implications for organic food and farming. 2.1 The new legislative framew ork for organic farming. In C. Mikkelsen \& M. Schlüter (Eds.), The new EU regulation for organic food and farming: (EC) No 834/2007. Background, assessment, interpretation (pp. 14-18). Retrieved from the IFOAM EU Group website: http://www.ifoameu.org/sites/default/files/page/files/ifoameu_reg_organic_regulation_dossier_2009_en.pdf

Fouilleux, E., \& Loconto, A. M. (2017). Voluntary standards, certification, and accreditation in the global organic agriculture field: A tripartite model of techno-politics. Agriculture and Human Values, 34(1), 114. doi: 10.1007/s10460-016-9686-3

Fragment. (2014). Oxford English Dictionary Online. Retrieved 25 February, 2015, from http://www.oed.com Fragmentation. (2014). Oxford English Dictionary Online. Retrieved 25 February, 2015, from http://www.oed.com

Fransen, L. (2011). Why do private governance organizations not converge? A political-institutional analysis of transnational labor standards regulation. Governance-an International Journal of Policy Administration and Institutions, 24(2), 359-387. doi:10.1111/j.1468-0491.2011.01519.x

Fransen, L. (2015). The politics of meta-governance in transnational private sustainability governance. Policy Sciences, 48(3), 293-317. doi:10.1007/s11077-015-9219-8

Fransen, L., \& Conzelmann, T. (2014). Fragmented or cohesive transnational private regulation of sustainability standards? A comparative study. Regulation \& Governance, 9(3), 259-275. doi:10.1111/rego. 12055

Fuchs, N., \& Hoffmann, U. (2013). Commentary I: Ensuring food security and environmental resilience - The need for supportive agricultural trade rules. In Trade and Environment Review 2013 (Ed.), Wake up before it is too late: Make agriculture truly sustainable now for food security in a changing climate (pp. 266-275). UNCTAD/DITC/TED/2012/3: United Nations Publication.

Gagern, A., \& van den Bergh, J. (2013). A critical review of fishing agreements with tropical developing countries. Marine Policy, 38, 375-386. doi:10.1016/j.marpol.2012.06.016

Geier, B. (2007). IFOAM and the history of the international organic movement. In W. Lockeretz (Ed.), Organic farming: An international history. Trowbridge: Cromwell Press.

Gemmill, B., \& Bamidele-Izu, A. (2002). The role of NGOs and civil society in global environmental governance. In D. C. Esty \& M. H. Ivanova (Eds.), Global environmental governance: Options and opportunities (pp. 77100). Princeton, NJ: Yale School of Forestry and Environmental Studies.

Gereffi, G., Humphrey, J., \& Sturgeon, T. (2005). The governance of global value chains. Review of International Political Economy, 12(1), 78-104. doi:10.1080/09692290500049805

Gibbon, P. (2008). An analysis of standards-based regulation in the EU organic sector, 1991-2007. Journal of Agrarian Change, 8(4), 553-582. doi:10.1111/j.1471-0366.2008.00180.x 
Glasbergen, P. (2007). Setting the scene: The partnership paradigm in the making. In P. Glasbergen, F. Biermann, \& A. Mol (Eds.), Partnerships, governance and sustainable development: Reflections on theory and practice (pp. 1-28). Cheltenham, UK: Edward Elgar Publishing Limited.

Glasbergen, P. (2009, December). Meta-governance as a challenge. An analysis of global private governance for sustainable development. Paper presented at the Conference on the Human Dimensions of Global Environmental Change, Amsterdam.

Glasbergen, P. (2011). Mechanisms of private meta-governance: An analysis of global private governance for sustainable development. International Journal of Strategic Business Alliances, 2(3), 189-206. doi:10.1504/ijsba.2011.040886

Glasbergen, P. (2013). Legitimation of certifying partnerships in the global market place. Environmental Policy and Governance, 23(6), 354-367. doi:10.1002/eet.1625

GOMA. (2012). Proceedings of the global organic market access conference - February 2012. Retrieved from http://www.fao.org/docrep/015/an909e/an909e00.pdf

Gould, D. (2015). The organic market framework: Becoming organic 3.0. In H. Willer \& J. Lernoud (Eds.), The world of organic agriculture. Statistics and emerging trends 2015. FiBL-IFOAM Report. (pp. 137-140). Bonn: Research Institute of Organic Agriculture (FiBL), Frick, and IFOAM Organics International.

Green, J. F. (2005). Engaging civil society in global governance: lessons for member states and advice for civil society. Global Environmental Change, 15(1), 69-72. doi:10.1016/j.gloenvcha.2004.09.002

Guéneau, S. (2007). Certification as a new private global forest governance system: the regulatory potentialof the Forest Stewardship Council. In A. Peters, L. Koechlin, T. Forster, \& G. F. Zinkernagel(Eds.), Non-state actors as standard setters (pp. 379-408). Cambridge, UK: Cambridge University Press.

Gupta, A., Pistorius, T., \& Vijge, M. J. (2016). Managing fragmentation in global environmental governance: The REDD+ partnership as bridge organization. International Environmental Agreements, 16(3), 1-20. doi: 10.1007/s10784-015-9274-9

Guthman, J. (2004). The trouble with 'organic lite' in California: A rejoinder to the 'conventionalisation' debate. Sociologia Ruralis, 44(3), 301-316. doi:10.1111/j.1467-9523.2004.00277.x

Hafner, G. (2004). Pros and cons ensuing from fragmentation of international law. Michigan Journal of International Law, 25(4), 849-868.

Hassel, A. (2008). The evolution of a global labor governance regime. Governance, 21(2), 231-251. doi:10.1111/j.1468-0491.2008.00397.x

Held, D., \& Young, K. (2013). Global governance in crisis? Fragmentation, risk and world order. International Politics, 50(3), 309-332. doi:10.1057/ip.2013.9

Helfen, M., \& Sydow, J. (2013). Negotiating as institutional work: The case of labour standards and international framework agreements. Organization Studies, 34(8), 1073-1098. doi:10.1177/0170840613492072

Henderson, J., Dicken, P., Hess, M., Coe, N., \& Yeung, H. W. C. (2002). Global production networks and the analysis of economic development. Review of International Political Economy, 9(3), 436-464. doi: 10.1080/09692290210150842

Hendrickx, F. (2018). Regulating new ways of working: From the new 'wow' to the new 'how'. European Labour Law Journal, 9(2), 195-205. doi:10.1177/2031952518781449

Hendrickx, F., Marx, A., Rayp, G., \& Wouters, J. (2016). The architecture of global labour governance. International Labour Review, 155(3), 339-355. doi:10.1111/j.1564-913X.2015.00039.x

Henson, S., \& Humphrey, J. (2009). The Impacts of Private Food Safety Standards on the Food Chain and on Public Standard-Setting Processes. Retrieved from Food and Agriculture Organization of the United Nations website: http://www.fao.org/3/a-i1132e.pdf

Hepple, B. (2005). Labour laws and global trade. Oxford and Portland: Hart Publishing.

Hicks, B. L. (1999). Treaty congestion in international environmentallaw: The need for greater international coordination. University of Richmond Law Review, 32(4), 1643-1674. 
Huber, B., Schmid, O., \& Mannigel, C. (2015). Standards and regulations. In H. Willer \& J. Lernoud (Eds.), The world of organic agriculture. Statistics and emerging trends 2015. FiBL-IFOAM Report. (pp. 126-133). Bonn: Research Institute of Organic Agriculture (FiBL), Frick, and IFOAM Organics International.

Huber, B., Schmid, O., \& Möller, C. (2016). Standards and regulations. In The world of organic agriculture. Statistics and emerging trends 2016. FiBL-IFOAM Report. (pp. 140-146). Bonn: Research Institute of Organic Agriculture (FiBL), Frick, and IFOAM Organics International.

Ibnu, M., Glasbergen, P., Offermans, A., \& Arifin, B. (2015). Farmer preferences for coffee certification: A conjoint analysis of the Indonesian smallholders. Journal of Agricultural Science, 7(6), 20-34. doi:10.5539/jas.v7n6p20

IFOAM. (2014a). Family benefits frame. Retrieved from http://www.ifoam.bio/sites/default/files/family_ benefits_frame_web.pdf

IFOAM. (2014b). The IFOAM norms for organic production and processing. Version 2014. Retrieved from http://www.ifoam.bio/sites/default/files/ifoam_norms_version_july_2014.pdf

IFOAM. (2016a). The IFOAM family of standards. Retrieved from http://www.ifoam.bio/en/ifoam-familystandards

IFOAM. (2016b). Participatory guarantee systems (PGS). Retrieved from http://www.ifoam.bio/en/organicpolicy-guarantee/participatory-guarantee-systems-pgs

IFOAM EU. (2013, November). IFOAM EU input on the consultation document on the "European action plan on organic food and farming". Paper presented at the Advisory Group on Organic Farming, Brussels.

Ikerd, J. (2006). Contradictions of principles in organic farming. In P. Kristiansen, A. Taji, \& J. Reganold (Eds.), Organic agriculture: A global perspective (pp. 221-229). Collingwood: CSIRO Publishing.

ILO. (2013). The Oslo Declaration: Restoring confidence in jobs and growth. Ninth European Regional Meeting, Oslo, Norway, 8-11 April, ERM.9/D.7. Retrieved from http://www.ilo.org/wcmsp5/groups/public/--ed_norm/---relconf/documents/meetingdocument/wcms_210356.pdf

ILO. (2016). Assessment of labour provisions in trade and investment arrangements. Retrieved from http://www.ilo.org/wcmsp5/groups/public/---dgreports/---inst/documents/publication/wcms_498944.pdf

ILO. (2017). Handbook on assessment of labour provisions in trade and investment arrangements. Retrieved from https://www.ilo.org/wcmsp5/groups/public/---dgreports/---inst/documents/publication/wcms_564702.pdf

ILO. (n.d.). About the ILO. Retrieved from https://www.ilo.org/global/about-the-ilo/lang--en/index.htm Ingram, R. T. (2008). Ten Basic Responsibilities of Nonprofit Boards (2nd ed.). Washington, DC: BoardSource.

International Law Commission. (2000). Yearbook of the International Law Commission. Report of the Commission to the General Assembly on the work of its fifty-second session (Report No. A/CN.4/SER.A/2000/Add.1 (Part 2)/Rev.1). Retrieved from United Nations Office of Legal Affairs website: http://legal.un.org/ilc/publications/yearbooks/english/ilc_2000_v2_p2.pdf

International Law Commission. (2006). Fragmentation of international law: Difficulties arising from the diversification and expansion of international law. Report of the study group of the international law commission (Report No. A/CN.4/L.682). Retrieved from United Nations Office of Legal Affairs website: http://legal.un.org/ilc/documentation/english/a_cn4_1682.pdf

ISEAL Alliance. (2015). About us. Retrieved from http://www.isealalliance.org/about-us

Ivanova, M., \& Roy, J. (2007). The architecture of global environmental governance: Pros and cons of multiplicity. In L. Swart \& E. Perry (Eds.), Global environmental governance: Perspectives on the current debate. New York: Center for UN Reform Education.

Jänicke, M., \& Jacob, K. (2006). Lead markets for environmental innovations: A new role for the nation state. In M. Jänicke \& K. Jacob (Eds.), Environmental governance in global perspective: New approaches to ecological modernisation (pp. 30-50). Berlin: Freie Universität Berlin.

Janssen, M., \& Hamm, U. (2011). Consumer perception of different organic certification schemes in five European countries. Organic Agriculture, 1(1), 31-43. doi:10.1007/s13165-010-0003-y

Jenks, C. W. (1953). The conflict of law-making treaties. British Year Book of International Law, 30, 401-453. 
Jentoft, S., van Son, T. C., \& Bjørkan, M. (2007). Marine protected areas: A governance system analysis. Human Ecology, 35(5), 611-622. doi:10.2307/27654227

Jessop, B. (1997). Capitalism and its future: Remarks on regulation, government and governance. Review of International Political Economy, 4(3), 561-581. doi:10.1080/096922997347751

Jessop, B. (1998). The rise of governance and the risks of failure: The case of economic development. International Social Science Journal, 50(155), 29-45. doi:10.1111/1468-2451.00107

Jessop, B. (2002). The Future of the Capitalist State. Cambridge, UK: Polity.

Jessop, B. (2009). From governance to governance failure and from multi-level governance to multi-scalar metagovernance. In B. L. Arts, A.; van Houtum, H (Ed.), The disoriented state: Shifts in governmentality, territoriality and governance (pp. 79-98). Dordrecht: Springer.

Jessop, B. (2011). Metagovernance. In M. Bevir (Ed.), The SAGE Handbook of Governance (pp. 106-124). London: SAGE Publications Ltd.

Jones, T. (2002). Policy coherence, global environmental governance, and poverty reduction. International Environmental Agreements, 2(4), 389-401. doi:10.1023/a:1021319804455

Jordan, A. (2008). The governance of sustainable development: Taking stock and looking forwards. Environment and Planning C: Government and Policy, 26(1), 17-33. doi:10.1068/cav6

Kalfagianni, A., \& Pattberg, P. (2013). Fishing in muddy waters: Exploring the conditions for effective governance of fisheries and aquaculture. Marine Policy, 38(0), 124-132. doi:10.1016/j.marpol.2012.05.028

Klijn, E. H., \& Edelenbos, J. (2007). Meta-governance as network management. In E. Sørensen \& J. Torfing (Eds.), Theories of democratic network governance. Great Britain: Palgrave Macmillan.

Kolk, A. (2013). Mainstreaming sustainable coffee. Sustainable Development, 21(5), 324-337. doi:10.1002/sd.507

Kooiman, J. A. N., \& Jentoft, S. (2009). Meta-governance: Values, norms and principles, and the making of hard choices Public Administration, 87(4), 818-836. doi:10.1023/a:1021319804455

Koskenniemi, M., \& Leino, P. (2002). Fragmentation of international law? Postmodern anxieties. Leiden Journal of International Law, 15(3), 553-579. doi:10.1017/S0922156502000262

KRAV. (2018). KRAV is a key player in the organic market in Sweden since 1985. Retrieved from http://www.krav.se/in-english/

Kristiansen, P. (2006). Overview of organic agriculture. In P. Kristiansen, A. Taji, \& J. Reganold (Eds.), Organic agriculture: A global perspective (pp. 1-23). Collingwood: CSIRO Publishing.

Kuit, M., Rijn, F. C. v., \& Jansen, D. M. (2010). Assessing 4C implementation among small-scale producers. An evaluation of the effects of $4 C$ implementation in Vietnam, Uganda and Nicaragua. Retrieved from SustainabilityXchange website: http://www.sustainabilityxchange.info/filesagri/4C_Impact_Assesment_ Outcome_Summary.pdf

La Hovary, C. (2015). A challenging ménage à trois? Tripartism in the International Labour Organization. International Organizations Law Review, 12(1), 204-236. doi:10.2139/ssrn.2684455

La Hovary, C. (2018). The ILO's mandate and capacity: Creating, proliferating and supervising labour standards for a globalized economy. In H. Gött (Ed.), Labour standards in international economic law (pp. 37-55): Springer International Publishing. doi:10.1007/978-3-319-69447-4

Lindroos, A., \& Mehling, M. (2005). Dispelling the chimera of 'self-contained regimes' international law and the WTO. European Journal of International Law, 16(5), 857-877. doi:10.1093/ejil/chi148

Locke, R., Amengual, M., \& Mangla, A. (2009). Virtue out of necessity? Compliance, commitment, and the improvement of labor conditions in global supply chains. Politics \& Society, 37(3), 319-351. doi:10.1177/0032329209338922

Lockeretz, W. (Ed.) (2007). Organic Farming: An International History. TrowBridge: Cromwell Press.

Loureiro, M. L., McCluskey, J. J., \& Mittelhammer, R. C. (2001). Assessing consumer preferences for organic, eco-labeled, and regular apples. Journal of Agricultural and Resource Economics, 26(2), 404-416.

Macdonald, K. (2014). The Politics of Global Supply Chains. Cambridge: Polity Press. 
Machado-da-Silva, C. L., Filho, E. R. G., \& Rossoni, L. (2006). Organizational fields and the structuration perspective: Analytical possibilities. BAR. Brazilian Administration Review, 3(2), 32-56. doi:10.1590/ S1415-65552006000500009

Mapusua, K. (2012). The Pacific Islands. In H. Willer \& L. Kilcher (Eds.), The world of organic agriculture. Statistics and emerging trends 2012. FiBL-IFOAM report. Bonn: Research Institute of Organic Agriculture (FiBL), Frick, and IFOAM Organics International.

Mapusua, K. (2016). The Pacific Islands. In H. Willer \& J. Lernoud (Eds.), The world of organic agriculture. Statistics and emerging trends 2016. FiBL-IFOAM report. (pp. 273-280). Bonn: Research Institute of Organic Agriculture (FiBL), Frick, and IFOAM Organics International.

Mapusua, K. (2017). The Pacific Islands. In H. Willer \& J. Lernoud (Eds.), The world of organic agriculture. Statistics and emerging trends 2017. FiBL-IFOAM report. (pp. 282-289). Bonn: Research Institute of Organic Agriculture (FiBL), Frick, and IFOAM Organics International.

Mapusua, K., \& Maccari, M. (2007). An overview of organic agriculture in the Pacific. Retrieved from International Federation of Organic Agriculture Movements website: http://www.ifoam.bio/sites/default/ files/page/ files/ oa_pacific_web.pdf

Marx, A. (2008). Limits to non-state market regulation: A qualitative comparative analysis of the international sport footwear industry and the Fair Labor Association. Regulation \& Governance, 2(2), 253-273. doi:10.1111/j.1748-5991.2008.00037.x

Marx, A., Brando, N., \& Lein, B. (2017). Strengthening labour rights provisions in bilateral trade agreements: Making the case for voluntary sustainability standards. Global Policy, 8(S3), 78-88. doi:10.1111/17585899.12397

Marx, A., \& Wouters, J. (2015). Competition and cooperation in the market of voluntarysustainability standards. In P. Delimatsis (Ed.), The law, economics and politics of international standardisation (pp. 215241). Cambridge: Cambridge University Press.

Maupain, F. (2013). The ILO regular supervisory system: A model in crisis? International Organizations Law Review, 10(1), 117-165. doi:10.1163/15723747-01001004

Maupain, F. (2015). Revisiting the future. International Labour Review, 154(1), 103-114. doi:10.1111/j.1564913X.2015.00233.X

May, P. J., Sapotichne, J., \& Workman, S. (2006). Policy coherence and policy domains. Policy Studies Journal, 34(3), 381-403. doi:10.1111/j.1541-0072.2006.00178.x

McGaughey, E. (2018). Uber, the Taylor Review, mutuality and the duty not to misrepresent employment status. Industrial Law Journal. Advance online publication. doi:10.1093/indlaw/dwy014

Meadowcroft, J. (2007). Who is in charge here? Governance for sustainable development in a complex world. Journal of Environmental Policy and Planning, 9(3), 299-314. doi:10.1080/15239080701631544

Meardi, G., \& Marginson, P. (2014). Global labour governance: Potential and limits of an emerging perspective. Work, Employment and Society, 28(4), 651-662. doi:10.1177/0950017014534007

Meliado, F. (2017). Private standards, trade, and sustainable development: Policy options for collective action. Geneva: International Centre for Trade and Sustainable Development.

Meuleman, L. (2006, June). Internal meta-governance as a new challenge for management development in public administration. Paper presented at the EFMD conference on Post Bureaucratic Management: A New Age of Public Services, Aix-en Provence.

Mickwitz, P., Aix, F., Beck, S., Carss, D., Ferrand, N., Görg, C., . . . van Bommel, S. (2009). Climate policy integration, coherence and governance (Report No. 2). Retrieved from Partnership for European Environmental Research website: https://www.peer.eu/files/user_upload/user_upload/publications/ PEER_Report2.pdf

Mohler, C. L. (2009). Introduction. In C. L. Mohler \& J. S. E. (Eds.), Crop rotation on organic farms: A planning manual. Ithaca, NY: NRAES. 
Mola, L. (2016). Governance of financial crises: A role for the international protection of economic and social rights? In P. Pazartzis \& M. Gavouneli (Eds.), Reconceptualising the rule of law in global governance, resources, investment and trade (pp. 105-120). Oxford: Hart Publishing.

Möller, C., \& Huber, B. (2016). Survey October 2015, update December 2016. In The world of organic agriculture. Statistics and emerging trends 2017. FiBL-IFOAM Report. Bonn: Research Institute of Organic Agriculture (FiBL), Frick, and IFOAM Organics International.

Montesquieu. (1977). Book XXIX. Of the manner of composing laws. The spirit of laws, 1748. In D. W. Carrithers (Ed.), A compendium of the first English edition. Berkeley, Los Angeles, London: University of California Press.

Morgera, E., Caro, C. B., \& Durán, G. M. (2012). Organic agriculture and the law. Rome: Food and Agriculture Organization of the United Nations.

Moses, J. W., \& Knutsen, T. L. (2012). Ways of Knowing: Competing methodologies in social and political research (2nd ed.). Hampshire: Palgrave Macmillan.

Mutersbaugh, T. (2005). Fighting standards with standards: Harmonization, rents and social accountability in certified agrofood networks. Environment and Planning A, 37(11), 2033-2051. doi:10.1068/a37369

Muwanga, M. K. (2011). The East African Organic Products Standard (EAOPS). A tool to overcome constraints and increase trade in organic product from East Africa [PowerPoint slides]. Retrieved from European Commission website: http://ec.europa.eu/agriculture/events/2011/organic-africa-2011/muwanga_en.pdf

Nadvi, K. (2008). Global standards, global governance and the organization of global value chains. Journal of Economic Geography, 8(3), 323-343. doi:10.1093/jeg/lbn003

Nadvi, K., \& Wältring, F. (2004). Making sense of global standards. In H. Schmitz (Ed.), Local Enterprises in the Global Economy (pp. 53-94). Cheltenham, UK: Edward Elgar Publishing Limited.

Naqvi, A. (2009). The UNEP-UNCTAD CBTF activities for promotion of trade in organic agriculture. In H. Willer \& L. Kilcher (Eds.), The world of organic agriculture. Statistics and emerging trends 2009 (pp. 88-93). Bonn: Research Institute of Organic Agriculture (FiBL), Frick, and IFOAM Organics International.

Ndungu, S. K. (2015). Organic trade and value chain development in East Africa (OTEA). Baseline study 2015 report. Kenya, Uganda, Tanzania, Rwanda and Burundi. Unpublished report.

O'Rourke, D. (2003). Outsourcing regulation: Analyzing nongovernmental systems of labor standards and monitoring. Policy Studies Journal, 31(1), 1-29. doi:10.1111/1541-0072.00001

Oberthür, S. (2009). Interplay management: Enhancing environmental policy integration among international institutions. International Environmental Agreements, 9(4), 371-391. doi:10.1007/s10784-009-9109-7

Oberthür, S., \& Gehring, T. (2004). Reforming international environmental governance: An institutionalist critique of the proposal for a world environment organisation. International Environmental Agreements, 4, 359-381. doi:10.1007/s10784-004-3095-6

Oberthür, S., \& Stokke, O. S. (Eds.). (2011). Managing institutional complexity: Regime interplay and global environmental change. Cambridge, MA: The MIT Press.

OECD. (2013). Interconnected economies: Benefiting from global value chains. Retrieved from Organisation for Economic Co-operation and Development Publishing: https://read.oecd-ilibrary.org/science-andtechnology/interconnected-economies_9789264189560-en\#page4

Overdevest, C., \& Zeitlin, J. (2014). Assembling an experimentalist regime: Transnational governance interactions in the forest sector. Regulation \& Governance, 8(1), 22-48. doi:10.1111/j.17485991.2012.01133.x

Parker, B., \& Selsky, J. W. (2004). Interface dynamics in cause-based partnerships: An exploration of emergent culture. Nonprofit and Voluntary Sector Quarterly, 33(3), 458-488. doi:10.1177/0899764004266016

Parker, J., Arrowsmith, J., Fells, R., \& Prowse, P. (2016). The living wage: concepts, contexts and future concerns. Labour \& Industry: a journal of the social and economic relations of work, 26(1), 1-7. doi:10.1080/ 10301763.2016.1154671

Parkins, J. R. (2008). The metagovernance of climate change: Institutional adaptation to the Mountain Pine Beetle epidemic in British Columbia. Journal of Rural and Community Development, 3(2), 7-26. 
Paton, G. J. (2011). Seeking sustainability: On the prospect of an ecological liberalism. Oxon: Routledge.

Pattberg, P. H. (2004). Private environmental governance and the sustainability transition: Functions and impacts of NGO-business partnerships. In K. Jacob, M. Binder, \& A. Wieczorek (Eds.), Governance for industrial transformation (pp. 52-66). Berlin: Proceedings of the 2003 Berlin Conference on the Human Dimensions of Global Environmental Change, Environmental Policy Research Centre.

Pattberg, P. H. (2007). Private Institutions and Global Governance: The New Politics of Environmental Sustainability. Cheltenham, UK: Edward Elgar Publishing Limited.

Pattberg, P. H., \& Widerberg, O. (2015). Theorising global environmental governance: Key findings and future questions. Millennium - Journal of International Studies, 43(2), 684-705. doi:10.1177/0305829814561773

Pekdemir, C. (2018). On the regulatory potential of regional organic standards: Towards harmonization, equivalence, and trade? Global Environmental Change, 50, 289-302. doi:10.1016/j.gloenvcha.2018.04.010

Pekdemir, C., Glasbergen, P., \& Cörvers, R. (2015). On the transformative capacity of private fair labour arrangements. In A. Marx, J. Wouters, G. Rayp, \& L. Beke (Eds.), Global governance of labour rights (pp. 209-229). Cheltenham, UK: Edward Elgar Publishing Limited.

Pekdemir, C., Glasbergen, P., \& von Gagern, S. (2016). Private meta-governors and their practices: An inventory of their mechanisms of change. International Journal of Strategic Business Alliances, 5(2), 133-154. doi:10.1504/IJSBA.2016.079385

Peters, B. G. (2007). The meta-governance of policy networks: Steering at a distance, but still steering (Working Paper No. 78/2007). Retrieved from Universidad Autónoma de Madrid website: http://www.uam.es/ ss/Satellite/Derecho/es/home.htm

Pierrot, J., Giovannucci, D., \& Kasterine, A. (2011). Trends in the Trade of Certified Coffees. Retrieved from International Trade Centre website: http://www.intracen.org/Trends-in-the-trade-of-certified-coffees/

Ramus, C. A., \& Montiel, I. (2005). When are corporate environmental policies a form of greenwashing? Business \& Society, 44(4), 377-414. doi:10.1177/0007650305278120

Raynolds, L. T. (2004). The globalization of organic agro-food networks. World Development, 32(5), 725-743. doi:10.1016/j.worlddev.2003.11.008

Reinecke, J., Manning, S., \& von Hagen, O. (2012). The Emergence of a Standards Market: Multiplicity of Sustainability Standards in the Global Coffee Industry. Organization Studies, 33(5-6), 791-814. doi: $10.1177 / 0170840612443629$

Rhodes, R. A. W. (1996). The new governance: Governing without government. Political Studies, 44(4), 652667. doi:10.1111/j.1467-9248.1996.tb01747.x

Rhodes, R. A. W. (1997). Understanding governance: Policy networks, governance, reflexivity and accountability. Buckingham: Open University Press.

Rosenau, J. (2003). Globalization and governance: Bleak prospects for sustainability. Internationale Politik und Gesellschaft, 3, 11-29.

Rosin, C., \& Campbell, H. (2009). Beyond bifurcation: Examining the conventions of organic agriculture in New Zealand. Journal of Rural Studies, 25(1), 35-47. doi:10.1016/j.jrurstud.2008.05.002

Ruggie, J. G. (2004). Reconstituting the global public domain — issues, actors, and practices. European Journal of International Relations, 10(4), 499-531. doi:10.1177/1354066104047847

Rundgren, G. (2014). Global eating disorder. Uppsala, Sweden: Regeneration.

Sahota, A. (2018). The global market for organic food \& drink. In H. Willer \& J. Lernoud (Eds.), The world of organic agriculture. Statistics and emerging trends 2018. FiBL-IFOAM report. Bonn: Research Institute of Organic Agriculture (FiBL), Frick, and IFOAM Organics International.

Saldana, J. (2009). The coding manual for qualitative researchers. London: SAGE Publications Ltd.

Sayer, A. (2000). Realism and social science. London: Sage.

Schäferhoff, M., Campe, S., \& Kaan, C. (2009). Transnational public-private partnerships in international relations: Making sense of concepts, research frameworks, and results. International Studies Review, 11(3), 451-474. doi:10.1111/j.1468-2486.2009.00869.x 
Scherer, A. G., \& Smid, M. (2000). The downward spiral and the U.S. model business principles. Why MNEs should take responsibility for the improvement of world-wide social and environmental conditions. Management International Review, 40(4), 351-371.

Schlüter, M., \& Blake, F. (2009). History of the EU organic regulation and its recent revision. In C. Mikkelsen \& M. Schlüter (Eds.), The new EU regulation for organic food and farming: (EC) No 834/2007. Background, assessment, interpretation (pp. 8-13). Retrieved from the IFOAM EU Group website: http://www.ifoameu.org/sites/default/files/page/files/ifoameu_reg_organic_regulation_dossier_2009_en.pdf

Schmid, O., Huber, B., Ziegler, K., Jespersen, L. M., Hansen, J. G., Plakolm, G., . . Padel, S. (2007). Analysis of EEC Regulation 2092/91 in relation to other national and international organic standards. Retrieved from Organic Eprints website: http://orgprints.org/13101/1/schmid-etal-2007-final-report_organic-revision.pdf

Schmidt, H. (2011). A private concept's take-over by government and the continued leading role of the private sector. In B. M. J. van der Meulen (Ed.), Private food law: Governing food chains through contract law, selfregulation, private standards, audits and certification schemes (pp. 289-300). Wageningen Academic Publishers.

Schouten, G., \& Glasbergen, P. (2011). Creating legitimacy in global private governance: The case of the Roundtable on Sustainable Palm Oil. Ecological Economics, 70(11), 1891-1899. doi:10.1016/j.ecolecon. 2011.03.012

Schwindenhammer, S. (2015, July). Global organic agriculture governance through standards - When interinstitutional policy-making oscillates between global harmonization and regional integration. Paper presented at the International Conference on Public Policy, Milan.

Scott, C., \& Brown, C. (2010). Regulatory capacity and networked governance (Working Paper No. 2). Retrieved from University College Dublin website: http://www.ucd.ie/geary/static/publications/workingpapers/ gearywp201043.pdf

Secretariat of the Pacific Community. (2008). Pacific organic standard. Retrieved from http://www.spc.int/ 1rd/organic-pasifika-publications/cat_view/364-pacific-organic/ 369-pacific-organic-standard

Selsky, J. W., \& Parker, B. (2005). Cross-sector partnerships to address social issues: Challenges to theory and practice. Journal of Management, 31(6), 849-873. doi:10.1177/0149206305279601

Seufert, V., Ramankutty, N., \& Mayerhofer, T. (2017). What is this thing called organic? - How organic farming is codified in regulations. Food Policy, 68(C), 10-20. doi:10.1016/j.foodpol.2016.12.009

SFP. (2010). FishSource, reduction fisheries and aquaculture. Retrieved from http://cmsdevelopment. sustainablefish.org.s3.amazonaws.com/2011/03/21/SFP_Brief_FS_Reduc-3-193919e6.pdf

SFP. (n.d.-a). About SFP. Retrieved from https://www.sustainablefish.org/about-us

SFP. (n.d.-b). Global ocean health program. Retrieved from https://www.sustainablefish.org/global-programs/ global-ocean-health

Sianes, A. (2013). Shedding light on policy coherence for development: A conceptual framework. Journal of International Development, 29(1), 134-146. doi:10.1002/jid.2977

Smith, T. M., \& Fischlein, M. (2010). Rival private governance networks: Competing to define the rules of sustainability performance. Global Environmental Change, 20(3), 511-522. doi:10.1016/j. gloenvcha.2010.03.006

Sobel-Read, K. B. (2014). Global value chains: A framework for analysis. Transnational Legal Theory, 5(3), 364407. doi:10.5235/20414005.5.3.364

Sørensen, E. (2006). Metagovernance: The changing role of politicians in processes of democratic governance. The American Review of Public Administration, 36(1), 98-114. doi:10.1177/0275074005282584

Stephenson, S. (2013). Global value chains: The new reality of international trade. E15Initiative. Retrieved from the E15 Initiative website: http://e15initiative.org/wp-content/uploads/2015/09/E15-GVCs-StephensonFinal.pdf

Steurer, R. (2013). Disentangling governance: A synoptic view of regulation by government, business and civil society. Policy Sciences, 46(4), 387-410. doi:10.1007/s11077-013-9177-y 
Stoker, G. (1998). Governance as theory: Five propositions. International Social Science Journal, 50(155), 17-28. doi:10.1111/1468-2451.00106

Stupak, I., Lattimore, B., Titus, B. D., \& Tattersall Smith, C. (2011). Criteria and indicators for sustainable forest fuel production and harvesting: A review of current standards for sustainable forest management. Biomass and Bioenergy, 35(8), 3287-3308. doi:10.1016/j.biombioe.2010.11.032

Taylor, A. (2006). Overview of the current state of organic agriculture in Kenya, Uganda and the United Republic of Tanzania and the opportunities for regional harmonisation. Retrieved from the United Nations Conference on Trade and Development website: http://unctad.org/en/Docs/ditcted200516_en.pdf

TCC. (2008). Sweetness follows: A rough guide towards a sustainable cocoa sector (2nd ed.). Retrieved from the Cocoa Barometer website: http://www.cocoabarometer.org/cocoa_barometer/Download_files/Sweetness \%20Follows\%202008.pdf

Torfing, J. (2012). Governance networks. In D. Levi-Faur (Ed.), The Oxford handbook of governance (pp. 99112). New York: Oxford University Press.

Torfing, J., Peters, B. G., Pierre, J., \& Sørensen, E. (2012). Metagovernance: The art of governing interactive governance. In J. Torfing, B. G. Peters, J. Pierre, \& E. Sørensen (Eds.), Interactive Governance: Advancing the Paradigm (pp. 1-26). New York: Oxford University Press.

Twarog, S. (2008). East African organic products standard and more. In H. Willer, M. Yussefi-Menzler, \& N. Sorensen (Eds.), The world of organic agriculture. Statistics and emerging trends 2008 (pp. 71-72). Bonn: Research Institute of Organic Agriculture (FiBL), Frick, and IFOAM Organics International.

Twarog, S. (2011). International partnership for sustainable development: Promoting production and trade of organic agriculural products in East Africa. Retrieved from the Organisation for Economic Co-operation and Development website: http://www.oecd.org/aidfortrade/47718557.pdf

Twarog, S. (2013). Policies and actions to support organic agriculture. In N. Halberg \& A. Muller (Eds.), Organic agriculture for sustainable livelihoods (pp. 180-203). Oxon: Routledge.

UNCTAD. (2012, Februrary 17). Eased united states: European union flow of organic products approved; meeting also sees adoption of Asian regional organic standard [Press Release]. Retrieved from http://unctad.org/en/pages/PressRelease.aspx?OriginalVersionID=92

UNCTAD, FAO, \& IFOAM. (2012). Asia Regional Organic Standard (AROS). Retrieved from the Organisation for Economic Co-operation and Development website: http://www.fao.org/docrep/015/an765e /an765e00.pdf

UNDP. (2008). Capacity assessment practice note. Retrieved from http://www.undp.org/content/ dam/aplaws/publication/en/publications/capacity-development/capacity-assessment-practice-note/ Capacity\%20Assessment\%20Practice\%20Note.pdf

UNEP. (n.d.). Aid for trade case story: The East African organic products standard. Retrieved from the Organisation for Economic Co-operation and Development website: http://www.oecd.org/ aidfortrade/47719232.pdf

USDA. (n.d.). Fraudulent organic certificates. Retrieved from https://www.ams.usda.gov/services/ enforcement/organic/fraudulent-certificates

van Asselt, H. (2014). The fragmentation of global climate governance: Consequences and management of regime interactions. Cheltenham, UK: Edward Elgar Publishing Limited.

van Asselt, M. B. A., van 't Klooster, S. A., van Notten, P. W. F., \& Smits, L. A. (2010). Foresight in Action: Developing Policy-Oriented Scenarios. London, UK: Earthscan.

van der Ploeg, L., \& Vanclay, F. (2013). Credible claim or corporate spin?: A checklist to evaluate corporate sustainability reports. Journal of Environmental Assessment Policy and Management, 15(3), 1-21. doi:10.1142/s1464333213500129

Van Huijstee, M. M., Pollock, L., Glasbergen, P., \& Leroy, P. (2011). Challenges for NGOs partnering with corporations: WWF Netherlands and the Environmental Defense Fund. Environmental Values, 20(1), 4374. doi:10.3197/096327111X12922350166030 
Verbeek, B. (2011). Regime theory in International Relations. In K. Dowding (Ed.), Encyclopedia of power (pp. 559-562). Thousand Oaks, California: SAGE Publications, Inc.

Vermeulen, W. J. V. (2015). Self-governance for sustainable global supply chains: Can it deliver the impacts needed? Business Strategy and the Environment, 24(2), 73-85. doi:10.1002/bse.1804

Vogel, D., \& Kagan, R. A. (2002). An introduction. In Dynamics of regulatory change: How globalization affects national regulatory policies. Berkeley: University of California Press.

Vogl, C. R., Kilcher, L., \& Schmidt, H. (2005). Are standards and regulations of organic farming moving away from small farmers' knowledge? Journal of Sustainable Agriculture, 26(1), 5-26. doi:10.1300/ J064v26n01_03

Wai, O. K. (2015). Organic Asia 2014. In H. Willer \& J. Lernoud (Eds.), The world of organic agriculture. Statistics and emerging trends 2015. FiBL-IFOAM report. (pp. 154-162). Bonn: Research Institute of Organic Agriculture (FiBL), Frick, and IFOAM Organics International.

Wallach, L. M. (2002). Accountable governance in the era of globalization: The WTO, NAFTA, and international harmonization of standards. University of Kansas Law Review, 50(4), 823-866.

WCF. (2012a). CocoamAP program will track global cocoa sustainability. Retrieved from http://worldcocoafoundation.org

WCF. (2012b). WCF welcomes new members \& staff. Retrieved from http://worldcocoafoundation.org

WCF. (2015). CocoaAction progress report. November 2015. Retrieved from http://worldcocoafoundation.org/ wp-content/uploads/CocoaAction-Progress-Report-Collaboration-November-2015-ENGLISH.pdf

WCF. (n.d.-a). Our impact. Retrieved from http://worldcocoafoundation.org

WCF. (n.d.-b). Refining CocoaMAP biodiversity indicators and data collection methods. BACP WCF Grant-019, Deliverable 5. Retrieved from International Finance Corporation website: http://www.ifc.org/ wps/wcm/connect/f73e8a00432597608869ee19fbe4b2fe/WCF_cocoa_cocoamap_biodiversity_indicators _report.pdf?MOD=AJPERES

Whitehead, M. (2003). 'In the shadow of hierarchy': Meta-governance, policy reform and urban regeneration in the West Midlands. Area, 35(1), 6-14. doi:10.2307/20004284

Willer, H., \& Lernoud, J. (Eds.). (2018). The world of organic agriculture. Statistics and emerging trends 2018. FiBL-IFOAM report. Bonn: Research Institute of Organic Agriculture (FiBL), Frick, and IFOAM Organics International.

Williams, O. D., \& Rushton, S. (2011). Private actors in global health governance. In S. Rushton \& O. D. Williams (Eds.), Partnerships and foundations in global health governance (pp. 1-25). Hampshire: Palgrave Macmillan.

Winickoff, D. E., \& Klein, K. (2011). Food labels and the environment: Towards harmonization of EU and US organic standards. In D. David Vogel \& J. F. M. Swinnen (Eds.), Transatlantic regulatory cooperation: The shifting roles of the EU, the US and California. Cheltenham, UK: Edward Elgar Publishing Limited.

Winship, C. (2006). Policy analysis as puzzle solving. In M. Moran, M. Rein, \& R. E. Goodin (Eds.), The Oxford handbook of public policy (pp. 109-123). Oxford: Oxford University Press.

Wouters, J., \& Geraets, D. (2012). Private food standards and the World Trade Organization: Some legal considerations (Working Paper No. 82). Retrieved from Humanities and Social Sciences Group, Katholieke Universiteit Leuven website: http://ghum.kuleuven.be/ggs/publications/working_papers /new_series/wp81-90/wp82.pdf

Young, I. M. (2004). Responsibility and global labor justice. Journal of Political Philosophy, 12(4), 365-388. doi:10.1111/j.1467-9760.2004.00205.x

Young, I. M. (2006). Responsibility and global justice: A social connection model. Social Philosophy and Policy, 23(01), 102-130. doi:10.1017/S0265052506060043

Zandvliet, R., \& van der Heijden, P. (2015). The rapprochement of ILO standards and CSR mechanisms: towards a positive understanding of the 'privatization' of international labour standards. In A. Marx, J. Wouters, G. Rayp, \& L. Beke (Eds.), Global governance of labour rights (pp. 170-189). Cheltenham, UK: Edward Elgar Publishing Limited. 
Zelli, F., \& van Asselt, H. (2013). The institutional fragmentation of global environmental governance: Causes, consequences, and responses. Global Environmental Politics, 13(3), 1-13. doi:10.1162/GLEP_a_00180

Zumbansen, P. (2006). The parallel worlds of corporate governance and labor law. Indiana Journal of Global Legal Studies, 13(1), 261-312. doi:10.2139/ssrn.902650

Zürn, M. (2004). Global governance and legitimacy problems. Government and Opposition, 39(2), 260-287. doi:10.1111/j.1477-7053.2004.00123.x

Zürn, M., \& Faude, B. (2013). On fragmentation, differentiation, and coordination. Global Environmental Politics, 13(3), 119-130. doi:10.1162/GLEP_a_00186 



\section{Appendix}

\section{Case study interviews}

This dissertation is based on four case studies supported by information from research subjects. In principle, all interviewees have been offered confidentiality of information. To make identities unidentifiable, the following has been done. First, the names of the interviewees have been left out of the overview below. Second, many of the interviewees have multiple jobs or take on various roles and functions in relation to the topic for which they were interviewed. While this has contributed to the richness in insights on the interview topics, stipulating the combination of diverse roles, functions, and organisations and/or companies would lead to make the interviewees more identifiable. In the overview below, one main or most relevant role is mentioned. On several occasions, determining the main or most relevant role has felt somewhat arbitrary, as the different jobs, roles and functions could be considered equally relevant and weighty. Last, the titles of the main or most relevant positions have been categorised. The following categorisations have been used: policymaker, coordinator, advisor, consultant, analyst, and manager. The category of manager was further characterised with top-level (referring to the highest-ranking executives responsible for entire organisation) and mid-level (referring to managers who head specific departments, business units or who serve as project managers in flat organisations). 

Case study 1 - Private fair labour arrangements

\begin{tabular}{|c|c|c|c|c|c|}
\hline $\mathrm{N}$ & Organisation & Domain & Position & Survey type & Date \\
\hline 1 & Fair Wear Foundation & \multicolumn{2}{|c|}{ Civil Society Manager (top-level) } & $\begin{array}{l}\text { Face-to-face } \\
\text { interview }\end{array}$ & May 14,2013 \\
\hline 2 & $\begin{array}{l}\text { International Labour } \\
\text { Organization }\end{array}$ & Public & Manager (mid-level) & Skype interview & June 4, 2013 \\
\hline 3 & Clean Clothes Campaign & \multicolumn{2}{|c|}{ Civil Society Coordinator } & $\begin{array}{l}\text { Face-to-face } \\
\text { interview }\end{array}$ & June 6, 2013 \\
\hline 4 & $\begin{array}{l}\text { Social Accountability } \\
\text { International }\end{array}$ & \multicolumn{2}{|c|}{ Civil Society Advisor } & $\begin{array}{l}\text { Telephone } \\
\text { interview }\end{array}$ & June 19, 2013 \\
\hline 5 & $\begin{array}{l}\text { Worldwide Responsible } \\
\text { Accredited Production }\end{array}$ & \multicolumn{2}{|c|}{ Civil Society Manager (top-level) } & $\begin{array}{l}\text { Telephone } \\
\text { interview }\end{array}$ & $\begin{array}{l}\text { September 5, } \\
2013\end{array}$ \\
\hline 6 & Worker Rights Consortium & \multicolumn{2}{|c|}{ Civil Society Manager (mid-level) } & $\begin{array}{l}\text { Telephone } \\
\text { interview }\end{array}$ & $\begin{array}{l}\text { November 22, } \\
2013\end{array}$ \\
\hline 7 & Fair Labor Association & \multicolumn{2}{|c|}{ Civil Society Manager (top-level) } & Skype interview & $\begin{array}{l}\text { November 26, } \\
2013\end{array}$ \\
\hline 8 & $\begin{array}{l}\text { Business Social Compliance } \\
\text { Initiative }\end{array}$ & \multicolumn{2}{|c|}{ Civil Society Manager (mid-level) } & $\begin{array}{l}\text { Face-to-face } \\
\text { interview }\end{array}$ & $\begin{array}{l}\text { February 20, } \\
2014\end{array}$ \\
\hline
\end{tabular}

Case study 2 - Regional standards for organic production

$\mathrm{N}$ Organisation $\quad$ Domain Position $\quad$ Survey type Date

\begin{tabular}{|c|c|c|c|c|c|}
\hline 1 & $\begin{array}{l}\text { United Nations Forum on } \\
\text { Sustainability Standards }\end{array}$ & Public & Coordinator & Skype interview & $\begin{array}{l}\text { April } 24 \& \\
\text { August 24, } 2015\end{array}$ \\
\hline 2 & $\begin{array}{l}\text { International Federation of } \\
\text { Organic Agriculture } \\
\text { Movements, Organics } \\
\text { International }\end{array}$ & \multicolumn{2}{|c|}{ Civil Society Advisor } & Skype interview & $\begin{array}{l}\text { October 14, } \\
2015\end{array}$ \\
\hline 3 & Organic Alliance Malaysia & \multicolumn{2}{|c|}{ Civil Society Manager (top-level) } & Skype interview & March 4, 2016 \\
\hline 4 & $\begin{array}{l}\text { International Federation of } \\
\text { Organic Agriculture } \\
\text { Movements, Organics Asia }\end{array}$ & \multicolumn{2}{|c|}{ Civil Society Manager (top-level) } & Skype interview & March 15, 2016 \\
\hline 5 & $\begin{array}{l}\text { National Bureau of } \\
\text { Agricultural Commodity and } \\
\text { Food Standards, Thailand }\end{array}$ & Public & Manager (mid-level) & Skype interview & March 22, 2016 \\
\hline 6 & $\begin{array}{l}\text { Organic Certification Centre } \\
\text { of the Philippines }\end{array}$ & \multicolumn{2}{|c|}{ Civil Society Manager (top-level) } & Skype interview & April 6, 2016 \\
\hline 7 & $\begin{array}{l}\text { Women in Business } \\
\text { Development Inc., Samoa }\end{array}$ & \multicolumn{2}{|c|}{ Civil Society Manager (top-level) } & $\begin{array}{l}\text { Written response } \\
\text { to interview } \\
\text { questions }\end{array}$ & April 7, 2016 \\
\hline 8 & $\begin{array}{l}\text { Thailand Organic Trade } \\
\text { Association }\end{array}$ & \multicolumn{2}{|c|}{ Civil Society Manager (top-level) } & Skype interview & April 15, 2016 \\
\hline
\end{tabular}




\begin{tabular}{|c|c|c|c|c|c|}
\hline $\mathrm{N}$ & Organisation & Domain & Position & Survey type & Date \\
\hline 9 & $\begin{array}{l}\text { Ministry of Agriculture, } \\
\text { Livestock, Forestry, Fisheries } \\
\text { and Biosecurity, Vanuatu }\end{array}$ & Public & Manager (top-level) & $\begin{array}{l}\text { Telephone } \\
\text { interview }\end{array}$ & April 16, 2016 \\
\hline 10 & $\begin{array}{l}\text { Philippine Bureau of } \\
\text { Agriculture and Fishery } \\
\text { Standards }\end{array}$ & Public & Manager (mid-level) & $\begin{array}{l}\text { Written response } \\
\text { to interview } \\
\text { questions }\end{array}$ & April 18, 2016 \\
\hline 11 & $\begin{array}{l}\text { Kastom Gaden Association, } \\
\text { Solomon Islands }\end{array}$ & Civil Society & y Manager (top-level) & $\begin{array}{l}\text { Written response } \\
\text { to interview } \\
\text { questions }\end{array}$ & April 25, 2016 \\
\hline 12 & $\begin{array}{l}\text { Ministry of Agriculture, } \\
\text { Indonesia }\end{array}$ & Public & Manager (mid-level) & $\begin{array}{l}\text { WhatsApp } \\
\text { interview }\end{array}$ & April 26, 2016 \\
\hline 13 & $\begin{array}{l}\text { Pacific Organic and Ethical } \\
\text { Trade Community }\end{array}$ & Public & Coordinator & Skype interview & April 27, 2016 \\
\hline 14 & $\begin{array}{l}\text { International Federation of } \\
\text { Organic Agriculture } \\
\text { Movements, Organic } \\
\text { International }\end{array}$ & Civil Society & y Manager (mid-level) & Skype interview & May 5, 2016 \\
\hline 15 & European Commission & Public & Policymaker & $\begin{array}{l}\text { Telephone } \\
\text { interview }\end{array}$ & May 27, 2016 \\
\hline 16 & Grolink & Private & Consultant & Skype interview & August 12, 2016 \\
\hline 17 & $\begin{array}{l}\text { Kenya Organic Agriculture } \\
\text { Network }\end{array}$ & Civil Society & y Manager (top-level) & Skype interview & August 18, 2016 \\
\hline 18 & $\begin{array}{l}\text { United Nations Conference } \\
\text { on Trade and Development }\end{array}$ & Public & Advisor & $\begin{array}{l}\text { Telephone } \\
\text { interview }\end{array}$ & August 25, 2016 \\
\hline 19 & $\begin{array}{l}\text { African Organisation for } \\
\text { Standardisation }\end{array}$ & Public & Manager (mid-level) & Skype interview & July 20, 2017 \\
\hline 20 & $\begin{array}{l}\text { Ministry of Commerce and } \\
\text { Industry of Republic of } \\
\text { Panama }\end{array}$ & Public & Coordinator & $\begin{array}{l}\text { Telephone } \\
\text { interview }\end{array}$ & July 28,2017 \\
\hline
\end{tabular}


Case study 3 - Private metagovernance

\begin{tabular}{|c|c|c|c|c|c|c|}
\hline $\mathrm{N}$ & Organisation & Domain & Position & Survey type & Date & Conducted by \\
\hline 1 & $\begin{array}{l}\text { The Common Code } \\
\text { for the Coffee } \\
\text { Community } \\
\text { Association }\end{array}$ & Civil Society & $\begin{array}{l}\text { Manager } \\
\text { (mid-level) }\end{array}$ & $\begin{array}{l}\text { Written response } \\
\text { to interview } \\
\text { questions }\end{array}$ & June 6, 2013 & $\begin{array}{l}\text { Sophie von } \\
\text { Gagern }\end{array}$ \\
\hline 2 & Rainforest Alliance & Civil Society & $\begin{array}{l}\text { Manager } \\
\text { (top-level) }\end{array}$ & Skype interview & June 10, 2013 & $\begin{array}{l}\text { Sophie von } \\
\text { Gagern }\end{array}$ \\
\hline 3 & Racafe \& CIA S.C.A. & Private & $\begin{array}{l}\text { Manager } \\
\text { (top-level) }\end{array}$ & Skype interview & June 12, 2013 & $\begin{array}{l}\text { Sophie von } \\
\text { Gagern }\end{array}$ \\
\hline 4 & $\begin{array}{l}\text { Kenya Coffee } \\
\text { Research Foundation }\end{array}$ & Public & $\begin{array}{l}\text { Manager } \\
\text { (mid-level) }\end{array}$ & $\begin{array}{l}\text { Written response } \\
\text { to interview } \\
\text { questions }\end{array}$ & June 18, 2013 & $\begin{array}{l}\text { Sophie von } \\
\text { Gagern }\end{array}$ \\
\hline 5 & UTZ Certified & Civil Society & $\begin{array}{l}\text { Manager } \\
\text { (top-level) }\end{array}$ & Skype interview & June 25, 2013 & $\begin{array}{l}\text { Sophie von } \\
\text { Gagern }\end{array}$ \\
\hline 6 & $\begin{array}{l}\text { Deutsche Gesellschaft } \\
\text { für Internationale } \\
\text { Zusammenarbeit } \\
\text { GmbH }\end{array}$ & Public & $\begin{array}{l}\text { Manager } \\
\text { (mid-level) }\end{array}$ & Skype interview & July 2, 2013 & $\begin{array}{l}\text { Sophie von } \\
\text { Gagern }\end{array}$ \\
\hline 7 & Tchibo GmbH & Private & $\begin{array}{l}\text { Manager } \\
\text { (top-level) }\end{array}$ & Skype interview & July 9, 2013 & $\begin{array}{l}\text { Sophie von } \\
\text { Gagern }\end{array}$ \\
\hline 8 & $\begin{array}{l}\text { Sustainable Fisheries } \\
\text { Partnership }\end{array}$ & Civil Society & $\begin{array}{l}\text { Manager } \\
\text { (mid-level) }\end{array}$ & $\begin{array}{l}\text { Written response } \\
\text { to interview } \\
\text { questions }\end{array}$ & June 4, 2013 & $\begin{array}{l}\text { Sophie von } \\
\text { Gagern }\end{array}$ \\
\hline 9 & $\begin{array}{l}\text { Marine Stewardship } \\
\text { Council }\end{array}$ & Civil Society & Advisor & $\begin{array}{l}\text { Written response } \\
\text { to interview } \\
\text { questions }\end{array}$ & June 26, 2013 & $\begin{array}{l}\text { Sophie von } \\
\text { Gagern }\end{array}$ \\
\hline 10 & $\begin{array}{l}\text { Global Good } \\
\text { Agricultural Practices }\end{array}$ & Civil Society & $\begin{array}{l}\text { Manager } \\
\text { (mid-level) }\end{array}$ & $\begin{array}{l}\text { Written response } \\
\text { to interview } \\
\text { questions }\end{array}$ & June 27, 2013 & $\begin{array}{l}\text { Sophie von } \\
\text { Gagern }\end{array}$ \\
\hline 11 & $\begin{array}{l}\text { International } \\
\text { Fishmeal and Fish Oil } \\
\text { Organisation }\end{array}$ & Civil Society & $\begin{array}{l}\text { Manager } \\
\text { (mid-level) }\end{array}$ & Skype interview & July 4, 2013 & $\begin{array}{l}\text { Sophie von } \\
\text { Gagern }\end{array}$ \\
\hline 12 & $\begin{array}{l}\text { International Council } \\
\text { for the Exploration of } \\
\text { the Sea }\end{array}$ & Public & $\begin{array}{l}\text { Manager } \\
\text { (mid-level) }\end{array}$ & Skype interview & July 4, 2013 & $\begin{array}{l}\text { Sophie von } \\
\text { Gagern }\end{array}$ \\
\hline 13 & $\begin{array}{l}\text { Aquaculture } \\
\text { Stewardship Council }\end{array}$ & Civil Society & Coordinator & Skype interview & $\begin{array}{l}\text { July 11, } \\
2013\end{array}$ & $\begin{array}{l}\text { Sophie von } \\
\text { Gagern }\end{array}$ \\
\hline 14 & $\begin{array}{l}\text { Global Aquaculture } \\
\text { Alliance }\end{array}$ & Civil Society & $\begin{array}{l}\text { Manager } \\
\text { (mid-level) }\end{array}$ & Skype interview & $\begin{array}{l}\text { July 16, } \\
2013\end{array}$ & $\begin{array}{l}\text { Sophie von } \\
\text { Gagern }\end{array}$ \\
\hline 15 & $\begin{array}{l}\text { World Cocoa } \\
\text { Foundation }\end{array}$ & Civil Society & $\begin{array}{l}\text { Manager } \\
\text { (top-level) }\end{array}$ & $\begin{array}{l}\text { Telephone } \\
\text { interview }\end{array}$ & $\begin{array}{l}\text { May 29, } \\
2014\end{array}$ & $\begin{array}{l}\text { Ceren } \\
\text { Pekdemir }\end{array}$ \\
\hline
\end{tabular}




\begin{tabular}{|c|c|c|c|c|c|c|}
\hline $\mathrm{N}$ & Organisation & Domain & Position & Survey type & Date & Conducted by \\
\hline 16 & Olam International & Private & $\begin{array}{l}\text { Manager } \\
\text { (mid-level) }\end{array}$ & Skype interview & June 9, 2014 & $\begin{array}{l}\text { Ceren } \\
\text { Pekdemir }\end{array}$ \\
\hline 17 & Guittard Chocolate & Private & $\begin{array}{l}\text { Manager } \\
\text { (mid-level) }\end{array}$ & $\begin{array}{l}\text { Telephone } \\
\text { interview }\end{array}$ & June 12, 2014 & $\begin{array}{l}\text { Ceren } \\
\text { Pekdemir }\end{array}$ \\
\hline 18 & Cargill Company & Private & $\begin{array}{l}\text { Manager } \\
\text { (mid-level) }\end{array}$ & $\begin{array}{l}\text { Telephone } \\
\text { interview }\end{array}$ & June 26, 2014 & $\begin{array}{l}\text { Ceren } \\
\text { Pekdemir }\end{array}$ \\
\hline 19 & Toms Group & Private & $\begin{array}{l}\text { Manager } \\
\text { (mid-level) }\end{array}$ & $\begin{array}{l}\text { Telephone } \\
\text { interview }\end{array}$ & July 8, 2014 & $\begin{array}{l}\text { Ceren } \\
\text { Pekdemir }\end{array}$ \\
\hline 20 & Rainforest Alliance & Civil Society & $\begin{array}{l}\text { Manager } \\
\text { (top-level) }\end{array}$ & Skype interview & $\begin{array}{l}\text { September 3, } \\
2014\end{array}$ & $\begin{array}{l}\text { Ceren } \\
\text { Pekdemir }\end{array}$ \\
\hline 21 & UTZ Certified & Civil Society & $\begin{array}{l}\text { Manager } \\
\text { (top-level) }\end{array}$ & $\begin{array}{l}\text { Telephone } \\
\text { interview }\end{array}$ & $\begin{array}{l}\text { October 9, } \\
2014\end{array}$ & $\begin{array}{l}\text { Ceren } \\
\text { Pekdemir }\end{array}$ \\
\hline
\end{tabular}

Case study $4 \mathbf{a}$ - Tensions in global governance systems: labour rights

\begin{tabular}{|c|c|c|c|c|c|}
\hline $\mathrm{N}$ & Organisation & Domain & Position & Survey type & Date \\
\hline 1 & $\begin{array}{l}\text { Clean Clothes Campaign } \\
\text { International Office }\end{array}$ & Civil Society & Coordinator & $\begin{array}{l}\text { Questionnaire \& } \\
\text { Skype interview }\end{array}$ & May 9, 2017 \\
\hline 2 & University of Virginia & Research & Researcher & $\begin{array}{l}\text { Questionnaire \& } \\
\text { Skype interview }\end{array}$ & May 19, 2017 \\
\hline 3 & $\begin{array}{l}\text { London School of Economics } \\
\text { and Political Science }\end{array}$ & s Research & Researcher & Skype interview & May 29, 2017 \\
\hline 4 & Pennsylvania State University & yResearch & Researcher & $\begin{array}{l}\text { Questionnaire \& } \\
\text { Skype interview }\end{array}$ & May 30, 2017 \\
\hline 5 & $\begin{array}{l}\text { International Labour } \\
\text { Organization }\end{array}$ & Public & Advisor & $\begin{array}{l}\text { Questionnaire \& } \\
\text { Skype interview }\end{array}$ & June 2, 2017 \\
\hline 6 & $\begin{array}{l}\text { Federatie Nederlands } \\
\text { Vakbeweging }\end{array}$ & Civil Society & $\begin{array}{l}\text { Manager } \\
\text { (top-level) }\end{array}$ & $\begin{array}{l}\text { Face-to-face } \\
\text { interview }\end{array}$ & June 26, 2017 \\
\hline 7 & TZoro IBC & Private & $\begin{array}{l}\text { Manager } \\
\text { (top-level) }\end{array}$ & $\begin{array}{l}\text { Questionnaire \& } \\
\text { telephone interview }\end{array}$ & $\begin{array}{l}\text { August 24, } \\
2017\end{array}$ \\
\hline 8 & $\begin{array}{l}\text { International Labour } \\
\text { Organization }\end{array}$ & Public & Analyst & $\begin{array}{l}\text { Questionnaire \& } \\
\text { Skype interview }\end{array}$ & $\begin{array}{l}\text { August 25, } \\
2017\end{array}$ \\
\hline 9 & $\begin{array}{l}\text { International Labour } \\
\text { Organization }\end{array}$ & Public & Advisor & $\begin{array}{l}\text { Questionnaire \& } \\
\text { Skype Interview }\end{array}$ & $\begin{array}{l}\text { September 4, } \\
2017\end{array}$ \\
\hline 10 & $\begin{array}{l}\text { Confederation of Norwegian } \\
\text { Enterprise }\end{array}$ & Civil Society & Advisor & $\begin{array}{l}\text { Questionnaire \& } \\
\text { telephone interview }\end{array}$ & $\begin{array}{l}\text { September 7, } \\
2017\end{array}$ \\
\hline 11 & University of Cape Town & Research & Researcher & $\begin{array}{l}\text { Questionnaire \& } \\
\text { Skype interview }\end{array}$ & $\begin{array}{l}\text { September } \\
19,2017\end{array}$ \\
\hline 12 & $\begin{array}{l}\text { Centre de droit international } \\
\text { de Nanterre }\end{array}$ & l Private & Consultant & $\begin{array}{l}\text { Questionnaire \& } \\
\text { Skype interview }\end{array}$ & $\begin{array}{l}\text { September } \\
22,2017\end{array}$ \\
\hline
\end{tabular}




\begin{tabular}{|c|c|c|c|c|c|}
\hline $\mathrm{N}$ & Organisation & Domain & Position & Survey type & Date \\
\hline 13 & Randstad & Private & $\begin{array}{l}\text { Manager } \\
\text { (top-level) }\end{array}$ & $\begin{array}{l}\text { Questionnaire \& } \\
\text { face-to-face } \\
\text { interview }\end{array}$ & $\begin{array}{l}\text { September } \\
25,2017\end{array}$ \\
\hline 14 & Randstad & Private & $\begin{array}{l}\text { Manager } \\
\text { (mid-level) }\end{array}$ & $\begin{array}{l}\text { Questionnaire \& } \\
\text { face-to-face } \\
\text { interview }\end{array}$ & $\begin{array}{l}\text { September } \\
25,2017\end{array}$ \\
\hline 15 & $\begin{array}{l}\text { Institute for Human } \\
\text { Development, New Delhi }\end{array}$ & Research & Researcher & $\begin{array}{l}\text { Questionnaire \& } \\
\text { Skype interview }\end{array}$ & $\begin{array}{l}\text { September } \\
26,2017\end{array}$ \\
\hline 16 & Max Planck Institute & Research & Researcher & $\begin{array}{l}\text { Questionnaire \& } \\
\text { telephone interview }\end{array}$ & $\begin{array}{l}\text { November } \\
10,2017\end{array}$ \\
\hline
\end{tabular}

Case study $4 \mathbf{b}$ - Tensions in global governance systems: organic production

\begin{tabular}{|c|c|c|c|c|c|}
\hline $\mathrm{N}$ & Organisation & Domain & Position & Survey type & Date \\
\hline 1 & Grolink & Private & Consultant & $\begin{array}{l}\text { Questionnaire \& } \\
\text { Skype interview }\end{array}$ & $\begin{array}{l}\text { September } \\
11,2017\end{array}$ \\
\hline 2 & $\begin{array}{l}\text { International Federation of } \\
\text { Organic Agriculture } \\
\text { Movements }\end{array}$ & Civil Society & $\begin{array}{l}\text { Manager } \\
\text { (mid-level) }\end{array}$ & Questionnaire & $\begin{array}{l}\text { September } 7 \text {, } \\
2017\end{array}$ \\
\hline 3 & $\begin{array}{l}\text { Food and Agriculture } \\
\text { Organization of the United } \\
\text { Nations }\end{array}$ & Public & Coordinator & $\begin{array}{l}\text { Questionnaire \& } \\
\text { WhatsApp interview }\end{array}$ & $\begin{array}{l}\text { September } \\
15,2017\end{array}$ \\
\hline 4 & Earth Net Foundation & Civil Society & $\begin{array}{l}\text { Manager } \\
\text { (top-level) }\end{array}$ & $\begin{array}{l}\text { Questionnaire \& } \\
\text { Skype interview }\end{array}$ & $\begin{array}{l}\text { September } \\
15,2017\end{array}$ \\
\hline 5 & $\begin{array}{l}\text { Organic Certification Center } \\
\text { of the Philippines }\end{array}$ & r Private & $\begin{array}{l}\text { Manager } \\
\text { (top-level) }\end{array}$ & Questionnaire & $\begin{array}{l}\text { September } \\
22,2017\end{array}$ \\
\hline 6 & Circle Indonesia & Private & Consultant & $\begin{array}{l}\text { Questionnaire \& } \\
\text { Skype interview }\end{array}$ & $\begin{array}{l}\text { September } \\
23,2017\end{array}$ \\
\hline 7 & $\begin{array}{l}\text { United Nations Forum on } \\
\text { Sustainability Standards }\end{array}$ & Public & Coordinator & Questionnaire & $\begin{array}{l}\text { October 3, } \\
2017\end{array}$ \\
\hline
\end{tabular}



Summary 



\section{Introduction}

Issue areas concerned with sustainable practice are characterised by a growing number of standards and regulations. Particularly around the production of global public goods, the new global public domain has been subject to contending centres of economic and political power. Many elements of the regulatory process have been transferred to both public and private actors in global governance, on topics as diverse as human rights, the environment, health, trade and finance.

In consequence, global governance for sustainable development is considered as having various sources of authority and power. Next to mandatory laws and regulations, also more flexible and voluntary forms of regulation and implementation are offered. This phenomenon has led to the observation that many policy domains in international relations are characterised by fragmentation. Fragmentation is regarded as problematic when the capacity of governments or international organisations is weakened in their desired effects or more generally, if it constrains the efficient and effective realisation of generally accepted public values.

The changes in global governance and the accompanying growth in regulatory complexity also spurred the quest for cohesion, sometimes also referred to as 'convergence'. Initiatives for cohesion and the development of common global standards have brought the interests of public and private interests together in areas such as environmental, labour and social issues. Cohesion in regulations is considered favourable in the production for global public goods, for instance when standards, certification requirements and mutual recognition agreements converge in global value chains.

Characteristics of fragmentation and cohesion can be observed in many different issue areas of sustainable development. Issue fields are rooted in specific institutional contexts. For this reason, many governance approaches have developed in distinctive ways. The governance systems of some issue areas appear to have more regulatory cohesion, whereas other issue areas appear fragmented. It is assumed that some governance systems are more conducive to realise sustainable change than others. However, elaborate explorations why this is the case were identified to be lacking, and the formulated research questions intend to fill this knowledge gap. Through qualitative analysis, based on over seventy semi-structured in-depth interviews and document analysis, several case studies were examined in order to answer the following research questions: 
i. What tensions between fragmentation and cohesion manifest themselves in various global governance systems?

ii. How do these tensions influence the governance capacity of these systems?

iii. What attempts have been made to handle these tensions and how are they able to contribute to the governance capacity?

\section{Theorizing fragmentation and cohesion}

In this dissertation, the concept of fragmentation signifies the diversity, multiplicity, and distribution of regulatory powers of the overall institutional settings of different international and transnational policy domains. The term cohesion functions as its counterpart, and regulatory coherence is understood as a system of governance in which policies are aligned resulting in concerted aims and actions. In absence of a nonfragmented, universal, and coordinated system of global governance structured around coherent sets of rules, full coherence on the global level is considered a theoretical construct. The pursuit for alignment as a way to create policy coherence has been analysed through the notions of harmonisation, equivalence, and metagovernance. The following case studies were central in this examination.

In the first case study on private fair labour arrangements (chapter 2), dimensions along which fragmentation and cohesion of governance systems can be studied have been identified. This resulted in a conceptual framework, which advances that relations within governance systems can be observed from three levels, namely the organisational, normative, and relational level. In this dynamic field, relations may develop into collaborations and partnerships, but may as well be adversarial. The conceptual framework served as an analytical basis to understand the regulatory system of global labour rights. Based on an investigation of the private transnational arrangements for fair labour, the fragmentation recognisable on the three dimensions were considered to impair the transformative capacity of the governance system of the fair labour issue field.

The second case (chapter 3) analysed the regionalisation of standards on organic production as a way in which public and private actors aim to bring more cohesion in the governance system on the global level. By examining all the existing initiatives from across the world, it evaluates if the promise of regionalisation can make the regulatory field of organic standards more cohesive and whether it is conducive for regional and international trade. Regionalisation as a system of governance is considered to contribute to normative coherence within the issue field while allowing for the regional adaptation. In this chapter, it is argued that ineffective enforcement and inadequate allocation of legal, political, and funding resources seriously imperil the institutional alignment necessary for international trade purposes. 
The third case study (chapter 4) explored the concept of metagovernance. Based on a literature study, a conceptual framework was developed with a categorisation into four change mechanisms: (re)framing the (global) discourse, capacity building, networking and mainstreaming. Three private governance arrangements aspiring a key role in the advancement of sustainable production in diverse global value chains were analysed in terms of these mechanisms. It was found that the private uptake of meta-governance mechanisms for change are considered to relate to networking and capacity building, being mostly geared towards process management strategies, activating actors and resources, and arranging and facilitating interactions amongst stakeholders. In addition, efforts to frame the global sustainability discourse and mainstreaming of sustainability goals could be strengthened.

The fourth case study (chapter 5) examined the ways in which tensions in global governance systems manifest themselves through the quest for cohesion. It is postulated that the emerging tensions are dependent on the system characteristics of fragmentation in an issue field and are shaped by the ways in which cohesion is sought. By examining the global governance of labour rights and the global governance of organic production, it is found that a cause for these tensions, ironically, stem from non-alignment itself as particularly strategic coordination between actors is often lacking. Both case studies illustrate that there is ample room to seek partnerships and strengthen collaborative efforts. It is concluded that collaborative roadmaps for cohesion in global governance should not be treated alike, and require an issue based analysis to be functional for the governance systems itself.

\section{What tensions between fragmentation and cohesion manifest them selves in various global governance systems?}

The results of the various cases uncover that tensions between fragmentation and cohesion of global governance systems manifests themselves in several ways. The first tension area relates to the difficulties encountered in the relational aspect of governance in the transnational sphere. Specifically, while there is an understanding that collaboration and partnership can be beneficial, the governance arrangements have difficulties in arranging and maintaining collaborative efforts that can sustain and amplify their own working methods.

This ties in with another tension area between fragmentation and cohesion, namely, despite the quest for cohesion across the issue fields, the approach to achieving policy coherence is by and far not a settled issue amongst actors operating in them. As a result, the different working methods of the governance actors and their preferred ways for 
realising coherence is sometimes not only a non-shared endeavour, the preferred working methods also sustain or deepen the fragmented character of governance systems.

Another tension area between fragmentation and cohesion can be observed between inclinations toward either global or local methods. While an overarching, normative application of standards is often desired on the global level by transnational actors, these same actors stress the importance of the adaptation of standards to local characteristics as a way to safeguard their applicability and effectiveness.

\section{How do the se tensions influence the governance capacity of the se systems?}

Governance capacity was construed as an evaluative concept encompassing several elements. Beyond the applicability of the concept to the transnational and international sphere, we distinguished defining characteristics of governance capacity as the ability to contribute to policies, to implement policies, to put in certain resources, to achieve certain outcomes, and linked to the latter, the criterion of success. The influence of the tensions on the governance capacity of arrangements has been discussed in several ways throughout this dissertation. A general observation is that in most parts of the world, many transnational arrangements are tolerated to contribute and implement policies. An efficient and effective realisation of goals within issue fields are hard to achieve due to insufficiencies in (sharing) resources and concerted actions.

In the field of labour rights, while there is largely a desire for cooperation between the governance arrangements, the international and transnational system is largely characterised by the lack thereof. Next to the ILO, other international actors have increasingly started to define and adopt labour policies. Private arrangements largely focus on their own resources and capabilities, divide the issue field into different fractions through their focus on particular sectors, and compete for market share of businesses. An exploration into other intergovernmental organisations also revealed that formulations and reference to normative standards in provisions and policies differ, resulting from a reported lack of synergies for policy coherence. The characteristics of the governance system as a whole point to problems related to the fragmentation of the system. In this regard, the variety amongst the actors themselves, the lack of accountability, the uncoordinated efforts amongst various arrangements, and the weak links between and across the public and private divide, were all signified as unconducive to induce the envisioned changes.

The field of organic production is also rife of standards. An examination of regional organic standards showed that resources and capabilities are shared. Also in terms of alignment between standards, two normative standards - one from the public and 
another one from the private sphere-contribute to the regional standards development. The organic movement values diversity in standards if these are in line with organic values, and the endorsement of equivalency as a method allows standards to be adapted to the local context. The approach of public arrangements differs. Amongst major organic markets and developed nations, equivalence agreements exist but other actors must conform to the compliance regime. As a system of governance, the issue-field has many elements of collaborations and partnerships between both public and private actors. The system cannot however be described as cohesive due to the excluding characteristics of major public actors, and a divided view on the regulatory approach to achieving cohesion. The degree to which the sector is protected from fraudulent claims can be marked as quite effective, while regulatory complexity and concerns of Southern inclusivity remain challenging for the overall sector.

\section{What attempts have been made to handle these tensions and how are they able to contribute to the governance capacity?}

Various attempts have been undertaken by both public and private actors to handle the tensions arising from particularly fragmented state of governance affairs. In the empirical chapters, different approaches to reaching policy coherence were examined namely equivalence, harmonisation, common standard adoption, and metagovernance.

Under the equivalence model, actors accept each other's standards as if they are the same. Differences in provisions and variations in formulations are allowed. For this reason, the purpose of equivalence lies within its functionality. One standard may be used as a normative standard which other standards need to be equivalent with. With harmonisation, actors bring different standards in line with one common standard or regulatory framework. This way, a system of standards operates efficiently without inconsistencies or inequalities. With adopting a common standard, actors agree that one standard applies to all parties. In principle, there is not a necessity to duplicate the standard. Metagovernance can bring in more cohesion in the activities and regulatory processes within an issue field through a wide array of guidance mechanisms. Metagovernors can therefore employ any of the policy coherence mechanisms previously described.

The way in which policy mechanisms contribute to governance capacity are multiple. First, they offer a means in which expectations of actors concerning policy coherence can be managed. Once an approach is agreed upon, it furthermore offers a way in which the governance system can be structured. In that sense, the policy mechanisms are indicative of strategic relationships. This ties in with another observation, which is that the policy mechanisms and the agreements struck reveal where power lies. 
Analogously, the way a metagovernance organisation employs mechanisms for policy coherence discloses the governance capacity that the metagovernor itself has, as well as that of its members. Besides employing a variety of the mechanisms of change, metagovernors should employ one of the policy cohesion mechanisms, whether equivalence, harmonisation, or a common standard in order to be considered a metagovernor. In effect, this would contribute to the governance capacity of metagovernance arrangements and potentially to the governance system as a whole.

\section{Implications and reflections}

Fragmentation becomes problematic when the issues of sustainability and development become unmanageable. The concepts of fragmentation and cohesion within this study have been regarded normatively in so far that fragmentation was understood as being unconducive to realising societal goals as it may diffuse, or be counterproductive for, concerted aims and action. Contrarily, efforts for cohesion have been understood positively in so far that partnerships and cooperation can overcome the condition of fragmentation, enhance concerted aims and action, and result in regulatory coherence. When previously established values codified in laws and regulations are obscured or infringed upon, it is of crucial importance to understand the drivers and the accompanying agendas attached to them. While policy cohesion may be desired, the level and the extent to which will need to be determined. This can aid in the agenda to distinguish associated management efforts which tackle fragmentation. It is central then to navigate between fragmentation and cohesion in order to deal effectively with diversity and the tensions this poses on the governability of sustainable development. While universal coordination maybe lacking, central and authoritative actors can take a key role in fostering policy coherence.

On basis of the research findings of this dissertation, we argue that the type of cohesion that should be sought depends on the characteristics of underlying fragmentation and the issue at stake. The case study on regional standards for organic production demonstrated that diversity is arguably a valued characteristic for the standards system. For this reason, equivalence as a mechanism for policy coherence is a suitable system. However, for labour rights, harmonisation or a common standard of core labour standards is preferable as regulatory fragmentation leads to the continued violation of labour rights. The obscuring of normative standards in other regulations and policies rekindles the ineffective labour rights protection system.

Three approaches may be instructive in navigating between fragmentation and cohesion. First, fragmentation can be approached as an organisational problem. In this approach, it is not only important to identify actors and their responsibilities, but also to 
suggest where responsibilities lie, or shift, redistribute, and reorganise responsibilities. Second, fragmentation can be approached as a problem emanating from normative issues. A general normative framework may be required. In case this is present, not only more stringent or encompassing standards can be called for, but also a normative framework on the mechanism of policy coherence. Third, fragmentation can be approached as a relational problem. Collaborations and interactions between governance actors need to be fostered. Interplay management then becomes an important concept in this regard, which refers to the conscious efforts by any relevant actors or group of actors, regardless of form and forum, to address institutional interaction and its effects. Each of these approaches may however bring forth tensions, such as those relating to legitimacy and accountability. Nonetheless, for steering societies across the world towards sustainable trajectories, systemic transformation remains one of the biggest governance challenges of our times. 

Samenvatting 



\section{Introductie}

Mondiale beleidssystemen die zich bezighouden met duurzaamheidspraktijken worden gekenmerkt door een groeiend aantal standaarden en regelgeving. Veel elementen van het regelgevingsproces zijn daarbij verdeeld over publieke en private actoren, met betrekking tot bijvoorbeeld mensenrechten, het milieu, gezondheid, en handel.

Dit heeft als gevolg dat mondiale sturing van duurzame ontwikkeling meerdere bronnen van autoriteit en macht kent. Naast de verplichte wetten en regelgeving, zijn ook meer flexibele en vrijwillige vormen van regelgeving en implementatie ontwikkeld. Veel mondiale beleidssystemen worden gekarakteriseerd door fragmentatie. Fragmentatie wordt gezien als problematisch wanneer de capaciteit van overheden of internationale organisaties verzwakt is wat betreft het bereiken van het gewenste effect, of meer in het algemeen, als het de realisatie van efficiënte en effectieve algemene publieke waarden hindert.

De veranderingen in mondiale sturing en de bijkomende groei in de complexiteit van de regelgeving hebben tevens de zoektocht naar cohesie bevorderd, een proces dat ook wel 'convergentie' genoemd wordt. Initiatieven voor cohesie en de ontwikkeling van gedeelde, mondiale standaarden hebben de belangen van publieke en private actoren nader bij elkaar gebracht op het gebied van het milieu, arbeid en sociale beleidsterreinen. Cohesie in regelgeving wordt als overwegend positief gezien in de context van de productie van mondiale, publieke goederen, bijvoorbeeld in gevallen waarbij standaarden, certificeringseisen en wederzijdse erkenningsovereenkomsten convergeren in mondiale waardeketens.

Eigenschappen van fragmentatie en cohesie zijn waarneembaar in verschillende beleidssystemen van duurzame ontwikkeling. Ieder beleidssysteem heeft een specifieke, institutionele context, en is op idiosyncratische wijze ontwikkeld. Sommige systemen lijken meer cohesie te vertonen op het gebied van regelgeving, waar andere beleidssystemen meer gefragmenteerd lijken te zijn. Aangenomen wordt dat de mate van fragmentatie/cohesie van invloed is op de mogelijkheden om duurzame verandering te bewerkstelligen. Duidelijk onderbouwde uitleg waarom dit het geval is, lijkt echter te ontbreken. De onderhavige onderzoeksvragen beogen deze ontbrekende kennis aan te vullen. Door middel van kwalitatieve analyse, gebaseerd op meer dan zeventig semigestructureerde diepte-interviews en documentanalyse, zijn verschillende casestudies onderzocht om te komen tot antwoorden op de volgende vragen:

1. Welke spanningsvelden tussen fragmentatie en cohesie zijn waarneembaar in verschillende mondiale beleidssystemen?

2. Hoe beïnvloeden deze spanningsvelden de sturingscapaciteit van deze systemen?

3. Welke pogingen zijn ondernomen om de spanningsvelden weg te nemen en hoe dragen deze pogingen bij aan de sturingscapaciteit? 


\section{Theoretiseren van fragmentatie en cohesie}

Het concept fragmentatie in dit proefschrift duidt de diversiteit, de veelheid en de verspreiding van regelgevende machten aan in het kader van verschillende internationale en transnationale beleidssystemen. Er is sprake van cohesie, en coherentie in regelgeving, wanneer beleid op elkaar is afgestemd met als resultaat gecoördineerde doelen en acties. Aangezien een niet-gefragmenteerd, universeel en gecoördineerd systeem van mondiale sturing - geënt op coherente regelgeving - ontbreekt, wordt volledige coherentie op mondiaal niveau hier beschouwd als theoretisch construct. Het streven naar afstemming met als doel coherentie in beleid, is geanalyseerd middels de noties van harmonisatie, equivalentie en metagovernance. De hierna genoemde casestudies stonden centraal in deze analyse.

In de eerste casestudy inzake private initiatieven voor betere arbeidsomstandigheden (hoofdstuk 2) zijn drie dimensies geïdentificeerd waarlangs fragmentatie en cohesie bestudeerd kunnen worden: organisatorisch, normatief en relationeel. In dit dynamische veld kunnen relaties zich ontwikkelen tot samenwerkingsverbanden, maar ook tot vijandige relaties. Het conceptueel raamwerk fungeert als analytisch kader om de regelgevende systemen van het mondiale arbeidsrecht te begrijpen. Op basis van een onderzoek naar de private, transnationale afspraken voor betere arbeidsomstandigheden kan fragmentatie gezien worden als obstakel voor de transformationele capaciteit van het beleidssysteem voor betere arbeidsomstandigheden.

De tweede casestudy (hoofdstuk 3) analyseert de regionalisatie van standaarden voor biologische productie als een manier waarop publieke en private actoren trachten meer cohesie aan te brengen in het beleidssysteem op mondiaal niveau. Door het onderzoeken van alle bestaande initiatieven, wordt bekeken of de belofte van regionalisatie meer cohesie kan brengen in de regelgeving rondom biologische standaarden en of het bevorderlijk is voor regionale en internationale handel. Regionalisatie blijkt bij te dragen aan normatieve coherentie binnen het beleidsdomein, onderwijl ruimte biedend voor regionale aanpassingen. In dit hoofdstuk wordt betoogd dat ineffectieve handhaving en inadequate toewijzing van juridische, politieke en financiële middelen een ernstige bedreiging vormen voor de institutionele afstemming die nodig is voor het bereiken van beoogde internationale handelsdoelstellingen.

De derde casestudy (hoofdstuk 4) verkent het concept metagovernance. Op basis van een literatuurstudie is een conceptueel raamwerk ontwikkeld met een categorisatie in vier verandermechanismen: (her)formulering van (mondiale) discours, capaciteitsopbouw, netwerken en veralgemenisering. Drie private sturingsinitiatieven die een sleutelrol wilden zijn in het bevorderen van duurzame productie in verschillende mondiale waardeketen werden geanalyseerd op basis van deze vier mechanismen. Geconcludeerd werd dat de private verwezenlijking van metagovernance mechanismen voor verandering 
gerelateerd zijn aan netwerken en capaciteitsopbouw. Deze verandermechanismen zijn voornamelijk gericht op procesmanagementstrategieën waarbij actoren en middelen geactiveerd worden en ook wordt getracht interactie te faciliteren tussen stakeholders. De inspanningen omtrent de inkadering van het globale duurzaamheidsdiscours, alsook het nader veralgemeniseren van duurzaamheidsdoelen, zouden geïntensiveerd kunnen worden.

De vierde casestudy (hoofdstuk 5) onderzoekt de manier waarop spanningsvelden in mondiale beleidssystemen waarneembaar zijn in de zoektocht naar cohesie. Aangenomen wordt dat de vigerende spanningsvelden afhankelijk zijn van de systeemeigenschappen van fragmentatie in een beleidssysteem en gevormd worden door de manier waarop cohesie wordt nagestreefd. Door de mondiale sturing van arbeidsrecht en de mondiale sturing van biologische productie te onderzoeken, wordt duidelijk dat deze spanningen ironisch genoeg veroorzaakt worden door de niet-afstemming zelf, gegeven het feit dat duidelijke, strategische coördinatie tussen actoren vaak ontbreekt. Beide casestudies illustreren het feit dat er voldoende ruimte bestaat om samenwerkingsverbanden op te zetten en samenwerking te intensiveren. Geconcludeerd wordt dat plannen voor samenwerking ten behoeve van cohesie in mondiale sturing niet gegeneraliseerd kunnen worden, en een analyse behoeven om functioneel te kunnen zijn voor het beleidssysteem waartoe ze behoren.

\section{Welke spanningsvelden tussen fragmentatie en cohesie zijn waarne embaar in verschillende mondiale beleidssystemen?}

De uitkomsten van de verschillende cases laten zien dat spanningsvelden tussen fragmentatie en cohesie in mondiale beleidssystemen op verschillende manieren waarneembaar zijn. Het eerste spanningsgebied is gelinkt aan de moeilijkheden in het relationele aspect van governance in de transnationale sfeer. Specifiek houdt dit in dat, hoewel begrepen wordt dat samenwerking en samenwerkingsverbanden de sturing kunnen versterken, het moeilijk is om samenwerking te initiëren en te onderhouden die de eigen manier van werken voortzet en versterkt.

Dit is gelieerd aan een ander spanningsveld tussen fragmentatie en cohesie, namelijk dat er geen overeenstemming bestaat tussen de verschillende actoren over hoe coherentie in beleid te bereiken is. Als gevolg hiervan, zijn de verschillende werkwijzen van de governance-actoren en de verschillende voorkeuren voor hoe coherentie te realiseren soms niet alleen een niet-gedeelde onderneming, maar heeft de geprefereerde werkmethode ook als gevolg dat het gefragmenteerde karakter van een governancesysteem voortduurt of verdiept wordt. 
Een ander spanningsveld tussen fragmentatie en cohesie is waarneembaar bij de voorkeur voor mondiale of lokale methoden. Hoewel een overkoepelende, normatieve toepassing van standaarden vaak gewenst is op het mondiale niveau door transnationale actoren, zijn het juist deze actoren die het belang onderstrepen van het aanpassen van standaarden aan lokale omstandigheden om op die manier de toepasbaarheid en effectiviteit te waarborgen.

\section{Hoe beïnvloeden deze spannings velden de sturingscapaciteit van deze systemen?}

Sturingscapaciteit is een evaluatief concept bestaande uit verschillende elementen. Het concept is toepasbaar op de transnationale en internationale sfeer. Kenmerkend zijn de mogelijkheid om bij te dragen aan beleid, beleid te implementeren, middelen in te brengen, bepaalde uitkomsten te bewerkstelligen en, gelinkt aan dit laatste punt, succescriteria. De invloed van de spanningsvelden op de sturingscapaciteit is op verschillende manieren tot uitdrukking gekomen in dit proefschrift. Het is moeilijk om tot een efficiënte en effectieve realisatie van doelen binnen beleidsdomeinen te komen door tekortkomingen in (het delen van) middelen en op elkaar afgestemde acties.

Op het gebied van arbeidsrecht is het internationale en transnationale systeem grotendeels te karakteriseren door een absentie van samenwerking tussen sturingsinitiatieven, ondanks dat er een verlangen bestaat dit te realiseren. In navolging van de ILO zijn ook andere internationale actoren zich meer gaan richten op het definiëren en implementeren van arbeidsbeleid. Private initiatieven die zich grotendeels concentreren op de eigen middelen en capaciteiten, verdelen het beleidsdomein in verschillende fracties door hun focus op specifieke sectoren en beconcurreren elkaar voor marktaandeel onder bedrijven. Een verkenning van intergouvernementele organisaties toont ook aan dat formuleringen van en referenties naar normatieve standaarden en bepalingen verschillen als gevolg van een gebrek aan coherentie in beleid. De kenmerken van het sturingssysteem wijzen op problemen gelieerd aan de fragmentatie van het systeem. In dit opzicht, kunnen de diversiteit van de actoren, het gebrek aan verantwoordingsmechanismen, de ongecoördineerde acties binnen verschillende initiatieven en de zwakke links tussen de actoren in het publieke en private domein en tussen de domeinen, allen aangemerkt worden als niet bevorderlijk voor het bewerkstelligen van de beoogde veranderingen.

Op het gebied van biologische productie zijn ook vele standaarden ontwikkeld. Een onderzoek naar regionale biologische standaarden laat zien dat middelen en capaciteiten gedeeld worden. Ook in termen van afstemming tussen standaarden, twee normatieve standaarden - een vanuit de publieke, de ander vanuit de private sfeer - dragen bij aan de 
ontwikkeling van regionale standaarden. De biologische beweging hecht waarde aan diversiteit in standaarden als deze in lijn liggen met biologische waarden. Tevens staat het ondersteunen van equivalentie als methode toe dat standaarden aangepast kunnen worden aan de lokale context. De aanpak van publieke initiatieven verschilt. Tussen de meest ontwikkelde biologische markten en ontwikkelde naties bestaan er equivalentieovereenkomsten, maar andere actoren moeten zich wel conformeren aan nationale standaarden. Het beleidssysteem kent veel elementen van samenwerking en samenwerkingsverbanden tussen zowel publieke als private actoren. Het systeem kan echter niet worden gekwalificeerd als coherent aangezien de publieke actoren met de meest ontwikkelde biologische markten niet inclusief zijn en er een verdeelde visie binnen het beleidssysteem bestaat op hoe cohesie te verwezenlijken is. De mate waarin de sector beschermd is tegen frauduleuze claims kan beoordeeld worden als vrij effectief. Zorgen over inclusiviteit van markten van het mondiale zuiden, alsmede de complexiteit van de regelgeving blijven echter uitdagingen voor de gehele sector.

\section{Welke pogingen zijn ondernomen om de spanningsvelden weg te nemen en hoe dragen deze pogingen bij aan de sturingscapaciteit?}

Er zijn verschillende pogingen ondernomen door zowel publieke als private actoren om de spanningsvelden die voortvloeien uit fragmentatie te adresseren. In de empirische hoofdstukken zijn de verschillende aanpakken om beleidscoherentie te bereiken, te weten equivalentie, harmonisatie, gezamenlijke standaardadoptie en metagovernance, onderzocht.

In het equivalentiemodel, accepteren actoren elkaars standaarden alsof ze hetzelfde zijn. Verschillen in voorwaarden en variaties in formuleringen zijn toegestaan. Functionaliteit is het voornaamste doel van het equivalentiemodel. Een standaard kan worden gebruikt als een normatieve standaard, waar andere standaarden equivalent aan moeten zijn. In het harmonisatiemodel brengen actoren verschillende standaarden samen en stemmen ze af binnen een gedeelde standaard of regelgevingskader. Op deze manier kan een standaardensysteem efficiënt opereren zonder inconsistenties. Bij het gezamenlijk adopteren van een standaard, stemmen actoren ermee in dat één standaard geldt voor alle partijen. Metagovernance, wat gedefinieerd kan worden als de governance van governance-actoren, kan zorgen voor meer cohesie in de activiteiten en regelgevingsprocessen binnen een beleidsdomein middels een breed scala aan richtlijnen. Metagovernors kunnen daarom alle eerdergenoem debeleidscoherentiemechanismen inzetten.

Er zijn veel manieren waarop beleidsmechanismen bijdragen aan sturingscapaciteit. Ten eerste, bieden ze een manier waarop verwachtingen van de actoren aangaande beleidscoherentie kunnen worden gemanaged. Zodra er overeenstemming is over de aanpak, biedt het vervolgens ook een manier waarop het sturingssysteem kan worden 
gestructureerd. Dit is gerelateerd aan een andere observatie, namelijk dat beleidsmechanismen en de gesloten overeenkomsten onthullen waar de macht (daadwerkelijk) ligt en kan dan ook indicatief zijn voor strategische relaties tussen actoren onderling.

Analoog hieraan, laat de manier waarop een metagovernance organisatie beleidsmechanismen inzet zien wat de sturingscapaciteit is van de metagovernor. Buiten het aanwenden van verschillende mechanismen voor veranderingen, zouden metagovernors één van de beleidscoherentiemechanismen moeten inzetten, of dit nu equivalentie, harmonisatie of gezamenlijke standaardadoptie is, zodat zij als meta 'governor' aangemerkt kunnen worden. Dit draagt dan effectief bij aan de sturingscapaciteit van een metagovernance initiatief zelf, en hierdoor mogelijk ook aan het sturingssysteem in z'n totaliteit.

\section{Implicaties en overwegingen}

Fragmentatie wordt problematisch wanneer problemen rondom duurzaamheid en ontwikkeling niet langer te beheersen zijn. De concepten fragmentatie en cohesie zijn in de context van deze (de onderhavige) studie normatief geïnterpreteerd in de zin dat fragmentatie gezien werd als niet-bevorderlijk voor het bereiken van maatschappelijke doelen, daar het verdeeldheid zaait, of contraproductief is met betrekking tot gecoördineerde doelen en acties. Omgekeerd worden pogingen om cohesie te bewerkstelligen in een positief licht gezien in de zin dat samenwerkingsverbanden en samenwerking de staat van fragmentatie kunnen doen veranderen, afstemming van doelen en acties kan bevorderen en kan resulteren in coherentie in regelgeving. Wanneer gevestigde waarden gecodificeerd in wetten en regels vervagen of overtreden worden, is het van cruciaal belang dat de motivaties, aanleidingen en agenda's behorend bij dergelijke ontwikkelingen begrepen worden. Hoewel beleidscoherentie wenselijk is, dient de mate waarin en het niveau waarop vastgesteld te worden. Bestaande pogingen om fragmentatie te managen zouden hierbij gebaat zijn. Het is essentieel om te navigeren tussen fragmentatie en cohesie om zo effectief om te kunnen gaan met diversiteit en de spanningsvelden die dit oplevert voor de sturing van duurzame ontwikkeling.

Gebaseerd op de bevindingen in dit proefschrift, stellen wij dat het type cohesie dat nagestreefd dient te worden, afhangt van de kenmerken van de onderliggende fragmentatie en het beleidsdomein. De casestudy over regionale standaarden voor biologische productie liet zien dat diversiteit mogelijk een waardevol kenmerk kan zijn voor een standaardsysteem. Om deze reden, is equivalentie een passend systeem voor beleidscoherentie. Voor het beleidsdomein van arbeidsrecht heeft harmonisatie of een gezamenlijke standaard echter de voorkeur gegeven het feit dat beleidsfragmentatie leidt 
tot blijvende schendingen van arbeidsrecht. Het ineffectieve arbeidsrechtensysteem op mondiaal niveau wordt niet geholpen door het vervagen van normatieve standaarden van nieuwe en andere regels en beleidskaders.

Drie aanpakken zijn mogelijk leerzaam in het navigeren tussen fragmentatie en cohesie. Ten eerste kan fragmentatie benaderd worden als een organisatorisch probleem. In deze aanpak is het niet alleen belangrijk om de actoren en hun verantwoordelijkheden te identificeren, maar ook om te verkennen waar de verantwoordelijkheden gelegd, verschoven, of gereorganiseerd zouden moeten worden. Ten tweede kan fragmentatie benaderd worden als een probleem dat zijn wortels heeft in normativiteit. Een algemeen normatief raamwerk kan nodig zijn. Indien dit al aanwezig is, kan niet alleen gepleit worden voor strengere en verder reikende standaarden, maar ook voor overeenstemming voor een beleidscoherentiemechanisme. Ten derde kan fragmentatie benaderd worden als een relationeel probleem. Samenwerkings-management is in deze context een belangrijk concept en refereert naar de bewuste inspanning door een relevante actor of groep actoren, ongeacht de vorm of forum, om de institutionele interactie en de daar bijbehorende effecten te adresseren. Al deze benaderingen kunnen spanningen veroorzaken, bijvoorbeeld op het gebied van legitimiteit en accountability. Desalniettemin, in het sturen van mondiale beleidssystemen in de richting van duurzame paden, blijven systemische transformaties een van de grootste uitdagingen van onze tijd. 



\section{Valorisation}



Article 22 of the Maastricht University Regulation Governing the Attainment of Doctoral Degrees prescribes that a doctoral candidate adds a valorisation addendum to the dissertation. In this regulation, knowledge valorisation is described as referring to the "process of creating value from knowledge, by making knowledge suitable and/or available for social (and/or economic) use and by making knowledge suitable for translation into competitive products, services, processes and new commercial activities" (adapted definition based on the National Valorisation Committee, 2011, p. 8). In the following sections, three main issues in relation to valorisation of this dissertation are addressed. The first section relates to the social relevance of the research results that go beyond its scientific relevance. The second section concerns the societal groups other than the scientific community for which the research results may be of interest. The third section details the concrete activities in relation to disseminating research relevance and results beyond those activities that have specifically been undertaken for the scientific community.

\section{Social relevance}

The governance of sustainable development is characterised by a growing number of standards. In international and regional value chains, standards, regulations, and certification schemes from public, private and public-private actors and partnerships, have gained prominence. This trend can be observed in various policy domains and sectors of trade. The governance of some issue areas demonstrates more regulatory cohesion than others. It has been argued in this dissertation that the assessment of regulatory cohesion and fragmentation is pivotal in understanding whether the system of governance is conducive to realise sustainable development. One of the research results presented in this dissertation has been a mapping of different policy mechanisms that, based on the organisational, normative and collaborative context of a sustainability concern, can be considered desirable for creating policy cohesion. In this way, this dissertation offers a basis for making an assessment on whether a proposed policy mechanism for cohesion can be considered conducive to realise sustainable change.

More generally, the social relevance of the research results is to inform policy and decision-making for sustainable development. Particularly the role of collaboration and coordination (and the absence thereof in policy domains), both between but also across actors from the different societal domains, may specifically inform actors on the current drawbacks and future possibilities for policy and decision-making for sustainable development. The research results of this dissertation may be used as leverage points, that is, as an indication of places within various governance systems for sustainable development where policy is considered either too fragmented or too cohesive for the 
conducive realisation of sustainable change. In the following paragraphs, the various societal groups for which this dissertation is of particular relevance will be detailed.

\section{Societal groups}

The results of this research are of interest to those who govern, those who are governed, as well as those who are affected by sustainability standards more generally. Here we identify three particularly relevant societal groups, namely public actors from governmental or intergovernmental organisations, and private actors from civil society groups and the business domain. The first group of public actors increasingly deal with governance actors from the private sphere. Since the origins and solutions to sustainability problems transcend national boundaries, in an ever-globalising world, public actors must be informed on international, transnational, regional, and various national sources of authority. In advancing the public good, public actors must also recognise the ways in which fragmentation or cohesion in global governance may advance or impede their objectives. As for instance the case on tensions in global governance systems (chapter 5) illustrated, fragmentation or the choice for an ill fitted policy mechanism to foster cohesion - which may (un)purposefully be stimulated by public actors - can counter affect the efforts of public policy. This dissertation provides insight on the fact that tensions not only arise on basis of system characteristics of a policy domain, but may equally arise through the ways in which cohesion is sought. The concluding chapter of this dissertation offers an overview of various policy mechanisms actors can endorse to advance sustainable development.

The research results are also relevant for civil society groups. The case on private fair labour arrangements (chapter 2) showed that standard-setting and particularly certifying non-governmental organisations (NGOs) may diffuse and counteract the fulfilment of sustainability goals as some governance arrangements deviate from well-established standards and regulations. Coupled with the fact that certifying NGOs compete for market share and offer different compliance and enforcement mechanisms, the transformative capacity of certifying NGOs is questioned. Civil society groups which engage in standard-setting and certification may take from this that deviation on the content of standards, may very well be a way to self-preserve the organisation, but can counteract the broader goal of inducing transformative sustainable change. In addition to the case on private fair labour arrangements (chapter 2), which illustrated that advocacy groups not only raise awareness on misconduct or try to influence public opinion, the case on regional standards for organic production (chapter 3) also illustrates that the standards of civil society groups can be normative in international and transnational standard setting. 
Actors from the business domain are also a societal relevant group in relation to this research. In general, the objective of businesses is creating an environment that is suitable for business conduct, which may or may not be aligned with values for sustainable development. Present day, it is not abnormal for businesses to engage in partnerships with public or civil society actors, and an increasing number of businesses see a value for business in participating in governance arrangements and certification schemes as the case on fair labour arrangements (chapter 2) and the case on private metagovernance (chapter 4) has shown. The research results of this dissertation may inform businesses on the type of governance arrangement they want to align with, as well as inform them on possible private metagovernance mechanisms of change. As the case on private fair labour arrangements (chapter 2) showed that standard-setting and particularly certifying NGOs can deviate from well-established standards and regulations, the research results can raise awareness amongst businesses in understanding how their engagement in such certification schemes may diffuse and counteract the fulfilment of sustainability goals.

\section{Activities}

Research progress and results have been presented at academic conferences and international journals. However, I have also participated in a couple of debates in which I have communicated my research results to a wider academic audience. One such occasion was an event in April 2015 organized by Amnesty International students from Maastricht University, entitled 'Should I buy fair-trade products?' Here I participated as a panellist, presenting information on the case on private fair labour arrangements (chapter 2) and detailing the different approaches by fair labour arrangements. The student audience was particularly interested in finding out, which certification schemes in general are to be trusted and understanding whether buying certified products contributes to sustainable development. One of the key messages I brought to the table was that there is reason for some optimism on the work of fair trade labels, although we cannot assume that they hold the answer to bring about the necessary systemic change to alleviate fair labour violations on a global level. Another critical part of the discussion centred on the recognition of the audience that there may be trade-offs in the consumer choices they make, e.g. organic or fair trade products from distant countries as opposed to local produce.

Another event for which I was invited as a panellist was a debate café on responsibility and sustainability in December 2018. Organised by Studium Generale in close collaboration with the Green Office students of Maastricht University, the event was entitled 'Whose responsibility is it anyway? Making a sustainable world' and attendance was open for the academic community, as well as residents of the Maastricht area. The central themes of the debate concerned the relation between individual action towards a sustainable world, the 
responsibility of governments and big companies, the ways individuals can make impact through individual actions, and collective action to influence companies. In relation to the topic of this dissertation, the cases on private fair labour arrangements (chapter 2) and on tensions in global governance systems (chapter 5) have been relevant. These include the positions that: 1) all actors, whether public, private, individual or collective identities, are responsible for making this world more sustainable; 2) both individual and collective action is important for raising awareness and inducing change on corporate level; 3) although some levels of fragmentation in global governance can be conducive in striving for sustainable change, fragmentation also leads to adverse effects, such as regulatory uncertainty. In this regard, it is important that all actors adhere to well-established international norms and standards so as not to diffuse and counter the effective realisation of sustainable change.

Another way in which knowledge is disseminated is through education. For example, in a lecture for the course Governance for Sustainable Development, several aspects of this dissertation are used to explain and exemplify issues concerning partnerships and standardsetting by public and private actors. In the future, educational tasks can possibly be further developed specifically relating to the fragmentation and cohesion debate in global governance. 


\section{Acknowledgements}


First I would like to thank my promotor Pieter Glasbergen. I am grateful that I can successfully finish this $\mathrm{PhD}$ under your guidance. Here I would like to voice my appreciation for your analytical and critical mind. I also want to express my appreciation for my co-promotor Ron Cörvers. I have particularly appreciated your calm and down to earth working approach. I want to thank Anja van Bogaert for her collegiality as well as thank Pim Martens for taking me on board at the International Centre of Integrated assessment and Sustainable development (ICIS). I want to express gratitude to Annet Grol for extending this initial welcome at ICIS.

For a great extent, this dissertation is based on interviews I have conducted with persons whose identities I have not disclosed. I am very thankful of all the professionals who have provided me not only a window into their work, but often also to their worries, hopes and dreams concerning governance for sustainable development.

During the years I worked on my $\mathrm{PhD}$, I have had the luck to come to know many fine colleagues at ICIS, some of whom are still here and others who have continued their journey elsewhere. I would like to thank Jing Wang and Julia Backhaus for their support and friendship over these years. I am also appreciative of the many critical, as well as humour and laughter filled conversations with Bram Oosterbroek and Laura Kurth. I want to thank Bingtao Su for her companionship, and express my appreciation to Astrid Offermans, Saskia Jamin and Veronique Vasseur for their collegiality and for making my coffee breaks much more enjoyable than they once used to be. I have also enjoyed either the company, support, and/or feedback of my colleagues Alex Baker-Shelley, Annemarie van Zeijl-Rozema, Atika Wijaya, Christian Scholl, Dexon Pasaribu, Esther Sri Astuti Soeryaningrum Agustin, Ibnu Muhammad, Joana Figgin, Joop de Kraker, Luis Diego Segura Ramírez, Lukas Figge, Marc Davidson, Marc Dijk, Marjan Peeters, Maud Huynen, Mo Chen, Nia Hidayat, Nicole Rijkens, and Verena Bitzer. Carijn Beumer and Su-mia Akin, after leaving ICIS I am happy our ways have not parted.

I am also appreciative of my more formative years at University College Maastricht, where I have enjoyed the mentorship and collegiality of many staffers. Within the context of my $\mathrm{PhD}$, I would like to express my appreciation to Harm Hospers for welcoming the idea of my $\mathrm{PhD}$ trajectory and Jenny Schell for her fellowship in writing frenzies.

A big thanks to my family and friends who have supported and believed in me throughout the way. I will forego mentioning all of those whose presence I enjoy and who enrich my personal life, but like to mention a few of you nonetheless. Luc and Roos Hameleers, thinking back of the $\mathrm{PhD}$ jokes during our dinners has at times genuinely lifted my spirits. Astrid Van den Bossche, Birgit Veskioja, Floor Serbrock and Solange van Moll, no matter how short or long I have known you: thanks for your comradery. My brother Cem Pekdemir, thanks for believing in your little sister. 
Ayrıca, anneme ve babama teşekkür ederim. Babam, Ali Rıza Pekdemir, eğitim ve öğretimle ilgili konularda gelişmeme her zaman değer verdi. Annem, Dudu Koç ise, her zaman inanmıştır bana ve beni güçlü bir kadın olarak büyütmüştür. Ben, bana verdikleri değer ve güven için minnettarım onlara.

Lastly but surely, I'm grateful for the support and love of my husband Nicolai Dimitri Manie. Jij bent mijn rots in de branding. I am proud to form my family with you and Pax $\mathrm{Su}$. Together with our other little heartbeat, your presence makes all the difference in the world. 



\section{About the author}

Ceren Pekdemir holds various positions within Maastricht University. After obtaining her BA at University College Maastricht (2009) and a MSc in Conflict Resolution and Governance at the University of Amsterdam (2010), Ceren started working as a lecturer at University College Maastricht teaching a variety of courses, including strategy and negotiation, philosophy of science and law.

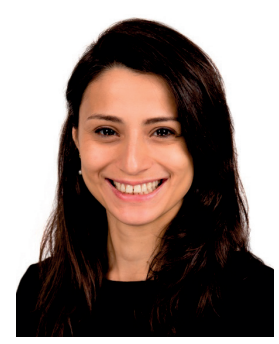

She started working at the International Centre for Integrated assessment and Sustainable development in 2012, where she also commenced on her $\mathrm{PhD}$ and specialised further on the topics of governance, global civil society, sustainable development, and partnerships. She has been involved in the MSc Sustainability Science and Policy in various roles, through teaching courses e.g. on the topic of governance for sustainable development, being responsible for the overall (selective) admissions procedure, and as member of the Board of Admissions (2012-2018), Education Programme Committee (2013-2018), and Board of Examiners (2018-present).

Since 2017 she is a representative of the Academic Union (VAWO) for the Local Consultative Body at Maastricht University. In 2018 she became the coordinator for Sustainable Education within the Sustainable UM 2030 Agenda. 

